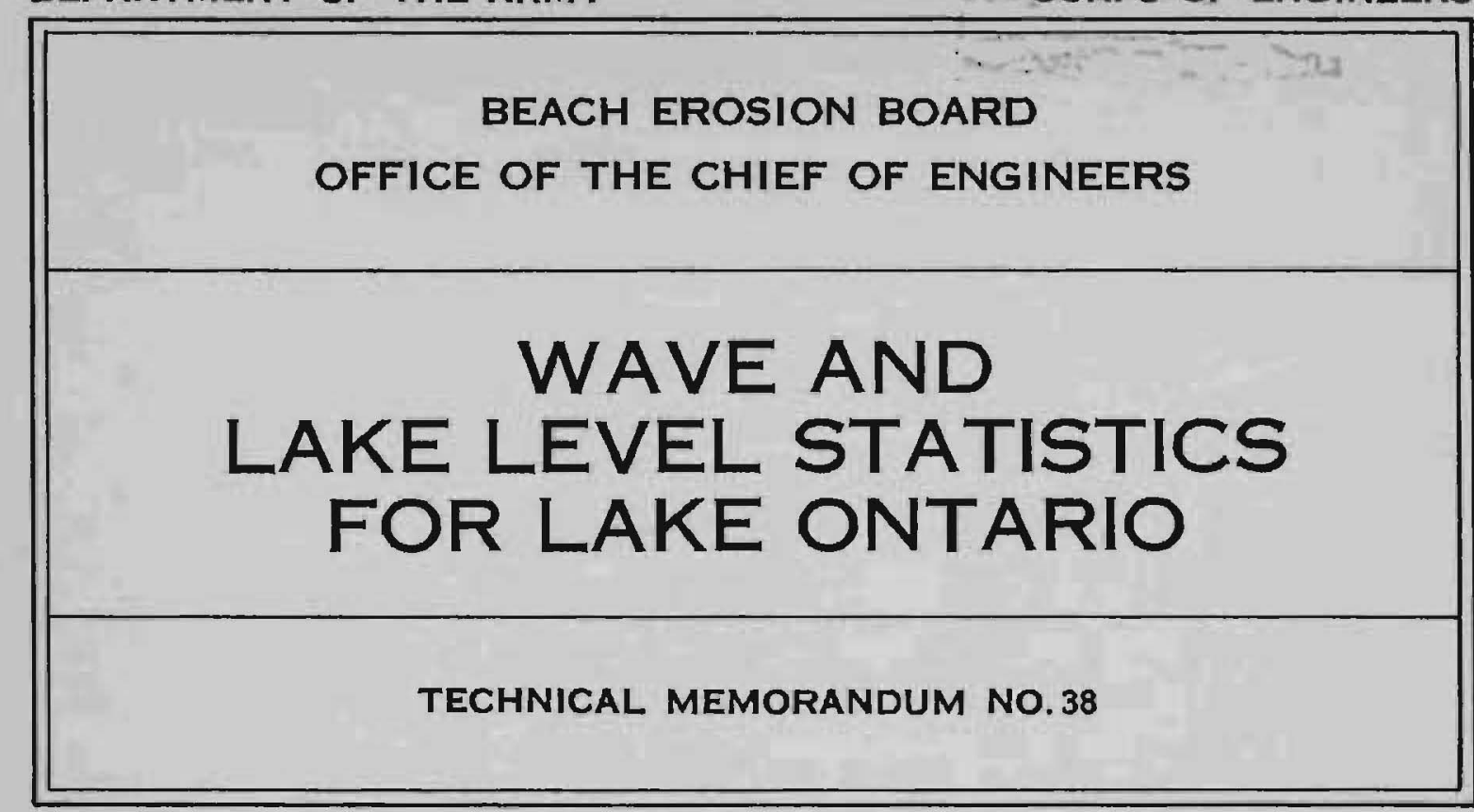




\section{WAVE AND \\ LAKE LEVEL STATISTICS \\ FOR LAKE ONTARIO}

TECHNICAL MEMORANDUM NO. 38

BEACH EROSION BOARD

CORPS OF ENGINEERS 


\section{FOREWORD}

This is the third of a series of reports to be issued by the Beach Erosion Board under its General Investigations program to provide wave statistics for selected regions. The need for such data is evident, and it is planned ultimately to supply it by actual wave measurement for sufficiently long periods to establish the wave climate at many locations. Suitable instruments for that purpose have not yet been developed and even after they become available much time must pass before the records can attain statistical value. The production of wave statistics by "hindcast" technique, admittedly of presently indeterminate quantitative accuracy, will nevertheless provide the engineer with better wave data than have heretofore been available.

Thorndike Saville, Jr., author of the report, is a Hydraulic Engineer in the Research Division of the Beach Erosion Board under the supervision of Joseph M. Caldwell, Chief of the Division. At the time this report was prepared, the technical staff of the Board was under the general supervision of Colonel E. E. Cesler, President of the Board and R. O. Eaton, Chief Technical Assistant.

The author was aided in the study by Robert $F$. Dearduff, Hydraulic Engineer; by John C. Fairchild, and Francis W. Kellum in computations and compilations; in map reduction by Philip A. Brown, Edward L. Hneftman, Duane E. Nelson, Joseph W. Rom, and Lloyd W. Zwingelberg; and in drafting by Wendell E. Reece. The report was edited for publication by Albert C. Rayner. Views and conclusions stated in the report are not necessarily those of the Beach Erosion Board.

This paper is published under authority of Public Law 166, 79th Congress approved July $31,1945$. 
TABLE OF CONTENTS

Page

Introduction

Wave Statistics

Lake Levels

APPENDICES

A - Wave Statistics for Hamilton, Ontario

$B$ - Wave Statistics for Rochester, New York

C - Wave Statistics for Stony Point, New York 


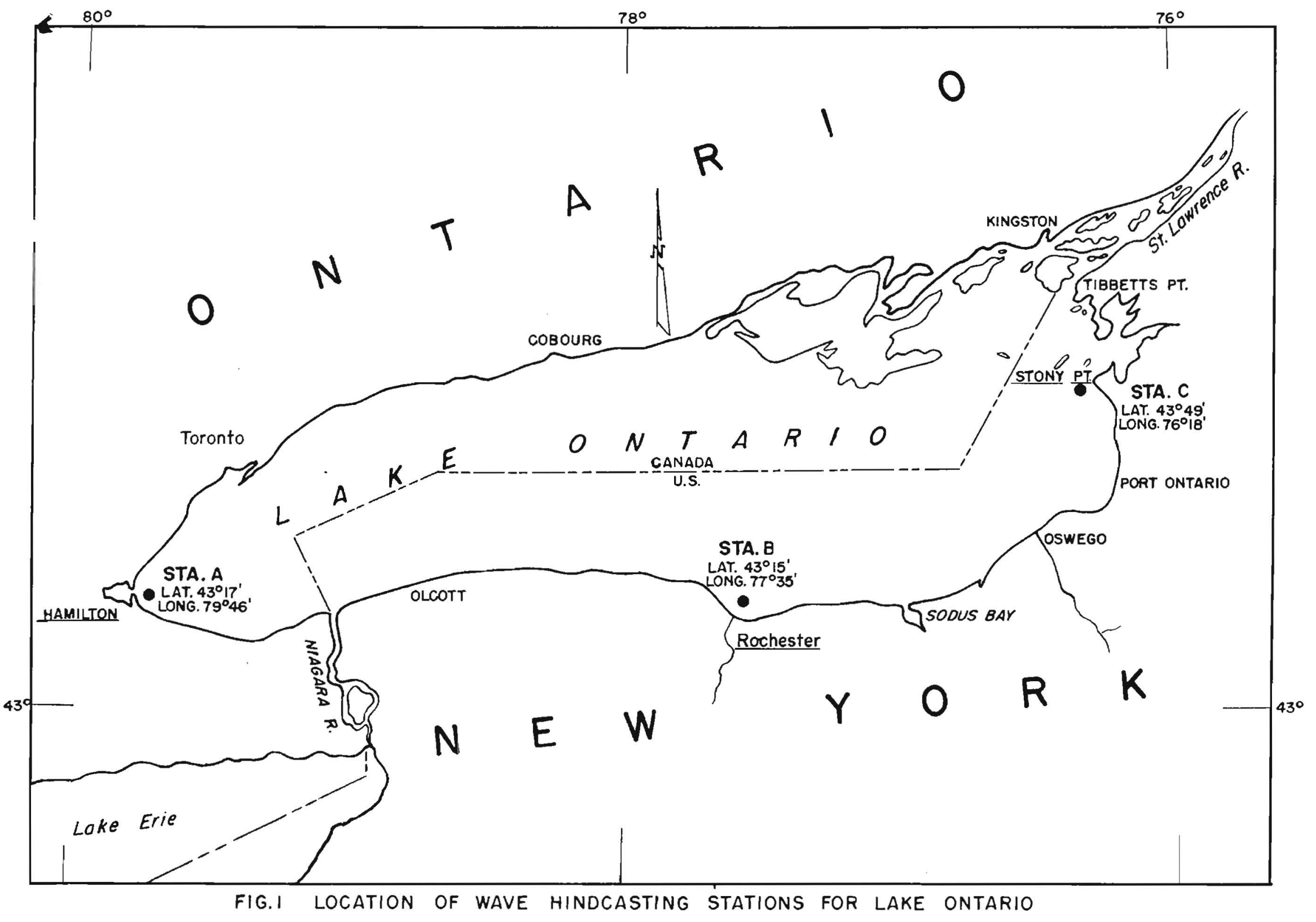


WAVE AND LAKE LEVEL STATISTICS FOR LAKE ONTARIO

\author{
by \\ Thorndike Saville, Jr. \\ Hydraulic Engineer, Research Division \\ Beach Erosion Board, Corps of Engineers
}

\title{
INTRODUCTION
}

The General Investigations program of the Beach Erosion Board comprises investigations, regional rather than local in scope, designed to improve, simplify, and expedite the solution of local problems, by giving a compilation of all existing data pertinent to shore processes in the particular region. As a first step in the compilation of these data, a study of wave and lake level conditions on the Great Lakes is being made. The results of such astudy for Lake Ontario are presented herein.

\section{WAVE STATISTICS}

Three stations on Lake Ontario were selected for a comprehensive wave analysis, the locations (see Figure 1) being as follows:

\begin{tabular}{|c|c|c|c|}
\hline Station & Latitude & Longitude & Vicinity \\
\hline A & $43^{\circ} 17^{\prime} \mathrm{N}$ & $79^{\circ} \quad 46^{\prime} \mathrm{W}$ & Hamilton, Ontario \\
\hline B & $43^{\circ} \geq 5^{\prime} \mathrm{N}$ & $77^{\circ} 35^{\prime} \mathrm{W}$ & Rochester, New York \\
\hline C & $43^{\circ} 49^{\prime} \mathrm{N}$ & $76^{\circ} 18^{\prime} \mathrm{W}$ & Stony Point, New York \\
\hline
\end{tabular}

These particular stations were selected since it was thought that they would give adequate coverage to the entire lake shore of the United States, and permit interpolation of values between stations, thus giving an accurate representation of wave action at any point along the United States shore line of Lake Ontario.

Wave characteristics were determined from synoptic weather charts for each station for the three-year period 1948-1950. The weather maps used were the North American Surface Synoptic Charts compiled at sixhour intervals by the U.S. Weather Bureau. Fetch areas, and the wind speads and durations in these areas, were determined directly from the weather maps; these values were used with the curves derived by Sverdrup and Munk (I)* and revised by Arthur (2.) and later by Bretschneider (3)

* Numbers in parentheses refer to References on page 15. 
to obtain the hindcast wave characteristics. The only major variation from the usual methods of wave forecasting or hindcasting (4) (other than that the new Bretschneider revised curves were used) was that the surface wind was determined directly from reported observations rather than frcm a gradient wind determined from the isobar spacing. It was thought that with the lake area so small in comparison to the area of the pressure cell, the isobaric pattern on the surface would be influenced to a large extent by the surface topography, and gradient winds determined from the isobar spacing would not necessarily give true values of wind velocity over the lake surface. Hence reported values of the surface wind could be expected to give a more realistic figure of the wind velocity. Observations have shown (5) that the greater surface friction serves to reduce the wind over land from what it may be over water. Since the reported values were almost always obtained at land stations, the wind speeds used in the analysis may have been lower than those actually occurring over the lake in the generating area. Some compensation was made for this by selecting the top speed of the Beaufort. range reported rather than the middle value.

The wave characteristics thus determined are for the significant wave -- that is, the period is that of the predominating waves, and the height is the average of the higher one-third of these predominant waves. These values are summarized for each station in Tables A-l through C-l (Appendices $\mathrm{A}$ through $\mathrm{C}$ ). It should also be noted that the wave conditions in these tables are deep water $\infty$ nditions. They must be used in conjunction with refraction diagrams to obtain inshore values. The tables show, for each station, the number of hours' duration that deep water waves of any given height, period, and direction occurred during any month of the three-year period; and also for each month (as summations) the number of hours' occurrence of waves of any particular height and period exclusive of direction; the number of hours' occurrence of waves of any particular height and direction exclusive of period; and the total number of hours' occurrence of waves of any particular height.

As an example of the data presented, from Table B-I (Table 1 for Station B) for the month of July, waves of 1 to 2 -foot height and 3 to 4-second period from the west-northwest occurred for 12 hours during 1948, 12 hours during 1949, and 36 hours during 1950. Thus, waves of this category occurred for a duration of 60 hours during the three-year period and hence can be expected to occur for about 20 hours (on the average) during July of any year in the future. Waves of 1 to 2-foot height and 3 to 4second period (from all directions) occurred for 156 hours over the threeyear period, or an average of 52 hours per year. Waves of 1 to 2 -foot height from the west-northwest (all periods) occurred for 66 hours over the three-year period, or an average of 22 hours per year. Waves of 1 to 2-foot height (all periods and all directions) occurred for 252 hours over the three-year period, or an average of 84 hours per year. Tables A-2 through $\mathrm{C}-2$ show the summation of the values in Tables $\mathrm{A}-1$ through $\mathrm{C}-1$ for the entire year and are read similarly to those tables. 
During much of the winter season, portions of the lake are covered with ice, and fetch areas are limited considerably. In addition, for 2 somewhat greater portion of the winter season, the coast area of the lake is covered with ice, and, even though waves are generated in offshore areas, they never reach the shore, being interrupted by the ice around the rim of the lake. No account of this effect of the ice was taken in the actual hindcasting of the waves, and the durations given for the various winter months are computed as though the re were no ice on the lake, a fact that should be remembered in using these data.

From yearly records of lake and air temperatures, and the dates of opening and closing of the lake for navigation, an average ice-isee period was determined. For Lake Ontario this appeared to run, on the average, from April through November, and the average ice-free period was determined as 1 April - 1 December for all three stations. A summation of the wave data for this ice-free period is shown in Tables A-3 through C-3. These tables are similar to Tables 1 and 2 and represent a summation of the values in Tables 1 for all months from April through November. The durations of waves of particular height and direction have also been tabulated as percentages of time for the threeyear period and are shown graphically in the wave roses for the full year and also for the icefree period in Figures $\mathrm{A}-1$ through $\mathrm{C}-1$. In these roses, as in all other curves contained herein, the durations are percentages of 365 days, for the ice-free period as well as the full year date.

Figures A-2 through $\mathrm{C}-2$ show the total percentages of time that the wave height may be expected to be greater than any particular height throughout the year. They thus show the (average) total duration time of specific waves over the year. Two curves are shown,-one based on the data gathered for the entire year, and the other on just the average ice-free period (April through November). For example, at Station B, the total duration of waves in excess of 10 feet in height during the ice-free period is expected to be 0.09 percent of the time; and 0.20 percent of the time during the full year. Hence waves 10 feet or higher can be expected to occur for a total duration of 18 hours $(0.002 \times 365 \times 24)$ over the course of each year, and, of this, 8 hours $(0.0009 \times 365 \times 24)$ will be during the ice-free portion of the year when the waves will be certain to reach the shore.

Figures A-3 through $\mathrm{C}-3$ show the frequency with which storms resulting in waves higher than a given height can be expected to occur. For example, at Station $B$, on 0.64 percent of the days each year the waves may be expected to be ten feet or greater in height, and on 0.29 percent of the days they may be expected to reach this height during the ice-free portion of the year. Thus waves ten feet or higher may be expected to occur (on the average) $2-1 / 3$ times each year $(0.0064 \times 365)$, or seven times every three years; of these occurrences, only one $(0.0029 \mathrm{x}$ 365) will be expected to occur during the ice-free portion of the year. 
Combining the data obtained from graphs on Figures B-2 and B-3, waves ten feet and higher may be expected to occur at Station B slightly more frequently than twice each year, and the average duration of each stcrm will be about 8 hours. During the ice-free portion of the year, waves of ten feet and higher may be expected to occur only once, and the duration of this storm is also expected to be about 8 hours.

There are, in general, two methods of plotting points to obtain frequency curves such as those shown in Figures A-3 through C-3. One, based on the so-called theory of sampling, involves the assumption that the known period of record (three years) is a fair average sample of all similar three-year periods over an infinite number of years, and that therefore the largest storm of this three-year period is the median of all storms of the same class in all other three-year periods. This results in a frequency given by the following equation:

$$
F=\frac{2 N-1}{2 T} \times 100
$$

where $F=$ frequency (in percent) of the occurrence of storms equalling or exceeding the given storm

$\mathrm{T}=$ number of days of record

$N=$ number of occurrences of a storm equal to or greater than the given storm

The second method essentially considers only the period of record, in which case the frequency becomes

$$
F=\frac{N}{T} \times 100
$$

Values of $F$ are the abscissa of points on the frequency curve. Using the second equation above, the largest storm which occurred in the known three-year period would have an abscissa of .0914 percent and would represent the storm which would most probably occur once in three years, i.e., would be the "three-year storm", etc. But this would be contrary to the theory of sampling, where (above) the assumption is made that the largest storm in the known three-year period was the median of the largest storms in a long succession of three-year periods. Therefore, over a long period such as 300 years, it will be exceeded not 100 times, but 50 times; ie., it is by definition not a "3-year storm", but a "6-year storm".

Either of the above two equations could be, and ha've been used to prepare frequency curves. Although the former is the one most generally used for hydrologic data, the latter method has been used in this case. The use of this formula $(F=100 \mathrm{~N} / \mathrm{T})$ will result in a somewhat more conservative interpretation of the data, and was thought justified in view of the extremely short period of record ( 3 years). 
The points plotted may be represented fairly closely by a continuous curve which frequently approximates a straight line, as may be seen from the figures. The curves shown have, in general, been drawn as lines of visual best fit; occasionally, however, more weight has been placed on the higher values. This tends to give a somewhat more conservative interpretation, which is thought warranted in some cases. The user is free to make his own interpretation of the plotted points. It is thought, also, that the very high waves occurring at Station A (Hamilton) may well represent storm. waves of lesser frequency (particularly as there is a very sharp break and steepening of slope in the curve for the higher values), but due to the shortness of the period of observation this could not be determined.

In view of the shortness of the period of record some doubt arose as to the validity of extrapolation from these curves, and as to whether the three years chosen were representative (i.e., that they represent average conditions, and not three years of abnormally high, or low, waves). In a similar report, on lake Michigan (6), hindcasts were made for one station for a period of 12 years (1939-1950) for all storms which were expected to give waves greater than 8 feet. The points determined were compared to those determined from the three-year data. These points fitted a straight line curve very closely and, though the points mostly lay slightly above those determined from the three-year data, the curve was not greatly different from that which had been drawn from the three-year data. Observations of the "average maximum" wave were obtained at this same station by the Mi]waukee lightship over the period 10 April 1931 to 28 September 1932 (7) and these points were also compared to those hindcast. Although the exact correspondence between the significant waves hindcast and the "average maximum" waves observed is not known, values should be closely comparable -- and although the observed points lay somewhat higher for the lower waves, agreement was good for the higher waves. The comparison of these various points is shown in Figure 2 .

Although comparisons were made for a station on Lake Michigan rather than on Lake Ontario, it is thought that the same degree of accuracy should be observed on Lake Ontario, and that therefore reasonable confidence can be put in the curves shown, at least for values of the waves occurring with frequencies less than about once in 10 years (with the possible exception of Station A).

Although for structural design purposes the important factor is the size of the maximum probable wave (within a certain time period), for computations involving sand movement and littoral drift, a more desirable parameter would be some averaged factor including within it the effect of both height and period, the variation of these parameters, and the duration that waves of each particular category exist. Present day knowledge indicates that sand movement by wave action is best correlated with the amount of energy transmitted forward (and eventually on to the beach) by the waves. The total energy per unit width in each wave is, 


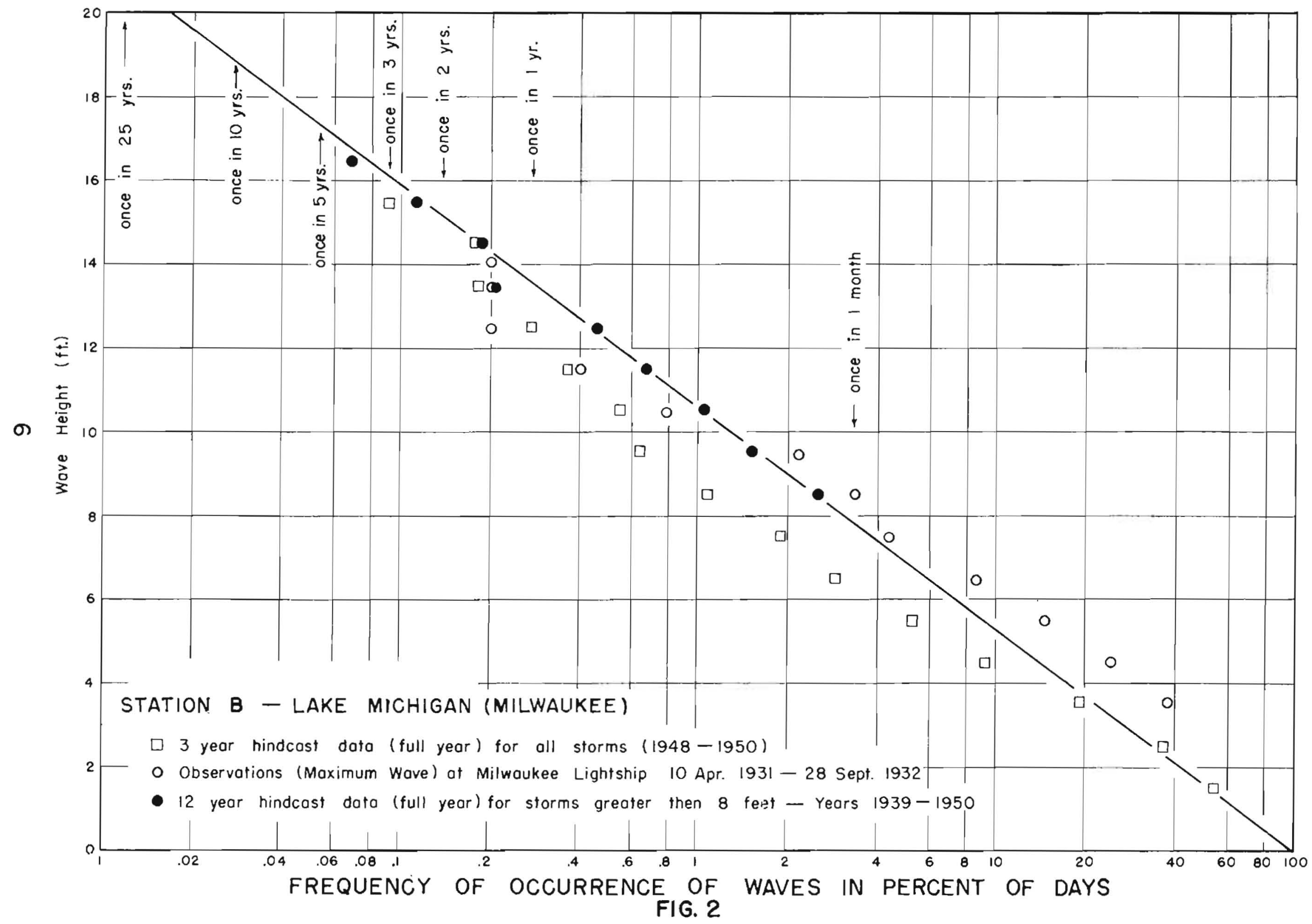


in deep water

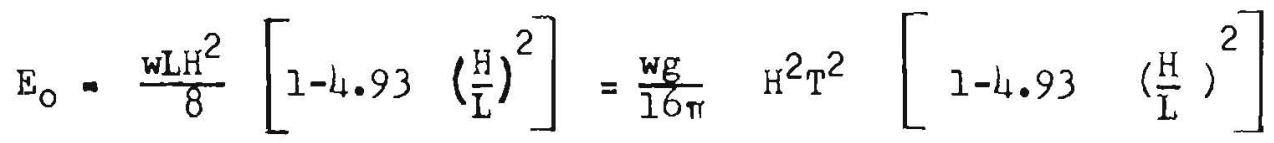

where $w=$ unit weight of water $=62.4 \mathrm{lbs} . / \mathrm{cu}$. ft.

$\mathrm{g}$ - acceleration due to gravity $=32.2 \mathrm{ft} . / \mathrm{sec} . / \mathrm{sec}$.

$\mathrm{H}=$ wave height (ft.)

$\mathrm{T}=$ wave period (sec.)

$L$. wave length (ft.)

One-half of this energy is transmitted forward from deep water toward the shore, and it is this amount of energy that eventually reaches the shore line. The total energy transmitted forward in any given period of time $\left(E_{T}\right)$ is then $E_{0} / 2$ times the number of waves occurring in that period of time,

and $\quad E_{T}=\frac{E_{O}}{2} \frac{(3600 t)}{T}=7.195 \times 10^{4} \mathrm{H}^{2} \mathrm{~T} t\left[1-4.93\left(\frac{\mathrm{H}}{\mathrm{L}}\right)^{2}\right]$

where $t$ is the duration of the waves in hours. If some particular time interval (say one month) is considered during which waves of varying height and period pass a given point toward shore, then the heights and associated periods may be tabulated (as in Tables A-I through C-I) and there will be $\mathrm{n}$ groups. If the height of the ith group is represented by its class mark $\bar{H}_{i}$, and the wave period in that group denoted by $T_{i}$, and the duration of the group by $t_{i}$, then the total amount of energy transmitted forward during the entire time interval is

$$
E_{\mathrm{T}}=E_{\mathrm{T} T}+E_{\mathrm{T} 2}+E_{\mathrm{T} 3}+\ldots \ldots+E_{\mathrm{Ti}}+\ldots \ldots+E_{\mathrm{Tn}}
$$

and

$$
E_{T}=7.195 \times 10^{4} \sum_{i=1}^{i=n} H_{i}^{2} T_{i} t_{i}\left[1-4.93\left(\frac{\mathrm{H}_{i}^{2}}{L_{i}}\right)\right]
$$

Tables $\mathrm{A}-4$ through $\mathrm{C}-4$ show a tabulation of the average energy transmitted forward from deep water toward the shore during the average ice-free period in each category of height, period, and direction. Thus for station B, waves of 1 to 2 -foot height and 3 to 4 -second period from the west-northwest may be expected to transmit forward toward the shore $6214 \times 10^{4}$ foot-pounds per foot of wave crest during the ice-free period of each year. Waves of 1 to 2-foot height and 3 to 4-second period (all directions) would be expected to send forward $31,295 \times 10^{4}$ foot-pounds per foot of wave crest each ice-free period; waves of 1 to 2-foot height from the west-northwest (all periods) would be expected to send forward $7225 \times 104$ foot-pounds of energy per foot of wave crest; and waves of 1 to 2-foot height (all periods and directions) would be expected to 
transmit toward the shore $37,214 \times 10^{4}$ foot-pounds of energy per foot of wave crest each ice-free period. Tables A-5 through $\mathrm{C}-5$ show a similar tabulation for the average full year. Since the values in Tables A-1 through $\mathrm{C}-1$ represent significant wave height and period, these energy values are those obtained if the wave system is uniform, and consists only of waves of significant height and period. Wave trains in nature are, however, exceedingly irregular, and have less energy than that determined by the significant wave concept. The relationship between the actual energy contained in any given wave train and that computed from the significant wave has been examined somewhat at Scripps Institution of Oceanography (8) and more recently by Barber and Darbyshire (10), and has been found to be very nearly a constant ratio (on the order of 0.58 ). The energies given, therefore, may be considered to be the true value of the energy multiplied by some nearly constant value, and hence can be used to detemine quite accurately ratios of energies from different directions. These latter represent very closely the ratios of the drift-producing forces. Summations of these energies for each direction and period grouping are shown in Figures $\mathrm{A}-4$ through $\mathrm{C}-4$.

All the wave data given in the tables refer to deep water conditions-that is, depths greater than one-half the wave length. As such, interpolation between stations to obtain values for other points along the shore is quite valid, and it is felt that adequate deep water hindcast values may be thus obtained for all points on the United States shores of Lake Ontario.

Although the deep water data are useful for many types of design work, particularly for preliminary considerations, it is usually the inshore, shallow water data which are of the most interest. These data may be readily obtained from the deep water data through the use of refraction diagrams. A partial example for Ludington Harbor on Lake Michigan has been worked out and presented in the pubilication dealing with wave statistics on that lake (6), to which the reader may refer if unacquainted with the techniques involved.

\section{LAKE LEVELS*}

The levels of the Great Lakes fluctuate from year to year and from month to month during each year, depending upon the volume of water in the lakes. Continuous records of lake levels have been kept by the Corps of Engineers since 1860. A summary of these records for Lake Ontario is shown in Figure 3 which is a hydrograph of the monthly average levels from 1860 to date. The monthly average was chosen to eliminate the effects of short period barometric or wind-induced changes in stage. For Lake Ontario, the a verage level during the period of record (18601952) was 246.00 feet (above mean tide at New York, 1935 Datum) the highest one-month average of 248.97 occurring in May 1870 and July 1947 and the lowest of 242.68 occurring in November 1934. The difference between the highest and lowest monthly average levels is thus 6.29 feet, al though the seasonal variation usually ranges between one and two feet

\section{8}

* Much of the following data on lake levels is taken almost verbatim from an unpublished report by the Great Lakes Div., Corps of Engrs., entitled "Preliminary Examination Report on Property Damage on the Great Lakes" issued in June 1952 (11). 


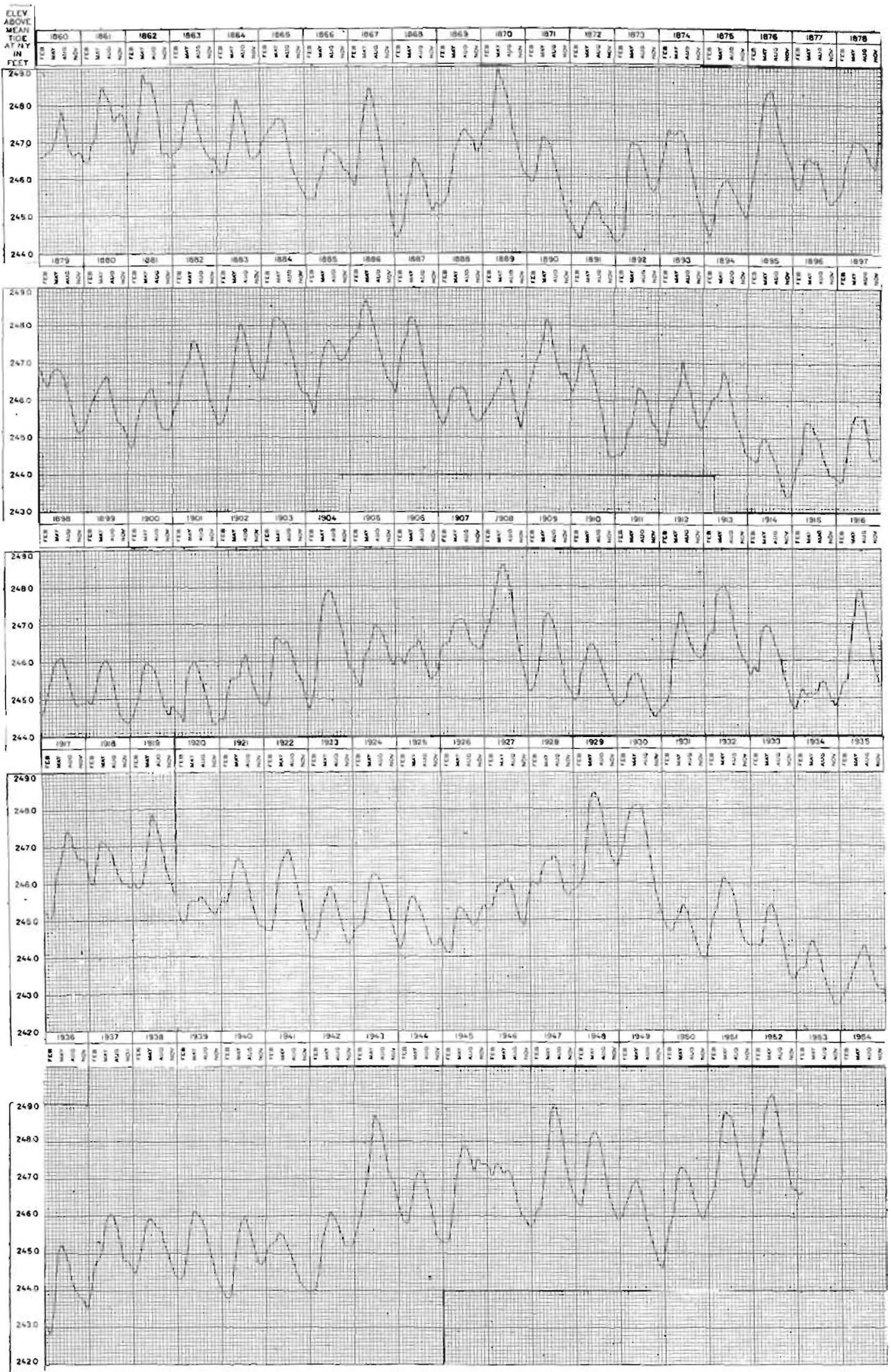

MONTHLY MEAN WATER LEVELS OF LAKE ONTARIO DATA COMPILED BY U.S. LAKE SURVEY, CORPS OF ENGINEERS 
(having an average range of $1.8 \mathrm{feet}$ ). The greatest range in level in a single season between the high and low ronth was 3.5 feet, and the lowest was 0.3 feet. The usual pattern of seasonal variation shows high levels in the summer and low levelr in lace winter (Figure 4 ). The highest monthly average level is usually reached in June and the lowest in January, though occasionally seasonal fluctuations have departed greatly from this usual pattern.

Figure 5 shows the percentage of time that the seasonal high average monthly level reaches various elevations on Lake Ontario for single, two, three, four, and five consecutive years. For example, it shows that the high monthly average each year reached elevation 245 feet or higher 97 percent of the time, reached elevation 246 feet or higher 80 percent of the time, reachea elevation 248 feet or higher 20 percent of the time, and so on. It also shows that while the high monthly average level reached 246 feet or higher 80 percent of the time in single years, it reached this elevation only 70 percent of the time in two consecutive years, only 62 percent of the time in three consecutive years, only 51 percent of the time in four consecutive years, and only 46 percent of the time in five consecutive years.

Superimposed on the long range and seasonal fluctuations resulting from the actual quantities of water present in the lake, are daily and even hourly fluctuations resulting from an unbalance or tilting of the lake surface. These are induced primarily by winds, though some have attempted to ascribe them to differential barometric pressures. Figure 6 is derived from data given in a report by tha Great Lake Division Engineer (1I) and shows the frequency of occurrence of short-period fluctuations at various gage sites on Lake Ontario during the period of record. Short-period rises at intermediate points between gage sites depend upon local conditions, but reference to the figures for points in the vicinity will provide an indication of the rises to be expected.

It has been found (12)(13) that, at least for shallow water areas, the rise in level due to wind stress may be predicted quite accurately by the formula

$$
S=1.165 \times 10^{-3} \frac{V^{2} F}{D} \quad N \cos \alpha
$$

where $S$ is the total set-up (difference in water surface'elevations at the windward and leeward sides of the lake) in feet, $F$ is the fetch length in statute miles, $V$ is the average wind velocity over the fetch in miles per hour, $D$ is the average depth in feet of that portion of the lake that is more or less contiguous to the fetch, $\alpha$ is the angle between the wind and the $f$ etch, and $\mathrm{N}$ is a shape coefficient dependent an the planform and nearshore hydrography of the particular area. Though methods of computing $N$ are available, unless the area is a very marked convergent bay, it is usually sufficient to assume values of $\mathrm{N}=1$. The actual rise in vater surface elevation above still water level will 


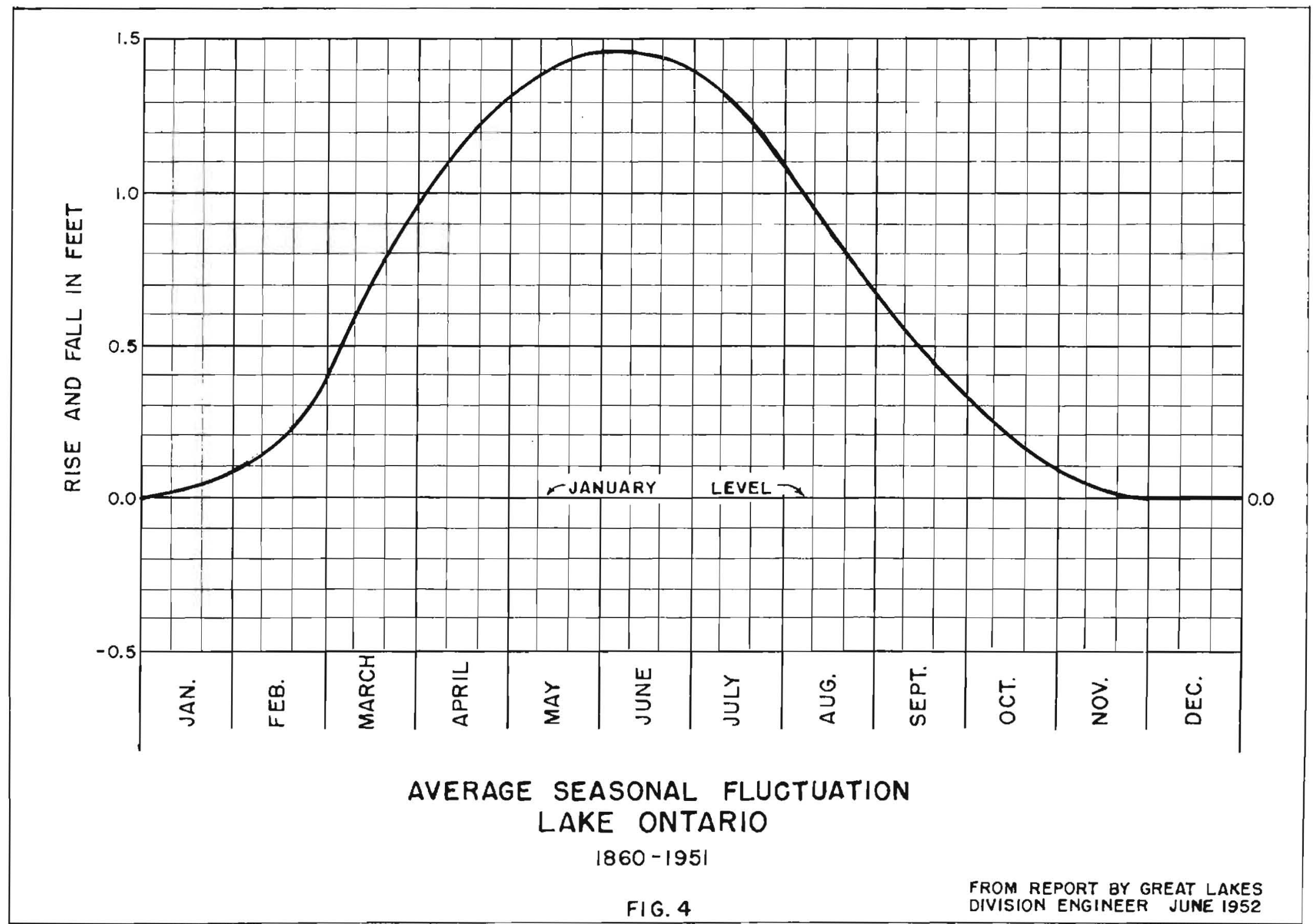




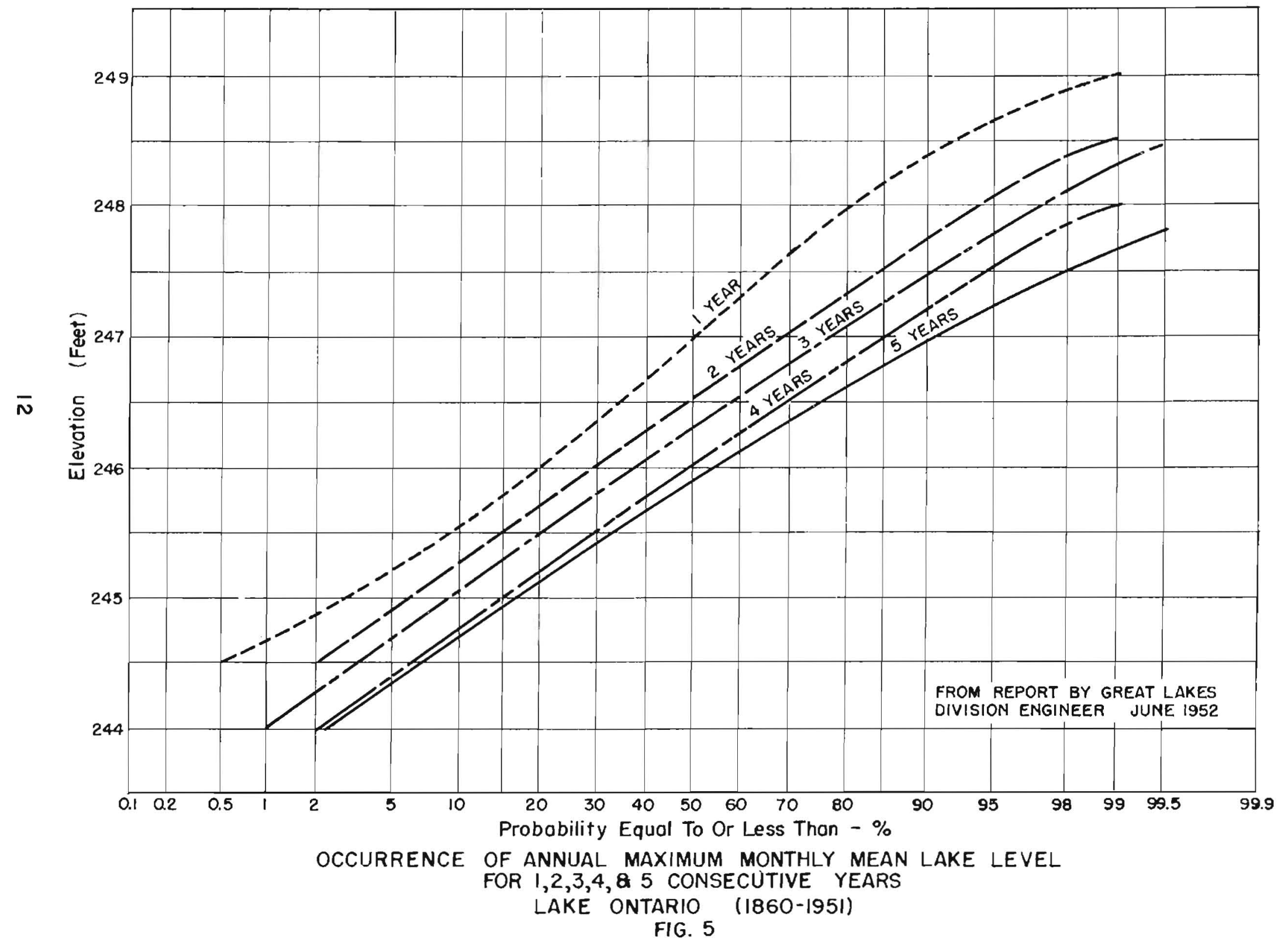




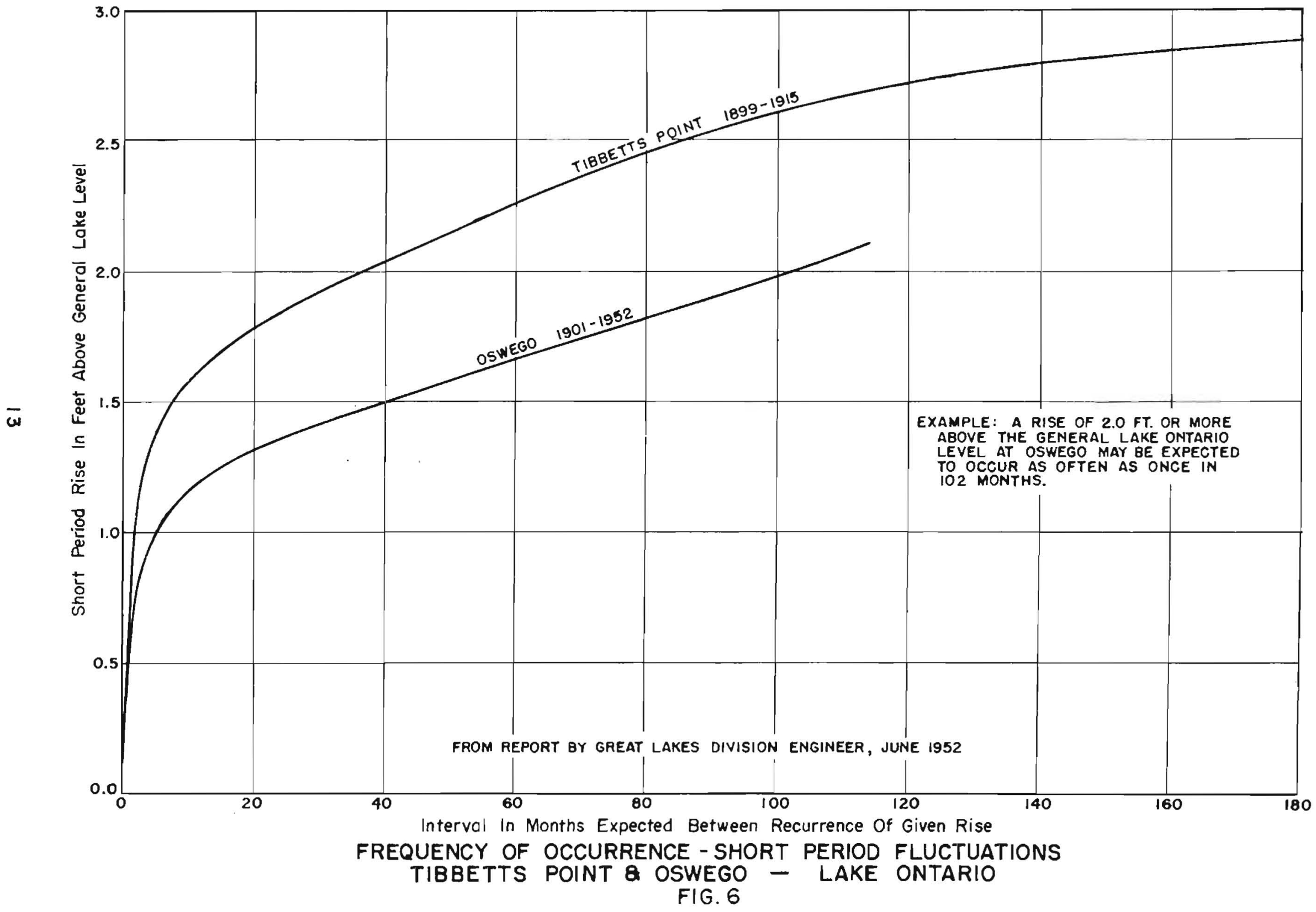


be slightly greater than $S / 2$ depending on the nearshore hydrography; an average value of 0.57 has been in general use, and is quite adequate. Although this formula has been checked quite adequately for shallow areas (experimental tanks, the Zuider-Zee, and lake Okeechobee) extension to deeper waters, as Eake Ontar10, may be unwarranted, and it should be used with some caution. 
1. Sverdrup, H. U. and W. H. Munk - Wind Sea and Swell: Theory of Relations for Forecasting, H. O. Pub. 601, 1947.

2. Arthur, R. S. - Revised Wave Forecasting Graphs and Procedures, Scripps Inst. of Oceang, Wave Report No. 73, 1947 (unpub.)

3. Bretschneider, C. L. - Revised Wave Forecasting Relationships, Proceedings of the 2nd Conf. on Coastal Engineering, 1951.

4. Hydrographic Office - Techniques for Forecasting Wind Waves and Swell, H. O. Pub. 604, 1951.

5. Hydrometeorological Section, U. S. Weather Bureau - Analysis of Winds over Lake Okeechobee During Tropical Storm of August 26-27, 1949, Hydromet. Report 26, 1951.

6. Saville, T., Jr. - Wave and Lake Level Statistics for Lake Michigan, Beach Erosion Board Tech. Memo.. 36, 1953.

7. Milwaukee District, Corps of Engineers - Lake Michigan Wave Measurements at Milwaukee, Wisconsin, Misc. rpt.20/203.1, 1933 (unpub.)

8. Scripps Institution of Oceanography - A Statistical Study of Wave Conditions at Five Open Sea Localities Along the California Coast, Wave Report 68, 1947 (unpub.)

9. Barber, N. F. - Ocean Waves and Swell, London Institution of Civi] Engineers, Maritime and Waterways Division, 1950.

10. Darbyshire, J. - The Generation of Waves by Wind, Proceedings of the Royal Society, Series A, Vol. 215, No. 1122, 1952.

11. Great Lakes Division, Corps of Engineers - Preliminary Examination Report on Property Damage on the Great Lakes Resulting from Changes in Lake Level, June 1952 (unpub.).

12. Keulegan, G. H. - Wind Tides in Small Closed Channels, Jour. Res. Nat'1. Bur. Stds., RP 2207, v. 46, n. 5, 1951.

13. Saville, T. Jr. - Wind Set-up and Waves in Shallow Water, Beach Erosion Board Tech. Memo 27, 1952. 
WAVE AND IAKE LEVEL STATISTICS

FOR

LAKE ONTARIO

APPENDIX A

WAVE STATISTICS

FOR

STATION A

HAMILTON, ONTARIO 
TARLE A.I

STATISTICAL HINOCAST CATA gOA LAKE ONTARIO STATION A, HAMILTON, ONTARIO

due but nof the unow
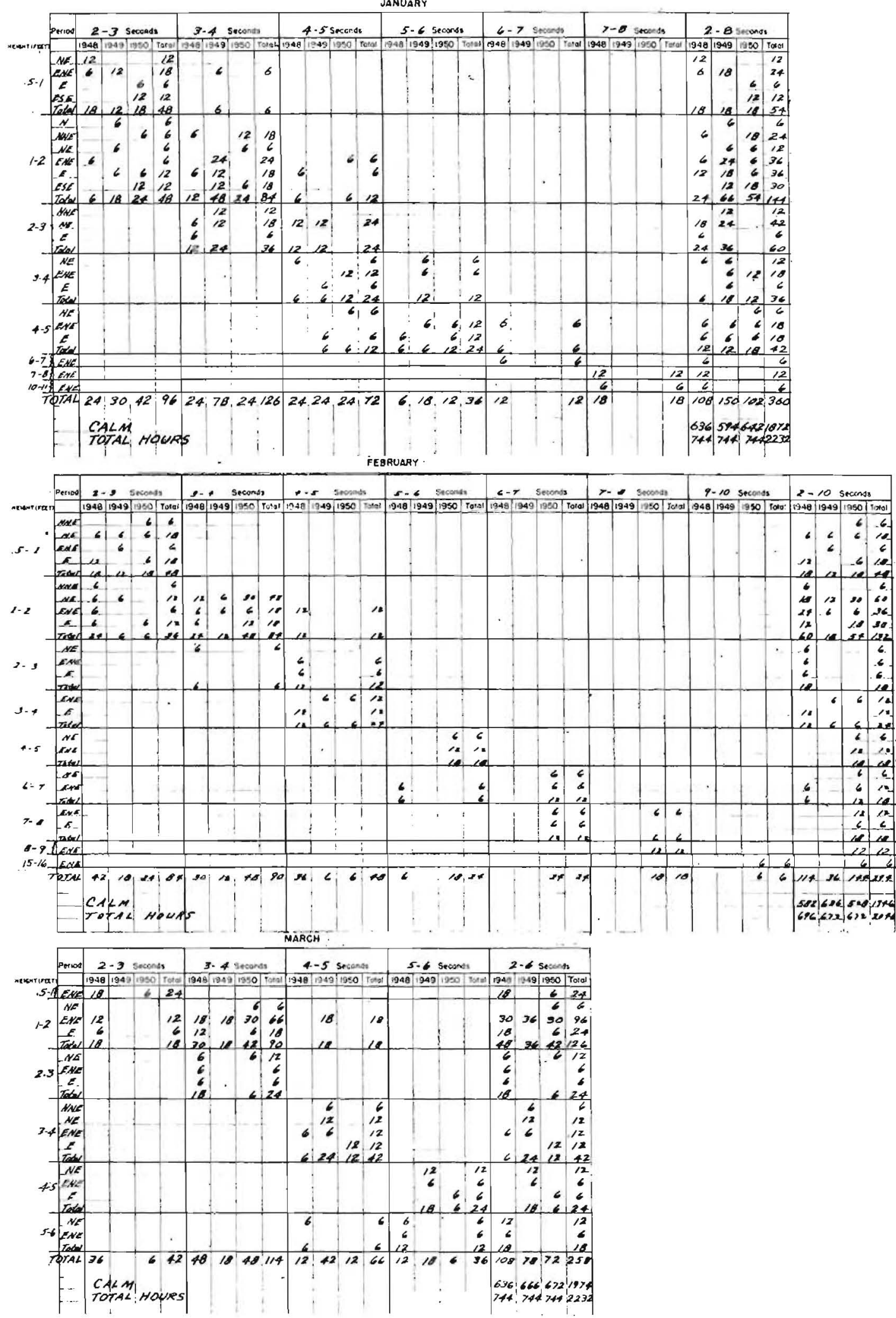


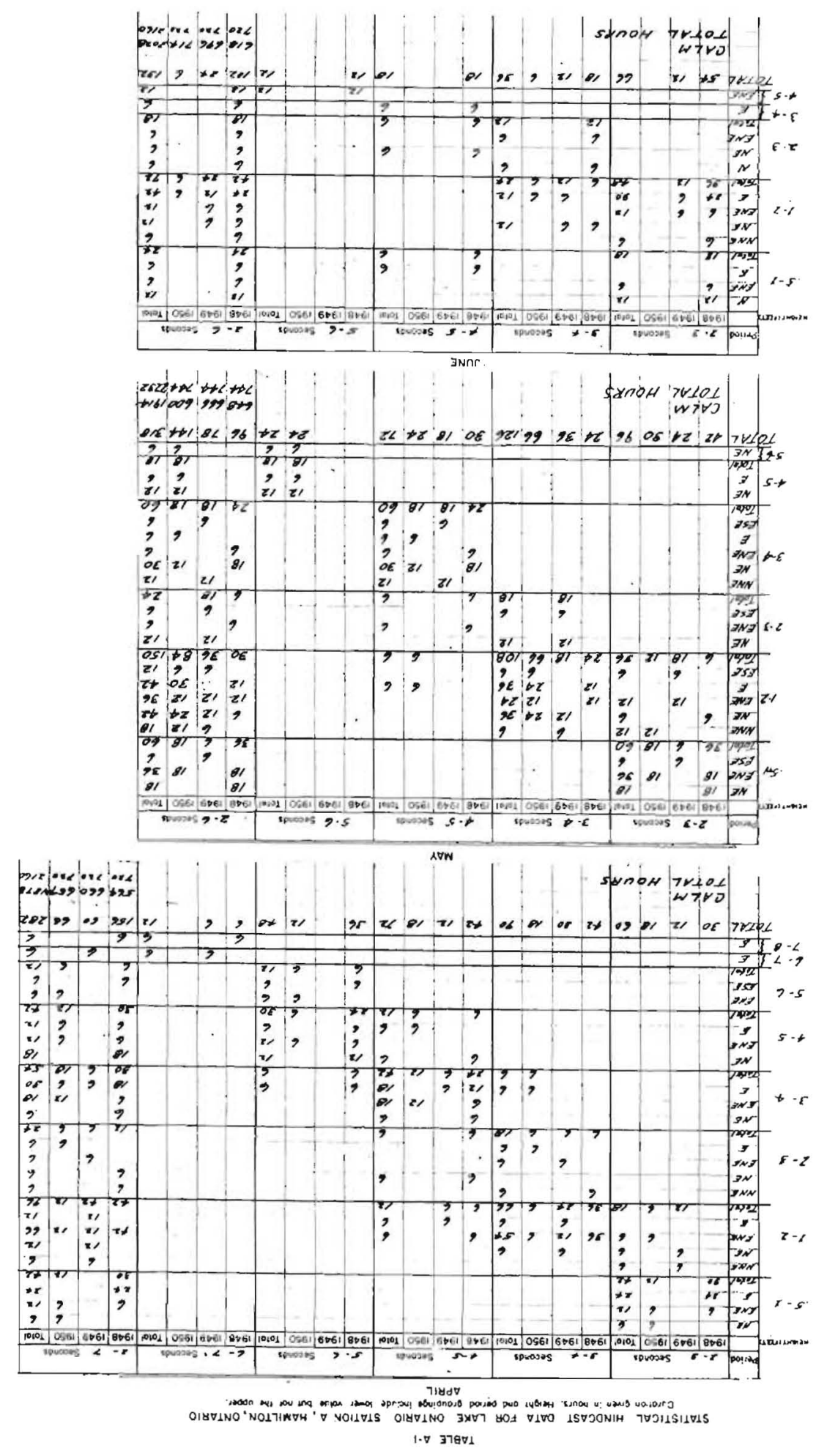


TABE A.I

STATISTICAL HINDCAST DATA FOR LAKE ONTARIO STATION A, MAMILTON, ONTARIO

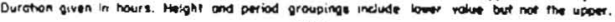
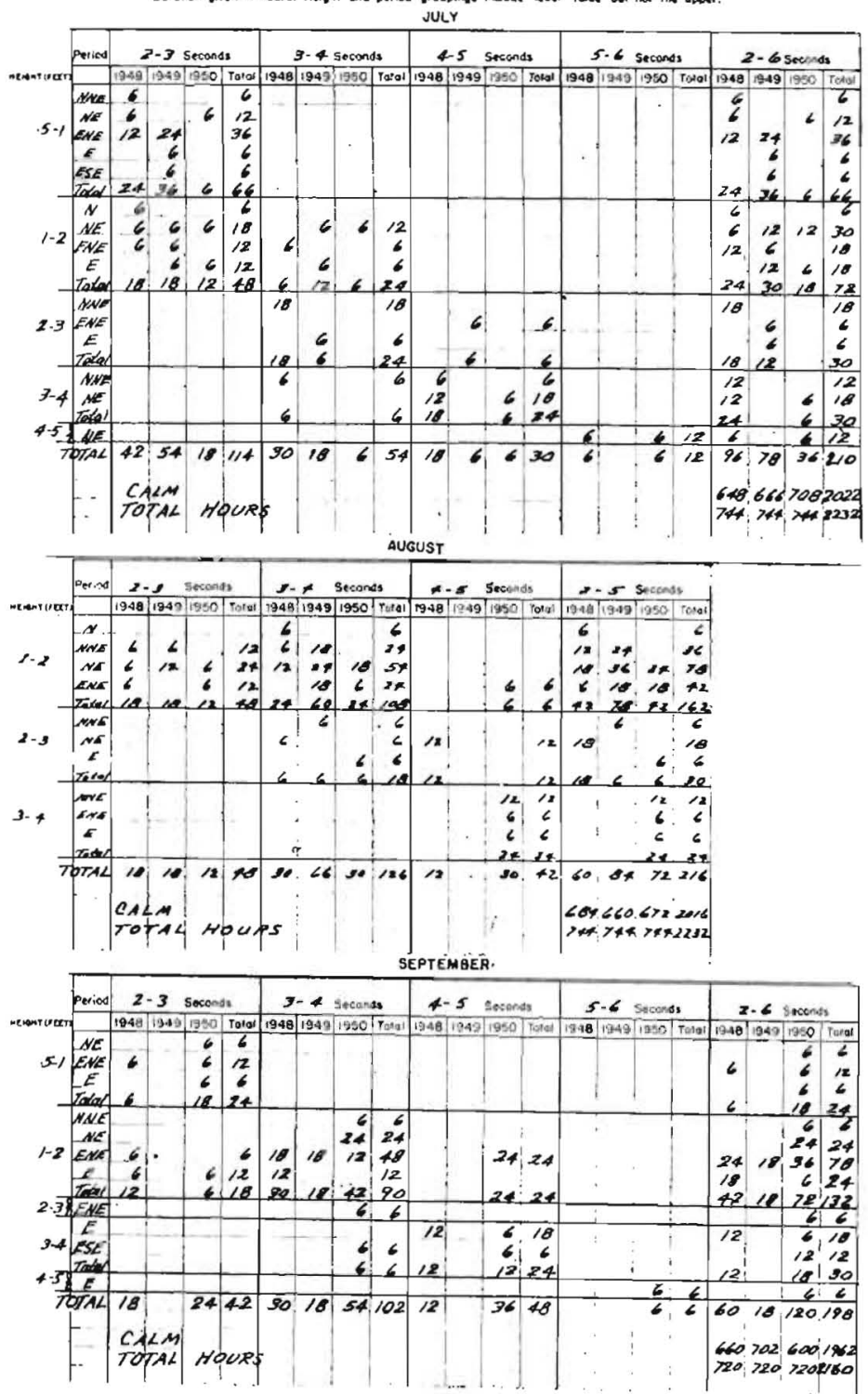
TABLE A.1

STATISTICAL MINDCAST DATA FOR LAXE ONTARIO STATION A, MAMILTON, ONTARIO

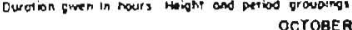
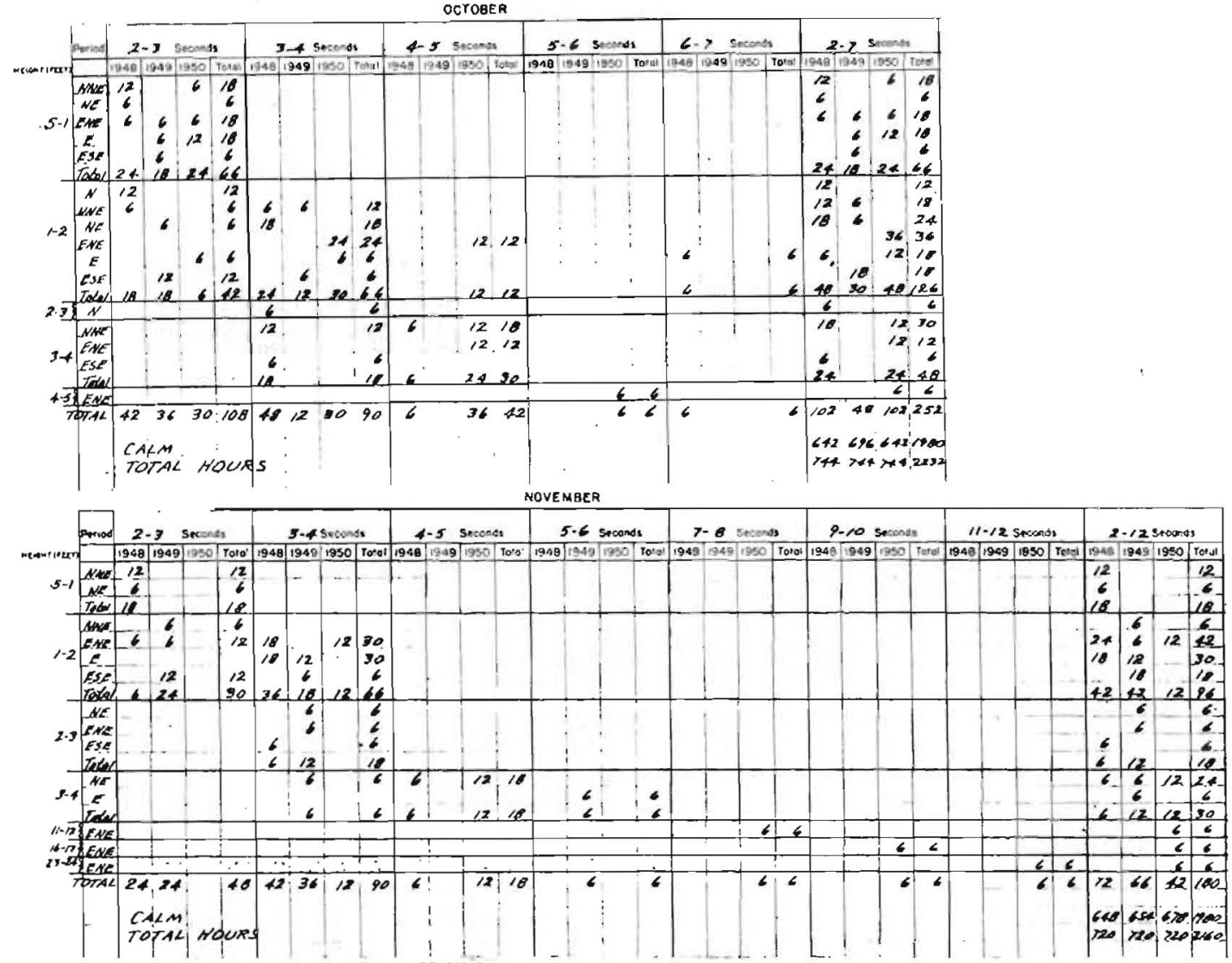

DECEMBER

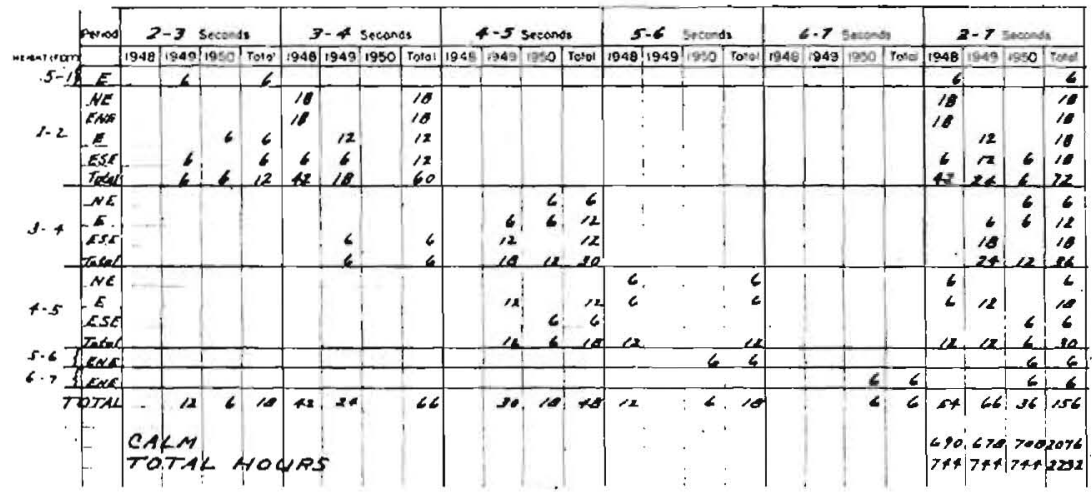




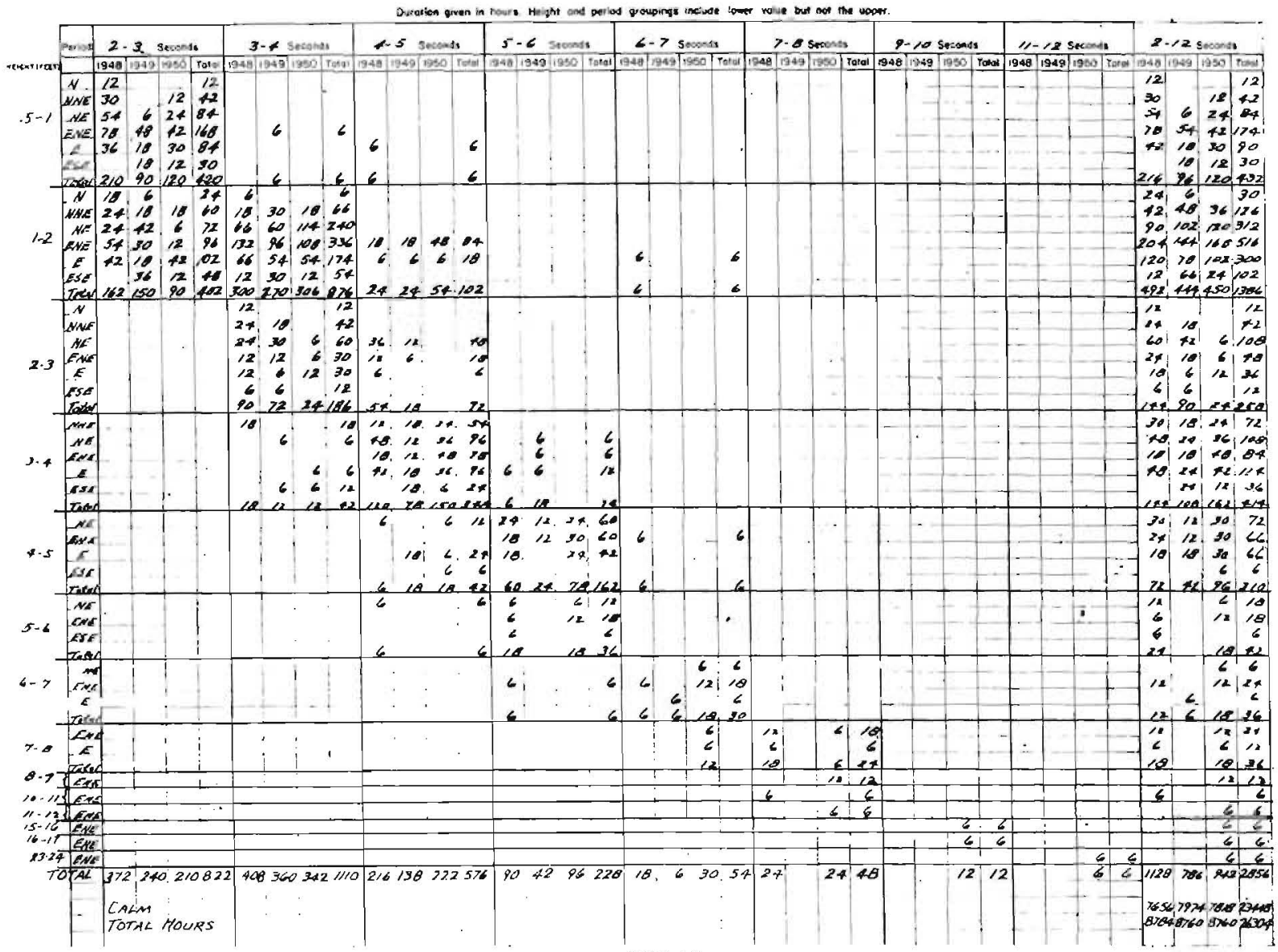

TABLE A.3

STATISTICAL HINOCAST DATA FOA LAXE ONTARIO STATION A, MAMILTON, ONTARIO ICE-FAEE PERIOD (I APRIL- 30 NOV)

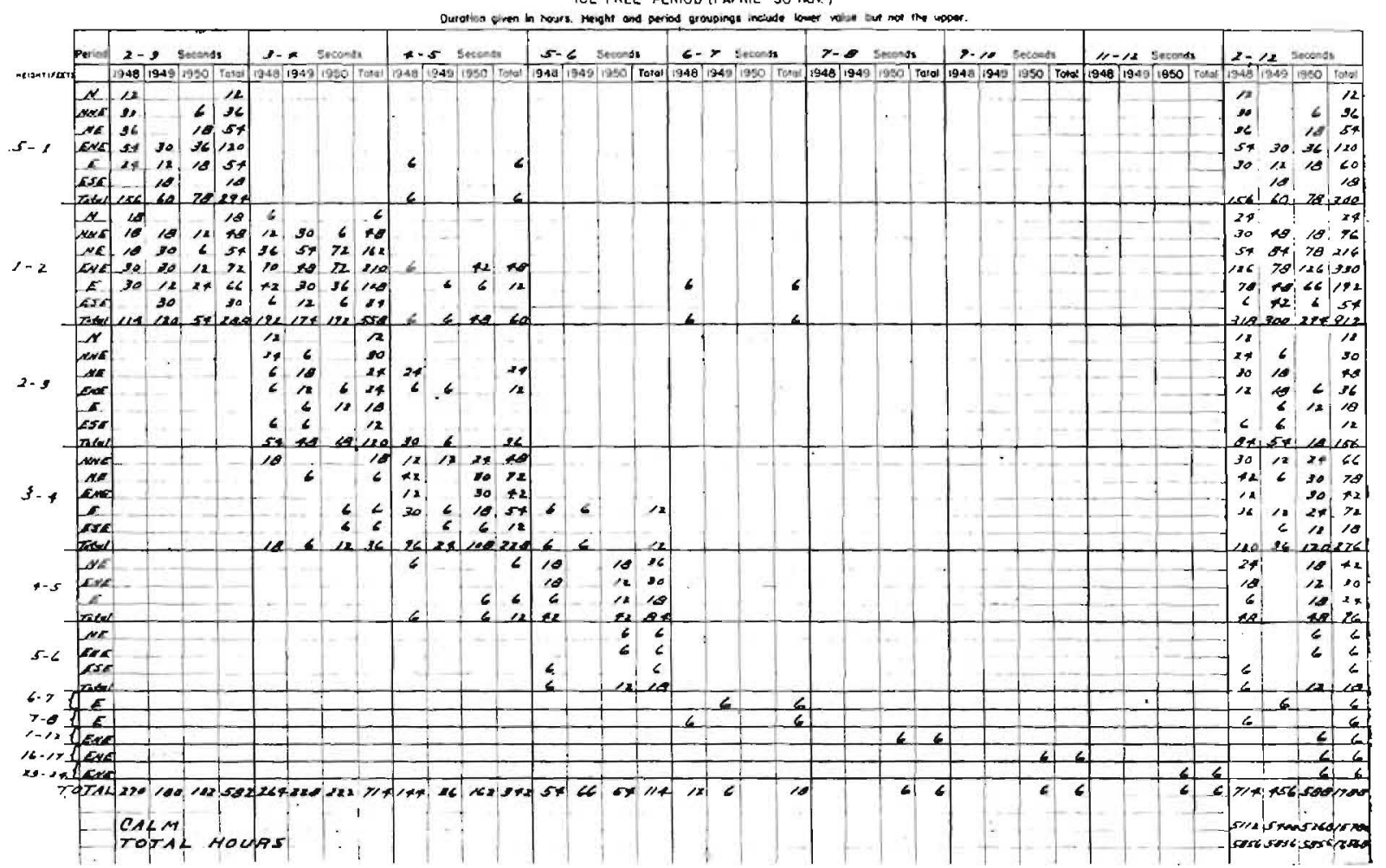


TABLE A-4

STATISTICAL ENERGY DATA FOA LAKE ONTARIO STATION A, RAMILTON, ONTARIO ICE-FREE PERIDO (I $\triangle P R I L$ - 30 NOV)

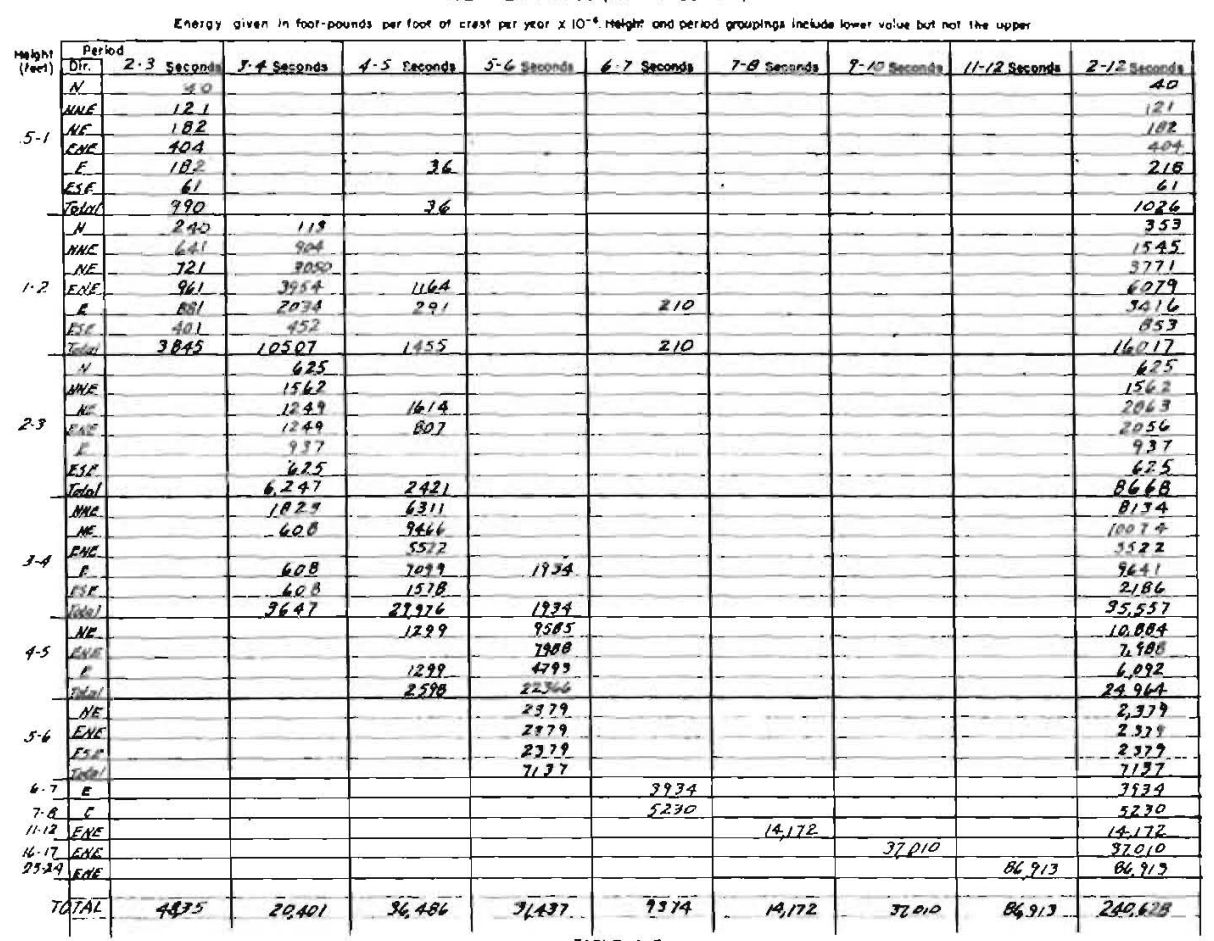

STATISTICAL ENERGY Data FOR LaKE ONTARIO STATION A, MAMILTON, ONTARIO FULL YEAA

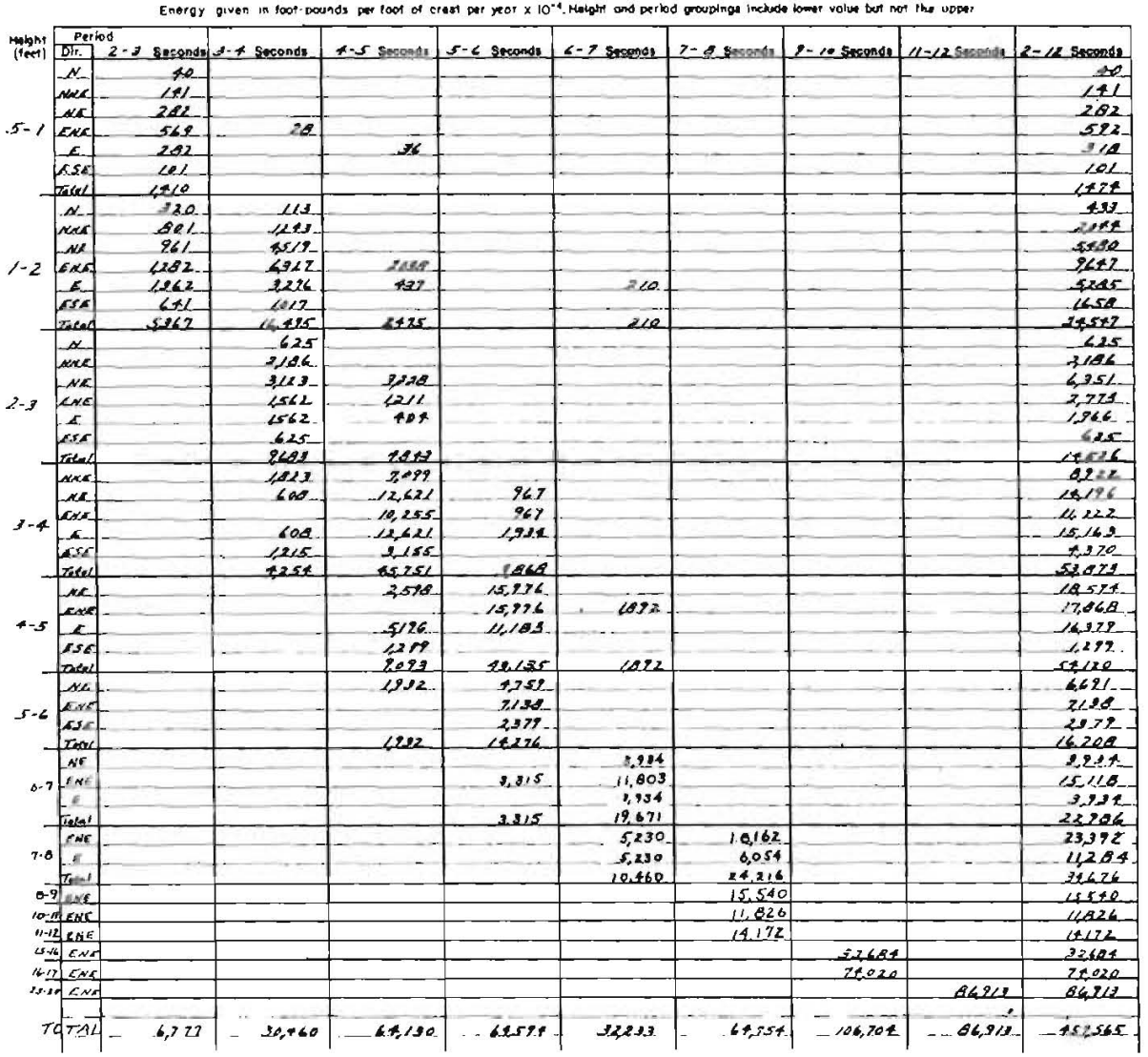




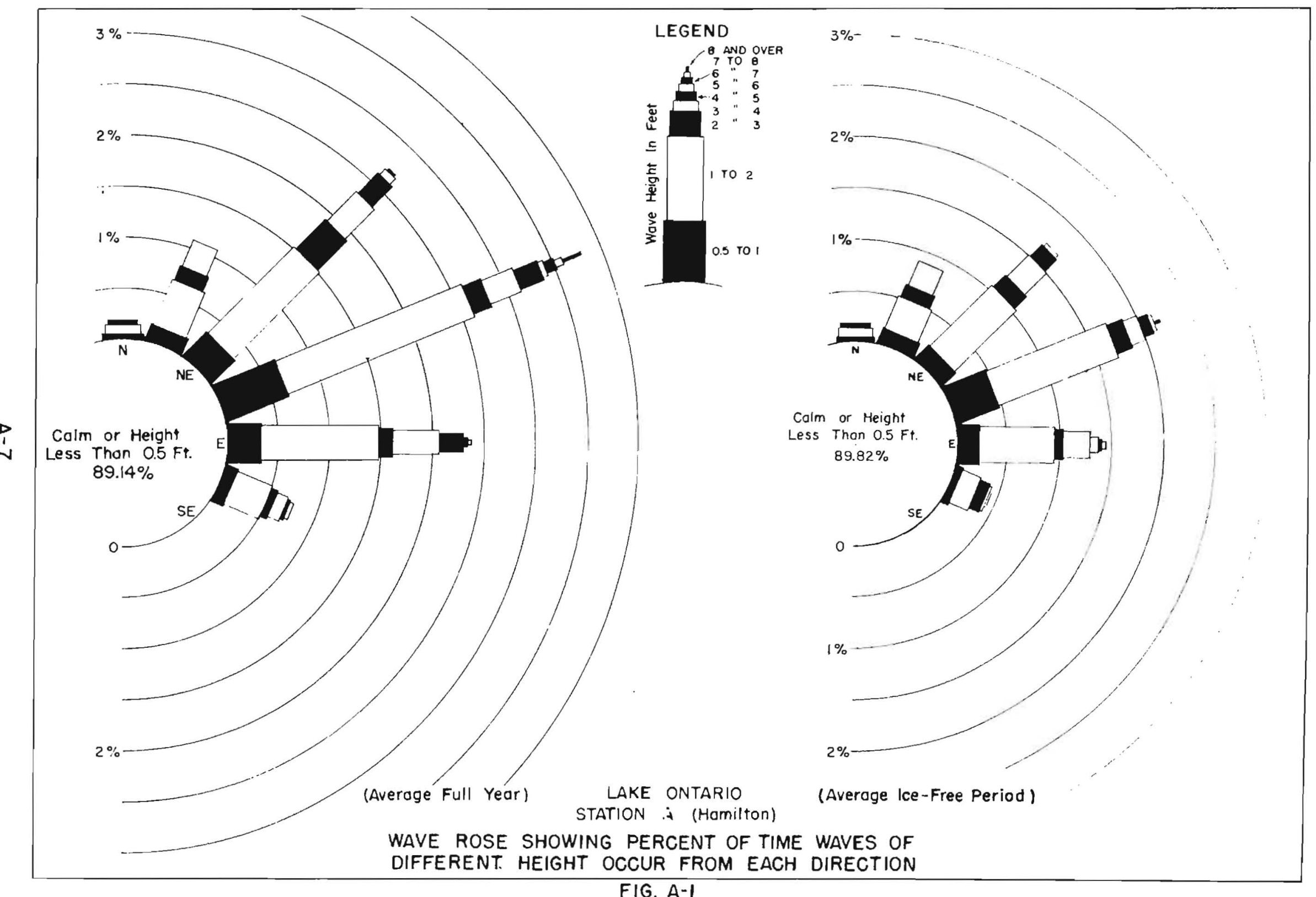

FIG. A-I 

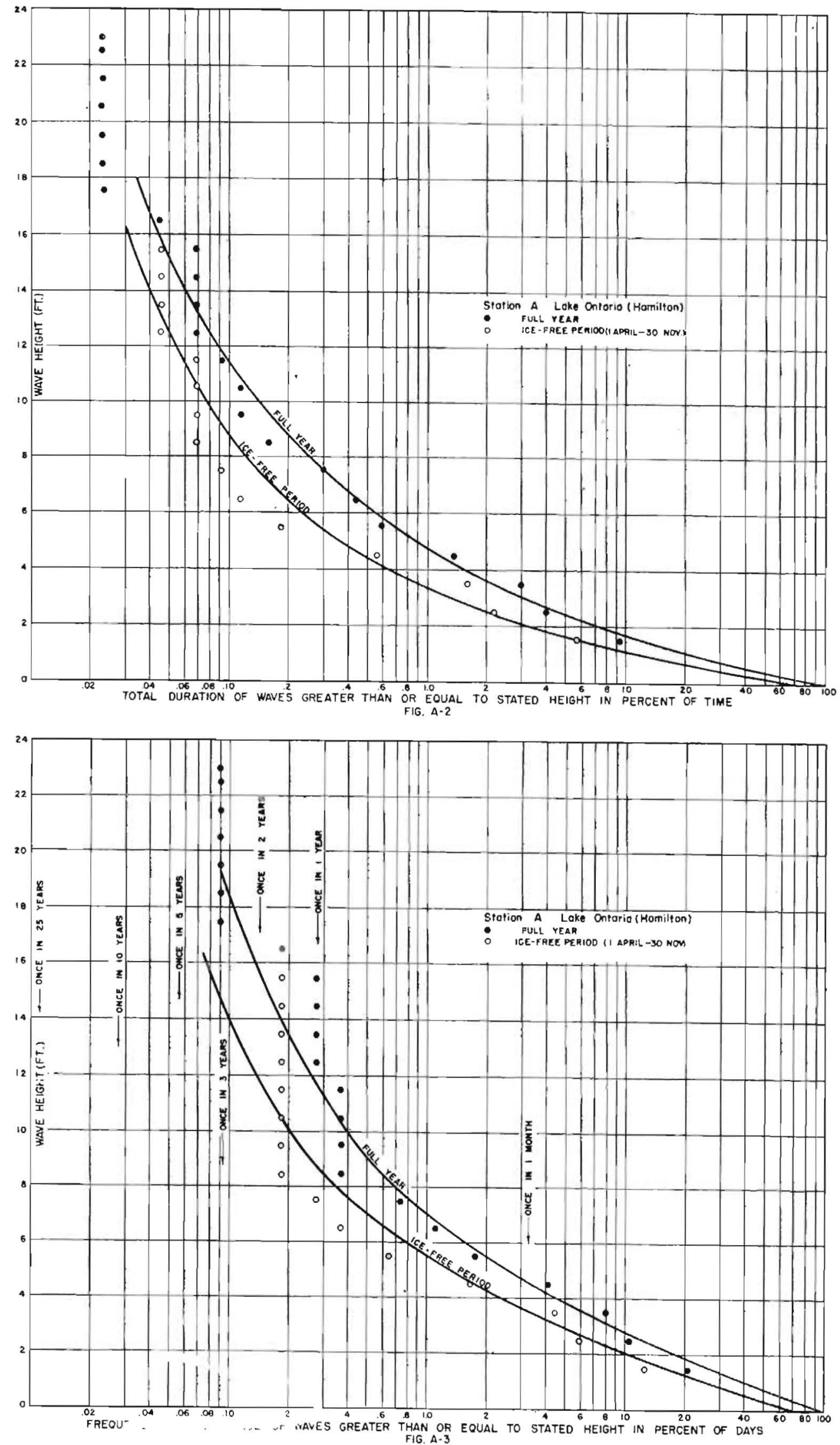


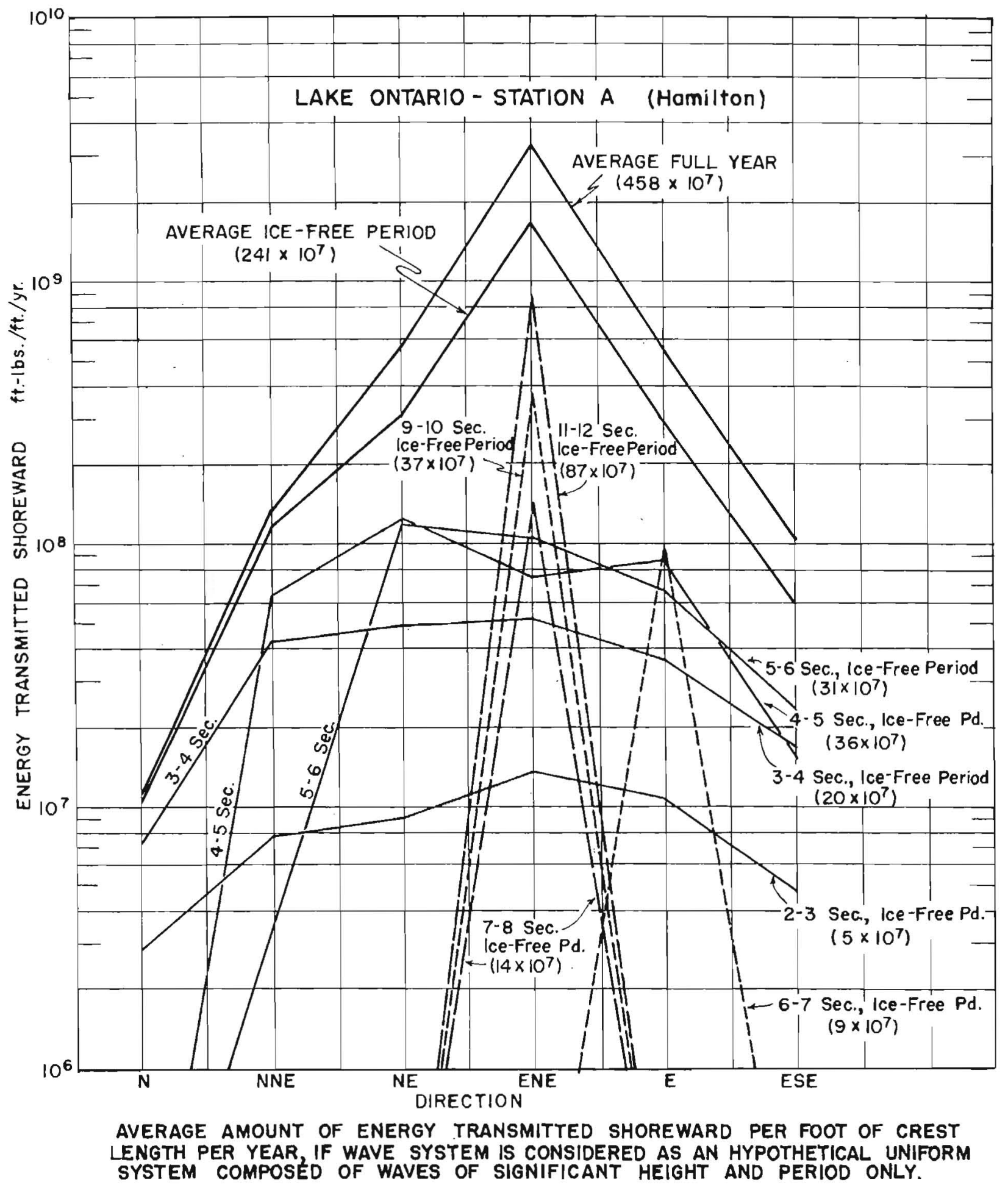

FIG. A-4 
WAVE AND LAKE LEVEZ STATISTICS

FOR

LAKE ONTARIO

APPENDIX B

WAVE STATISTICS

FOR

ROCHESTER, NEW YORK 
TABLE B.I

STATISTIGAL HINOCAST DATA FOR LAKE ONTARIO STATION B, ROCHESTER, N.Y auration grien in hours. Height and period groupings incluce beret value but not the upper.

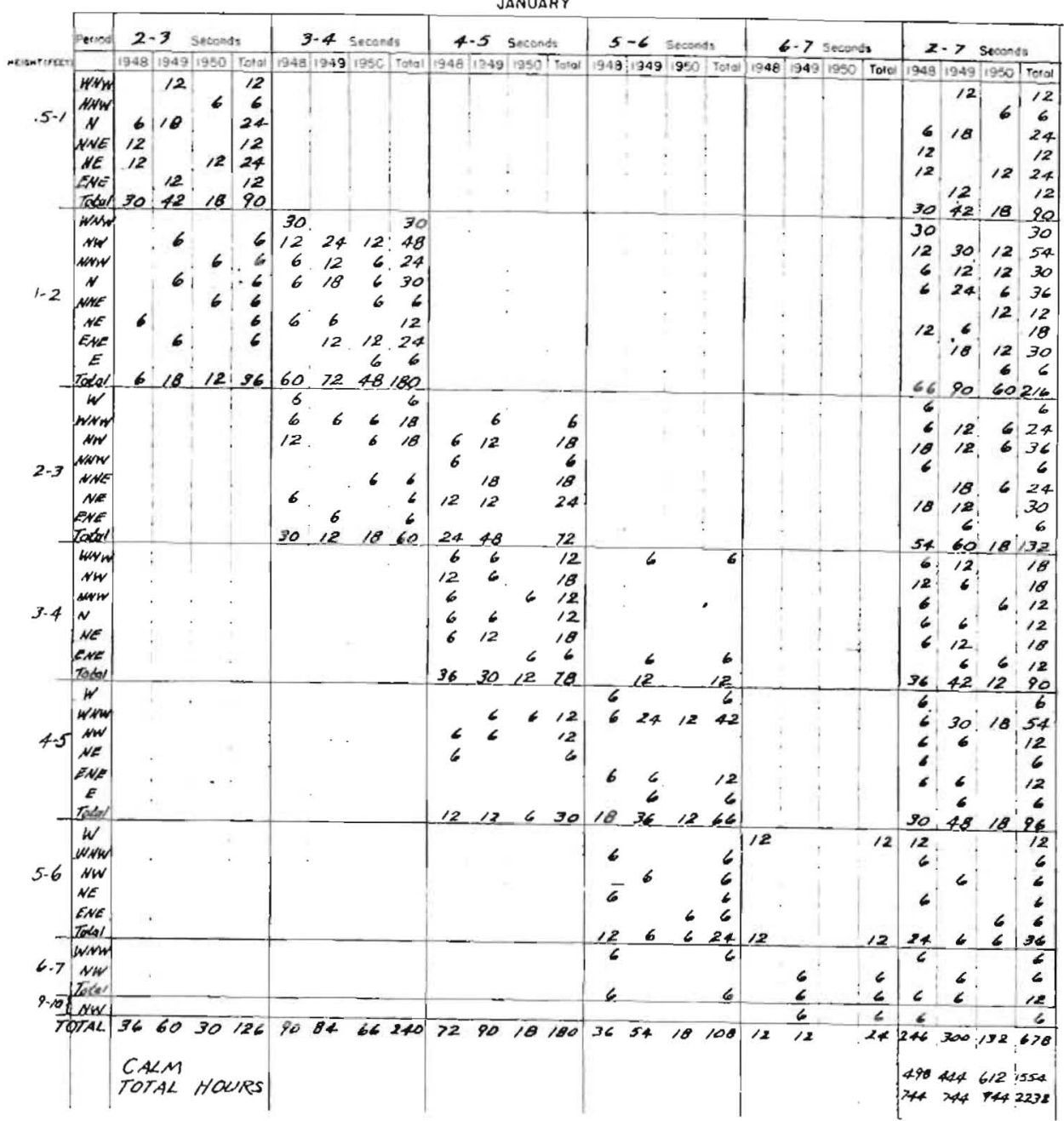


TABLE B-I

STATISTICAL RINDCAST DATA FOR LAKE ONTARIO STATION B, ROCHESTER, N.Y. Duration given in hours. Height ond Deriod groupings include tower wolue but not the uDper.

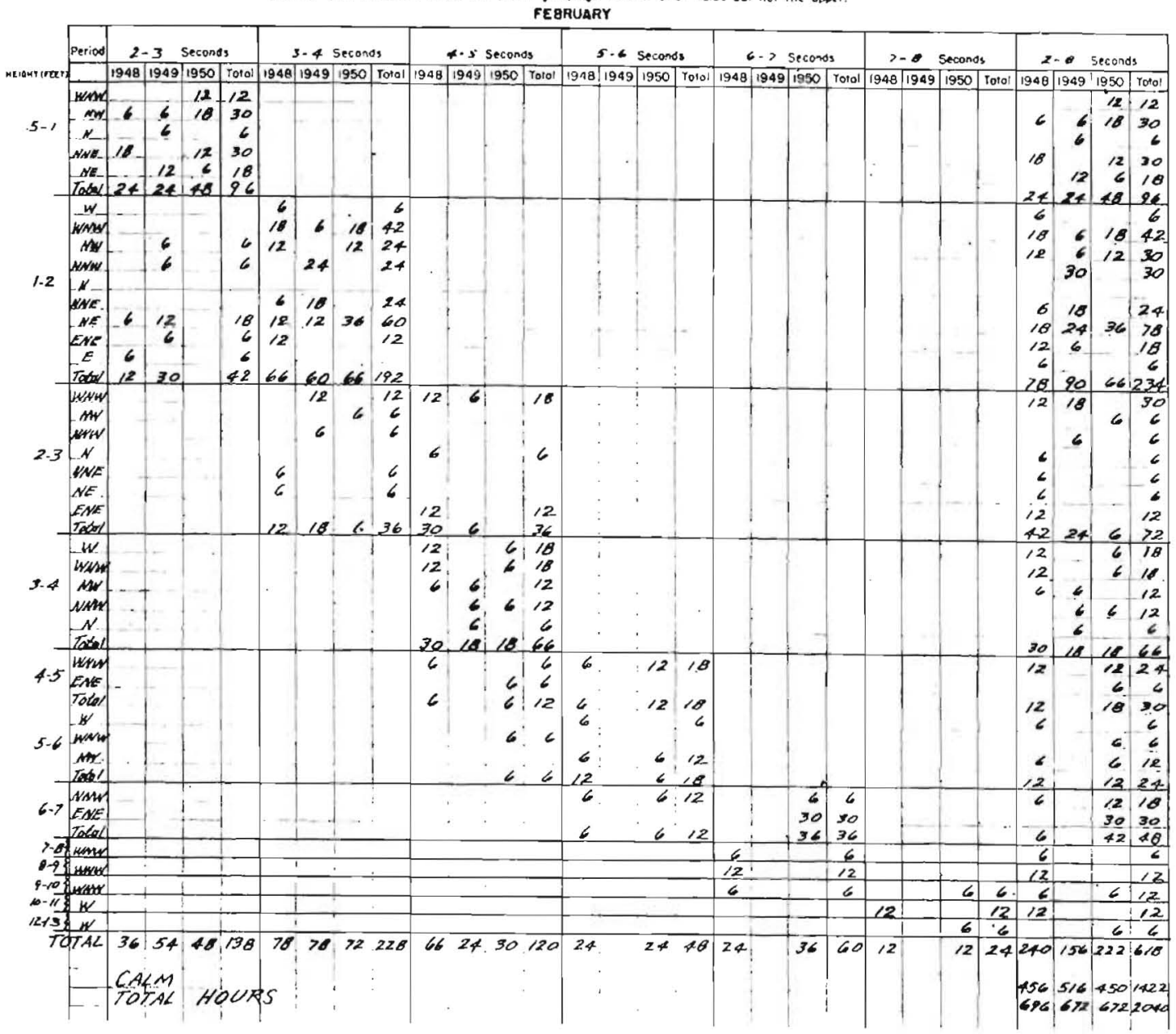


TABLE B-1

STATISTICAL HINOCAST DATA FOR LAKE ONTARIO STATION B, ROCHESTER, N.Y. Duration given in hours. Height and period groupings include loner value but not the upper

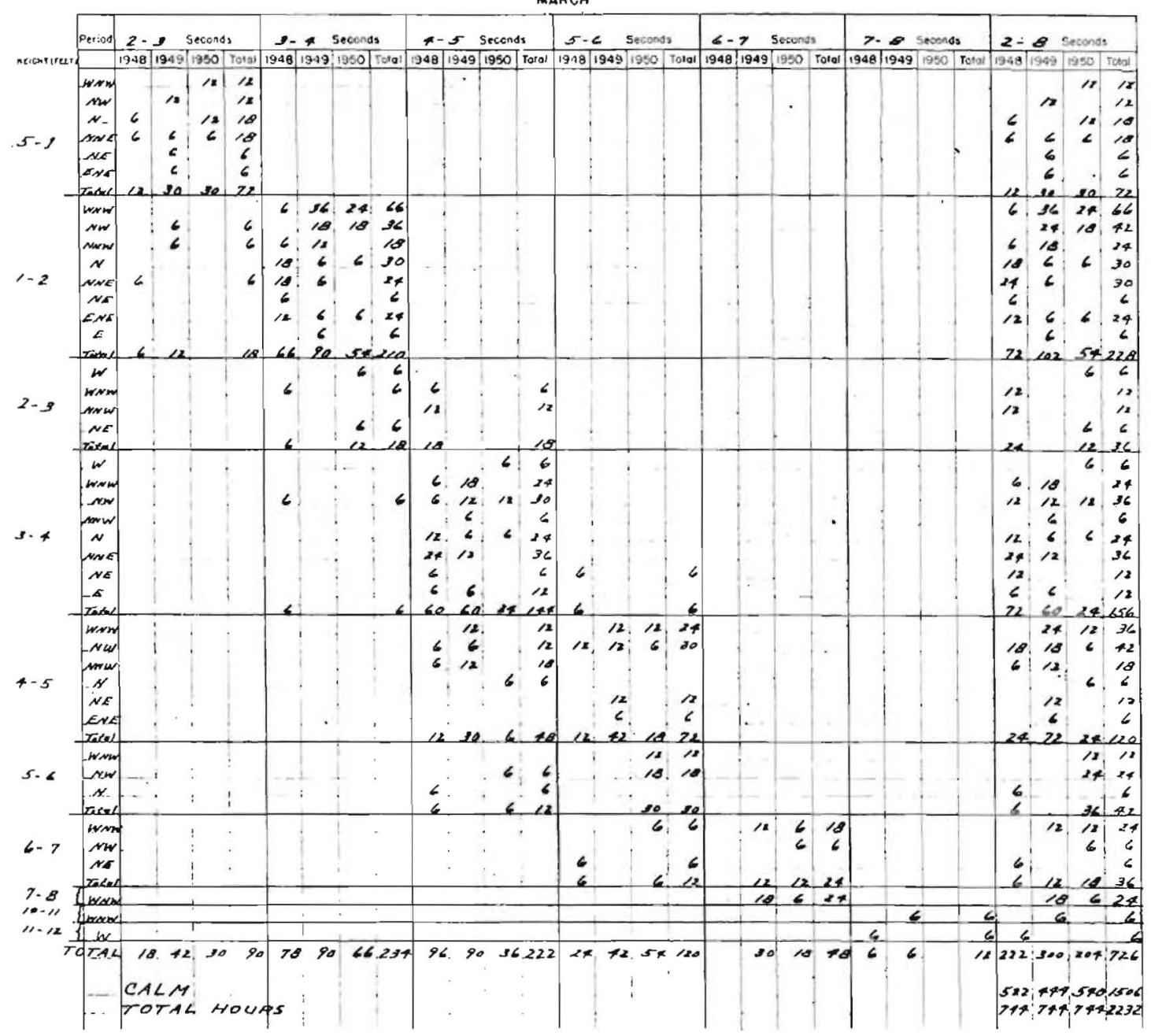


TABLE B-1

STATISTICAL HINOCAST DATA FOR LAKE ONTARIO STATION B, ROCHESTER, N.Y. burotion given in hours. Height and detrios groupings include bewer wolus but not the udoper

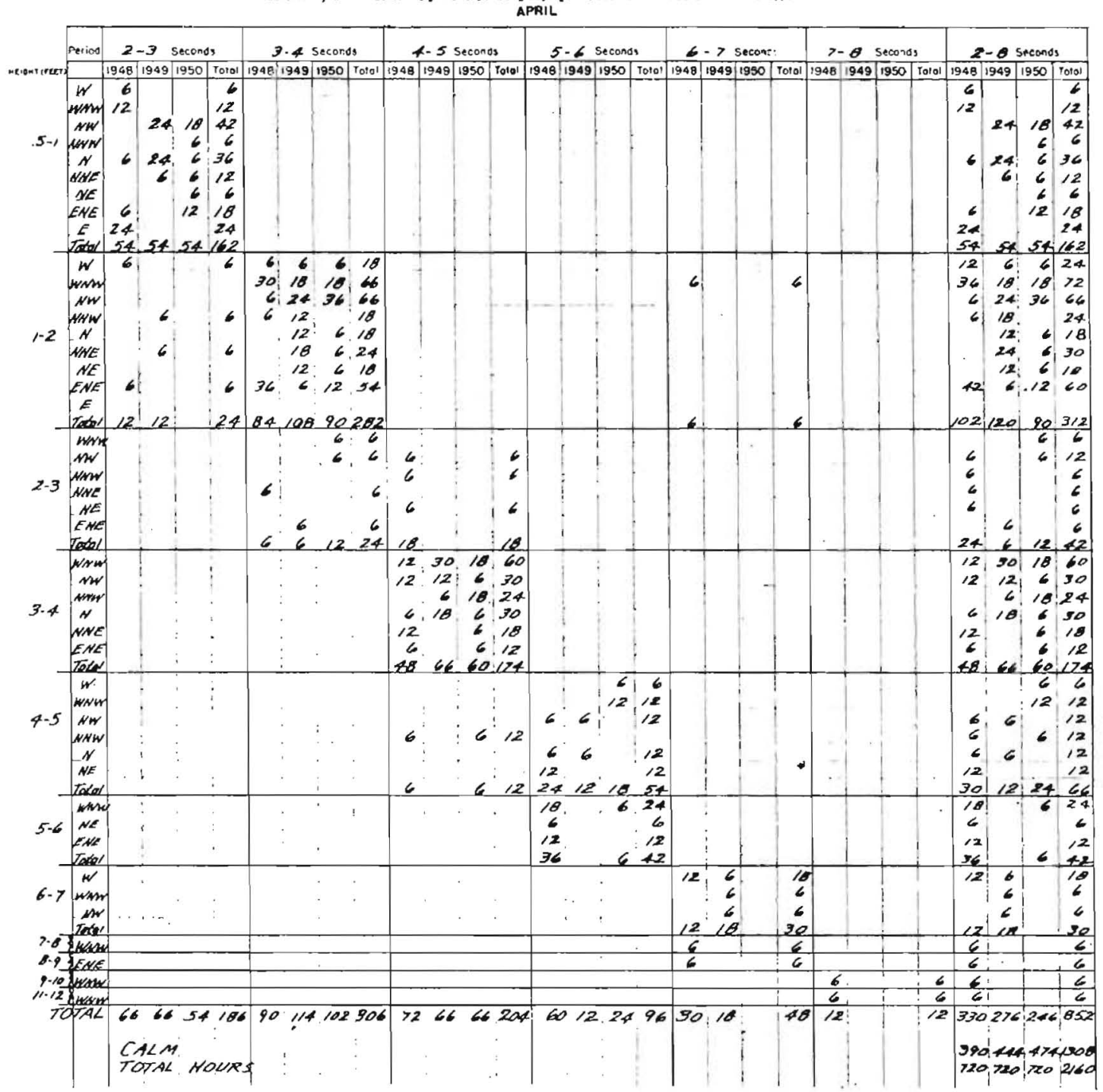


TABLE $B=1$

STATISTICAL MINDGAST DATA FOR LAKE ONTARIO STATION B, ROCHESTER, N.Y

Durotion given in hours. Height and period groupings include bower volue but not the upper.

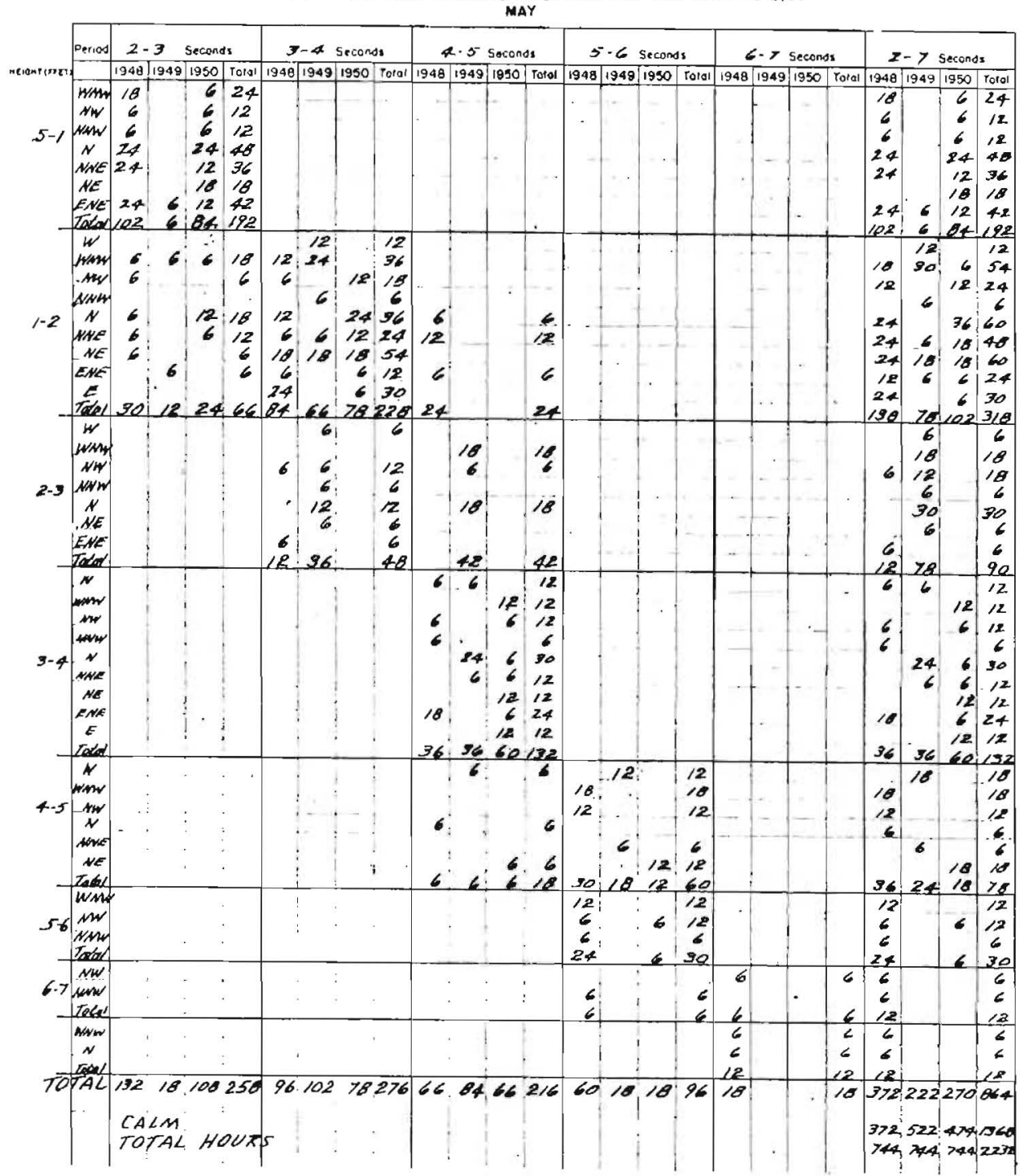


TABLE B-I

STATISTICAL HINDCAST DATA FOR LAKE ONTARIO STATION B, ROCHESTER, N.Y. Curation gien in hours. Height ond period groupings include lower value but not the ufper
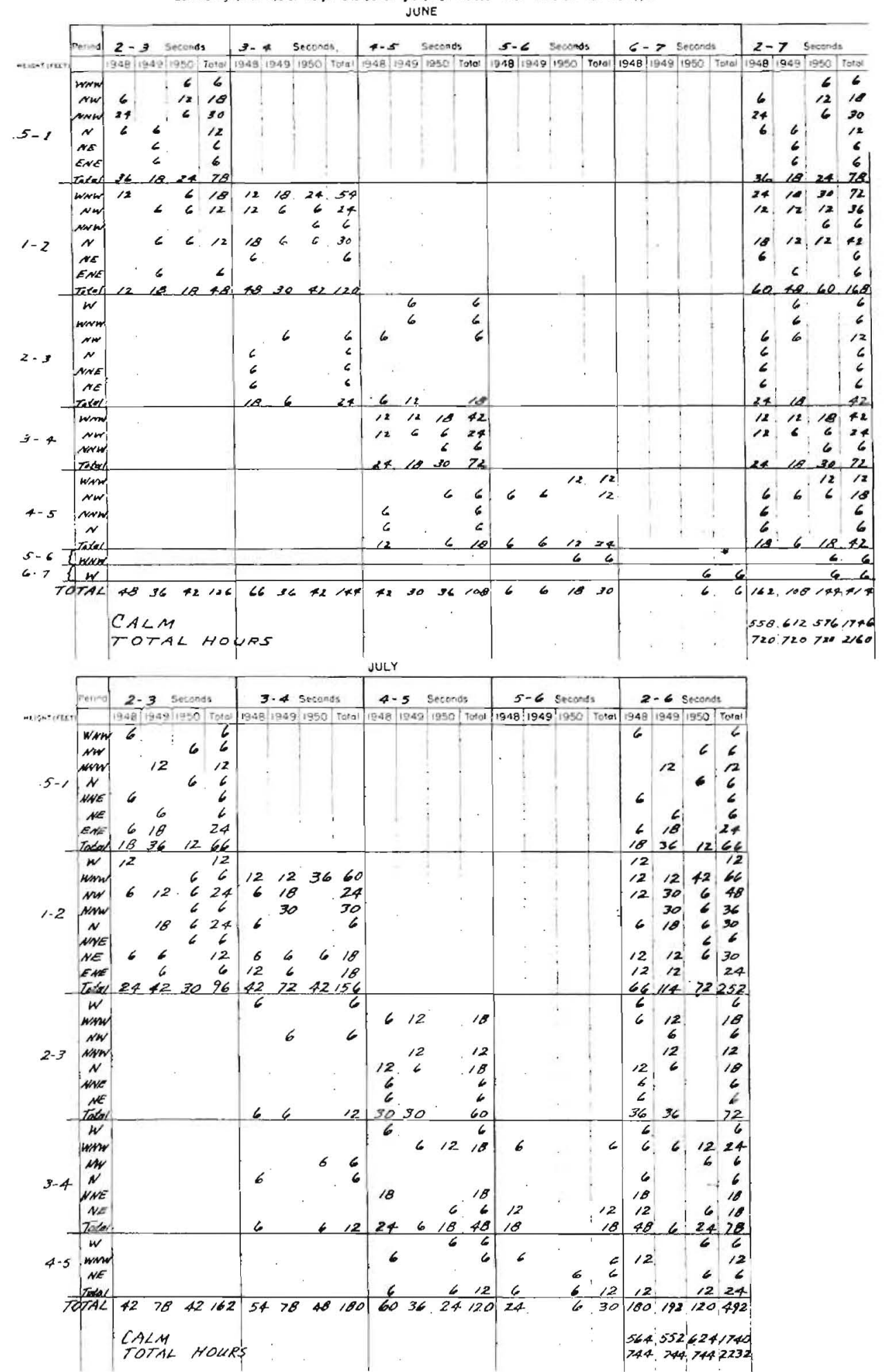
TABLE B-I

STATISTICAL MINDCAST DATA FOR LAKE ONTARIO STATION B, ROCHESTER, N.Y. Durgtion given in hours.

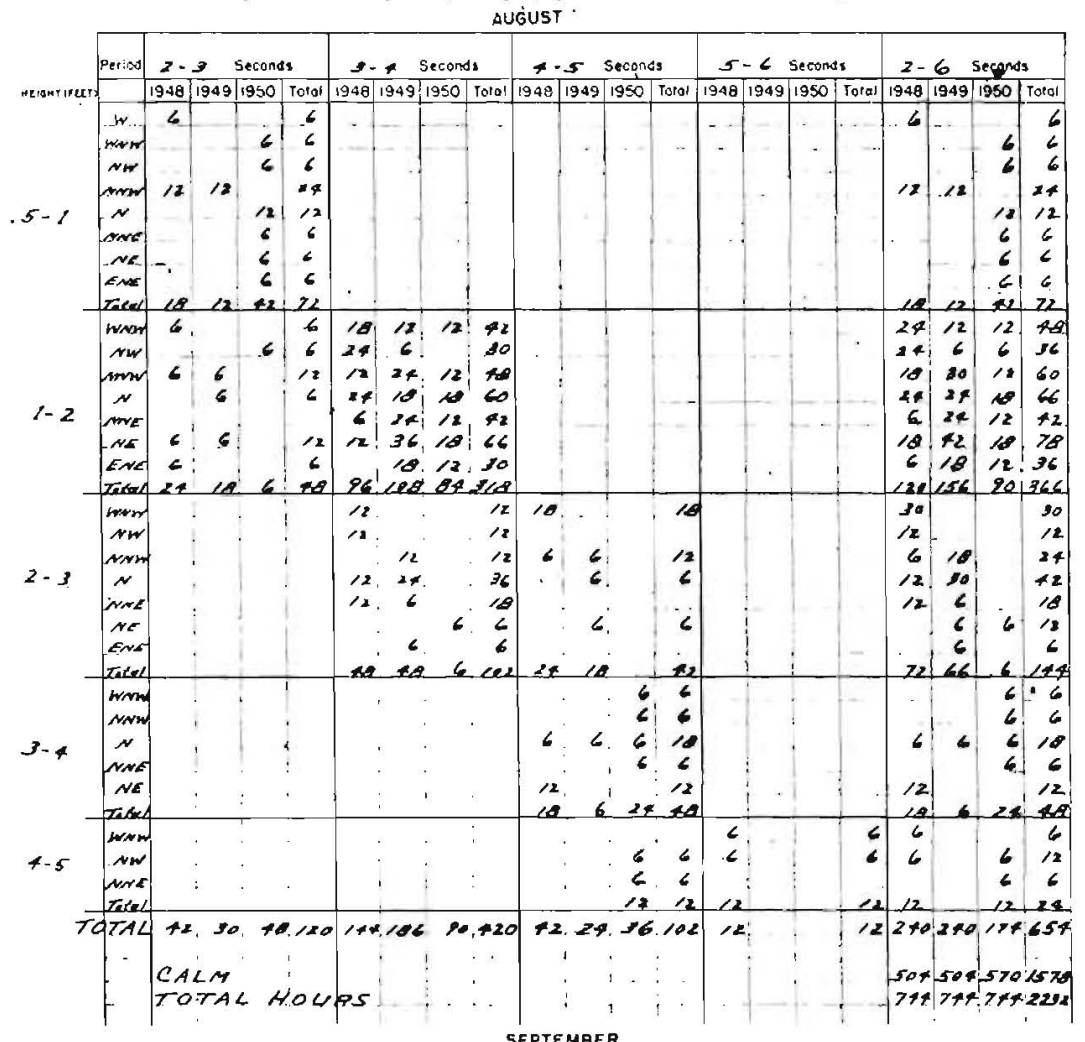

SEPTEMBER

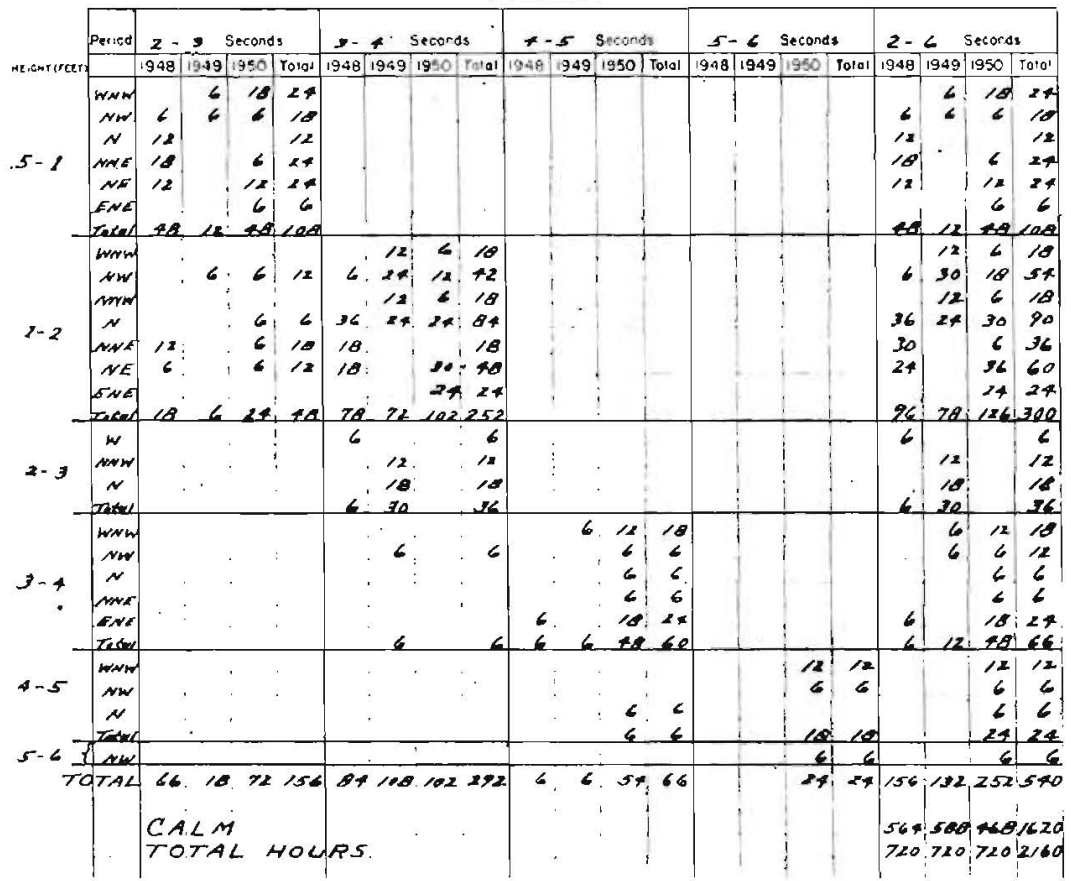


TABLE $8-1$

STATISTIGAL MINDGAST DATA FOR LAKE ONTARIO STATION \& ROCHESTER, N.Y.

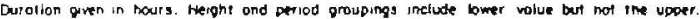

octoaen

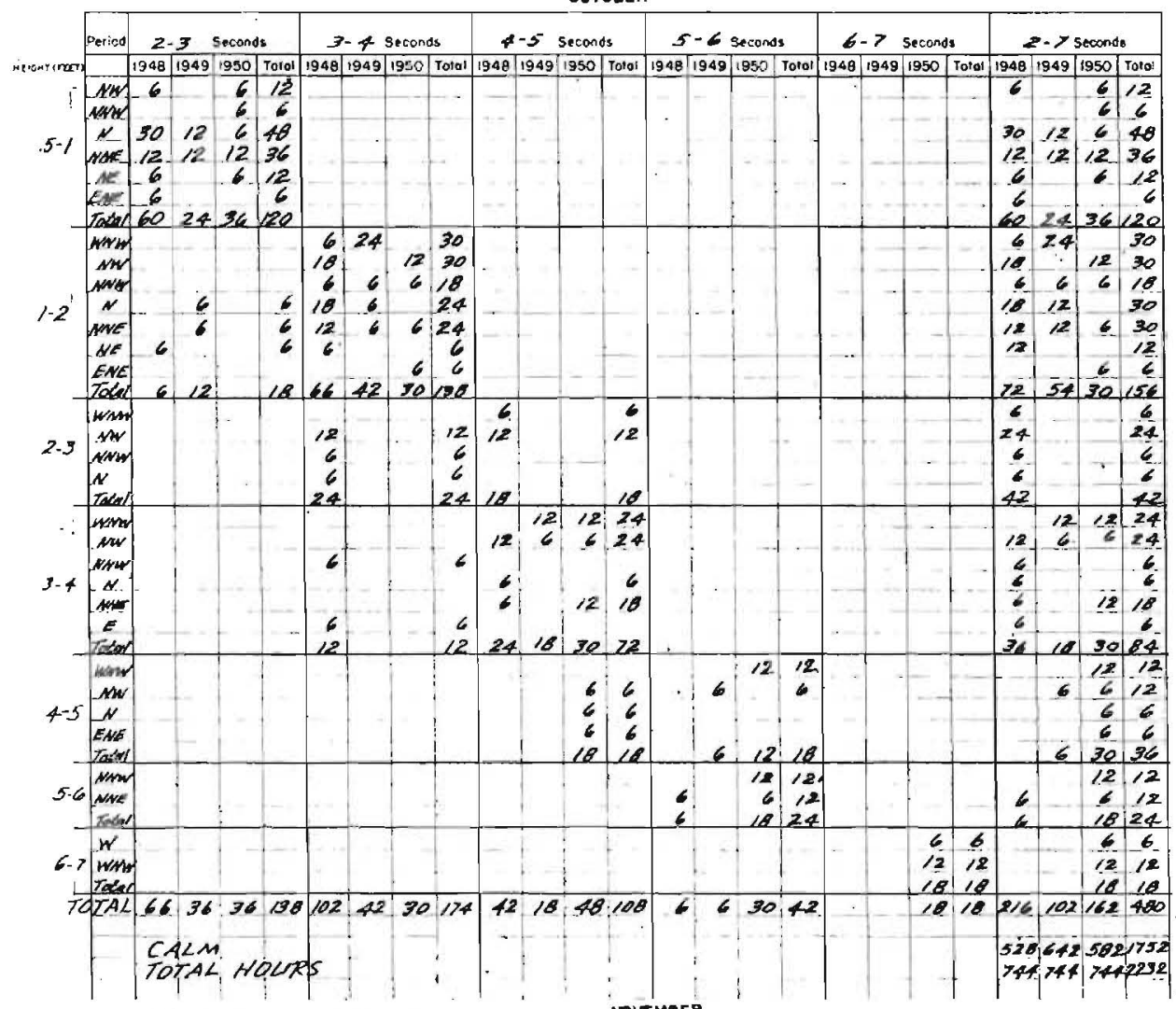

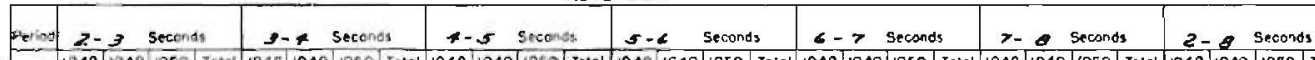

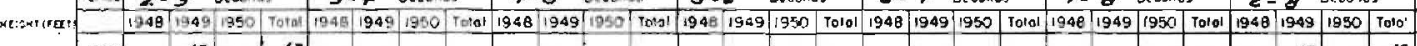

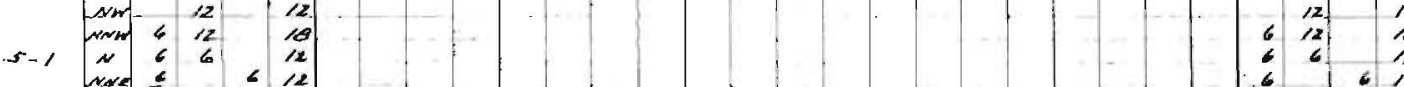

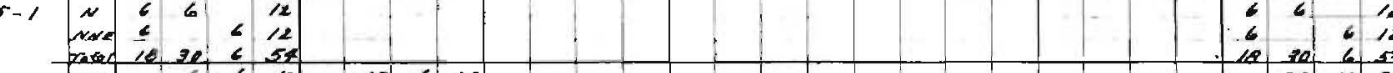

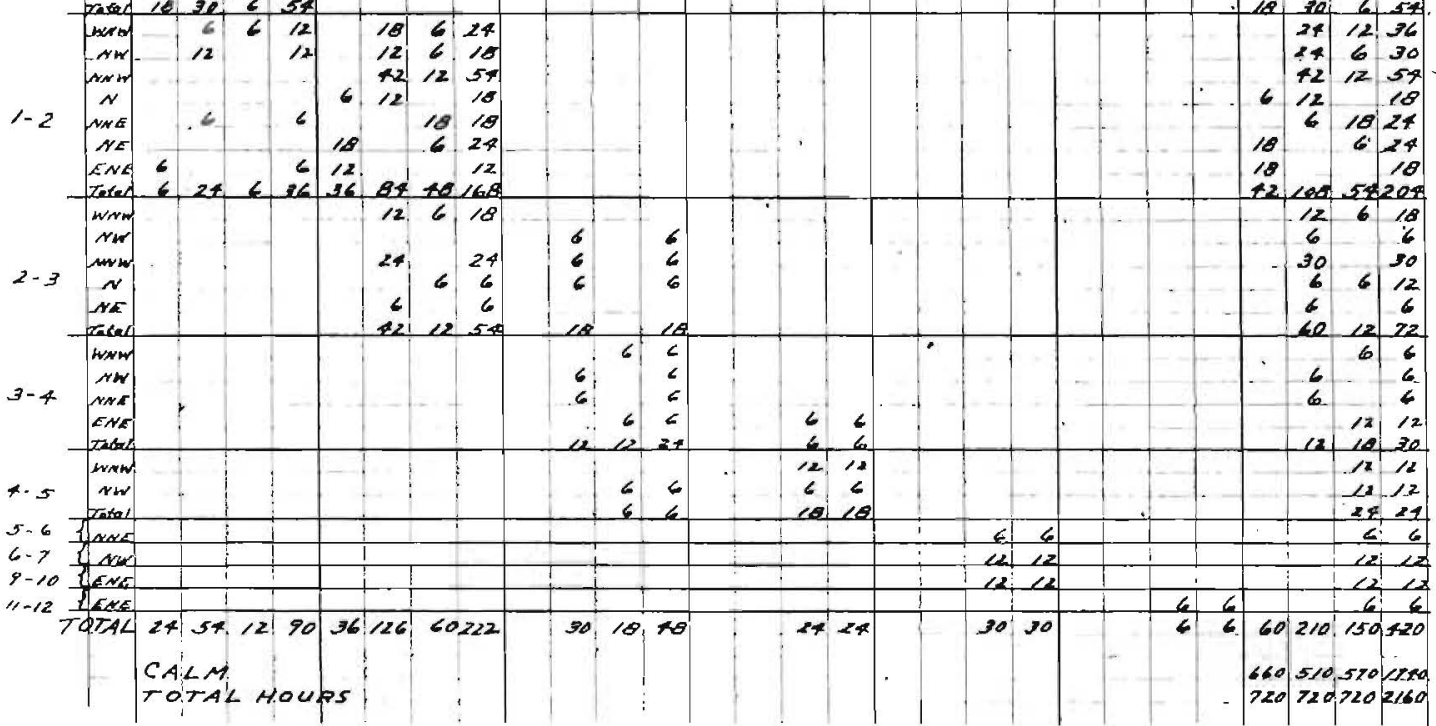


TABLE $8-1$

ITATISTICAL HINDCAST DATA FOR LAKE ONTARIO STATION $\theta$, ROCHESTER, N.Y.

Duration given in hases. Meight ord period groupings include bomer value but not ine upper.

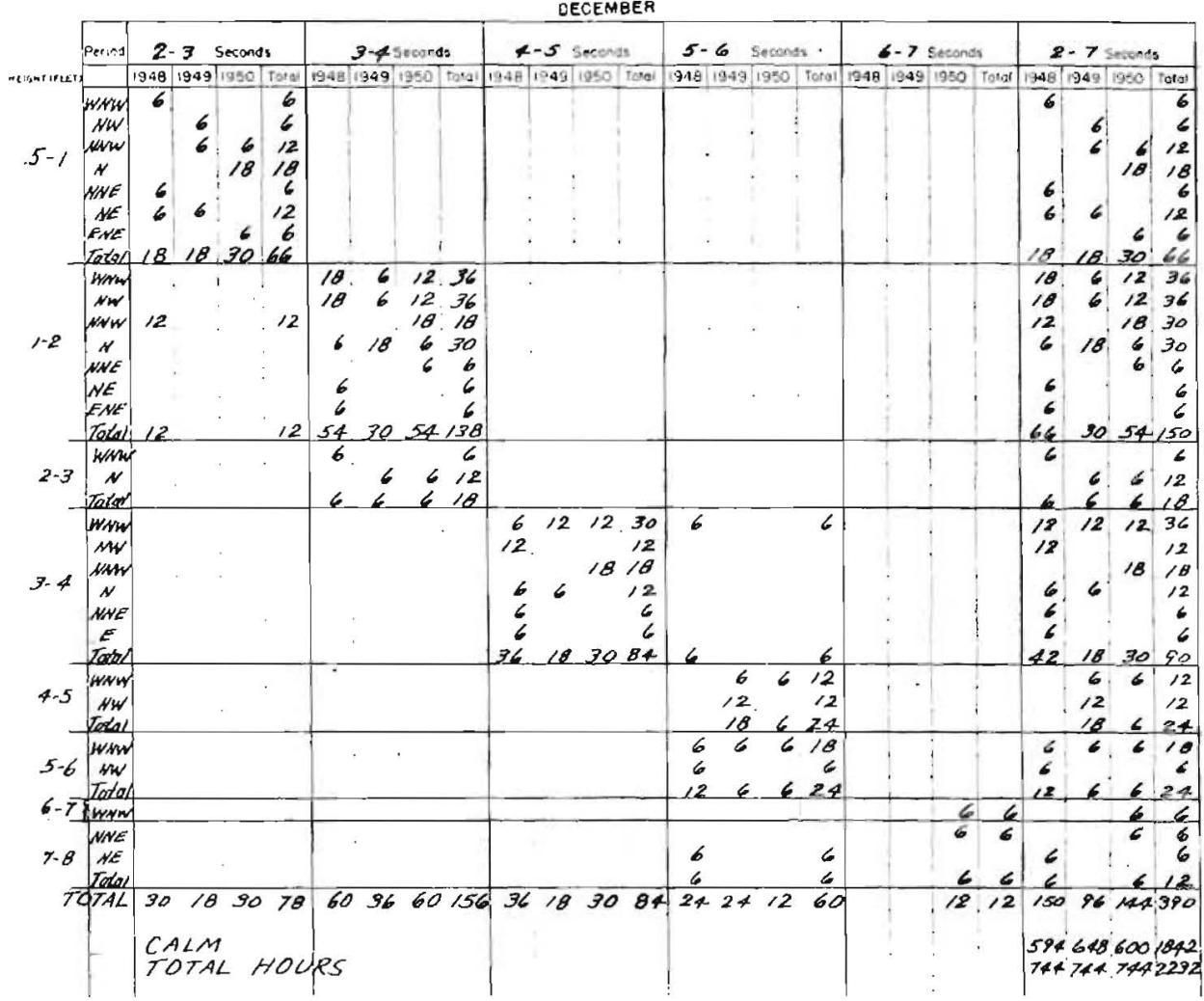


TABLE B-2

STATISTICAL HINDCAST DOTA FOR LAKE ONTARIO STATION B, ROCHESTER, N.Y. FULL YEAR

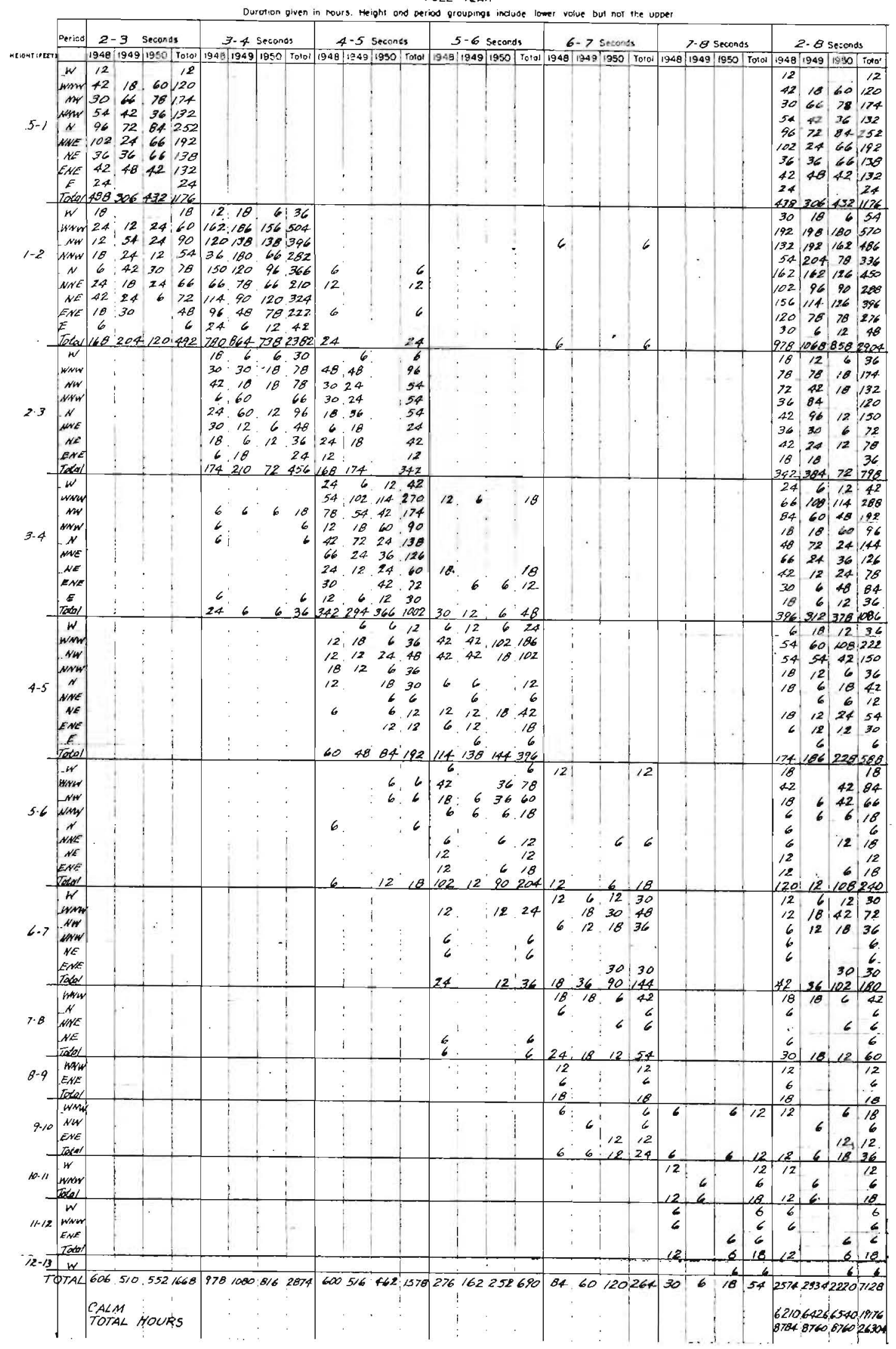


TABLE B-3

STATISTICAL HINDGAST DATA FOR LAKE ONTARIO STATION \&, ROCHESTER, N.Y ICE-FREE PERIOD II APRIL - 30 NOV.

Quration given in hours. Heaght and gersod groupings inciuce lower value but not the upper.

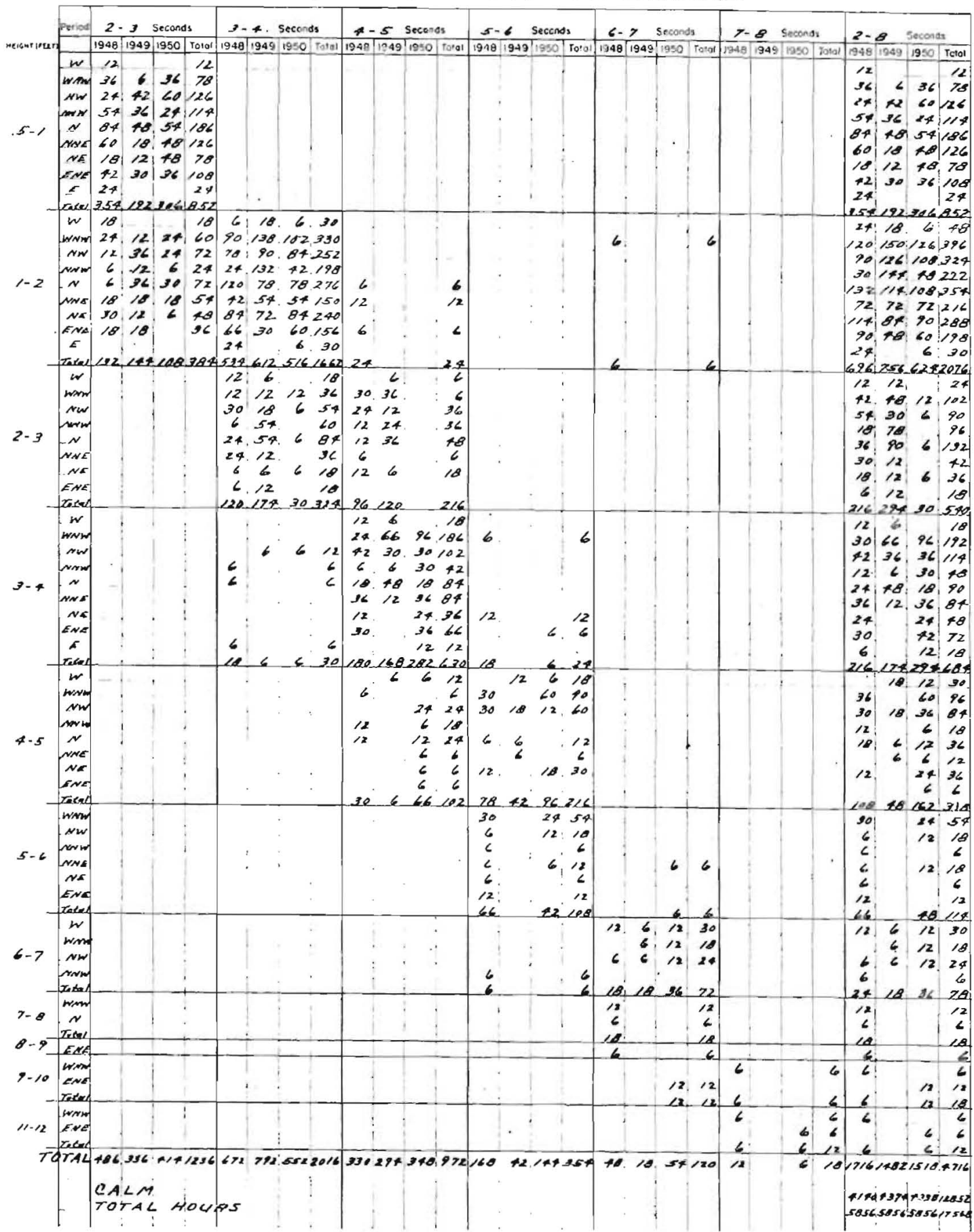


TABLE B-4

STATISTICAL ENERGY DATA FOR LAKE ONTARIO STATION B, ROCHESTER, N.Y

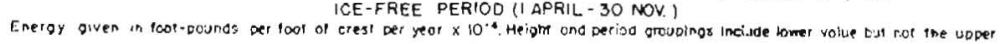

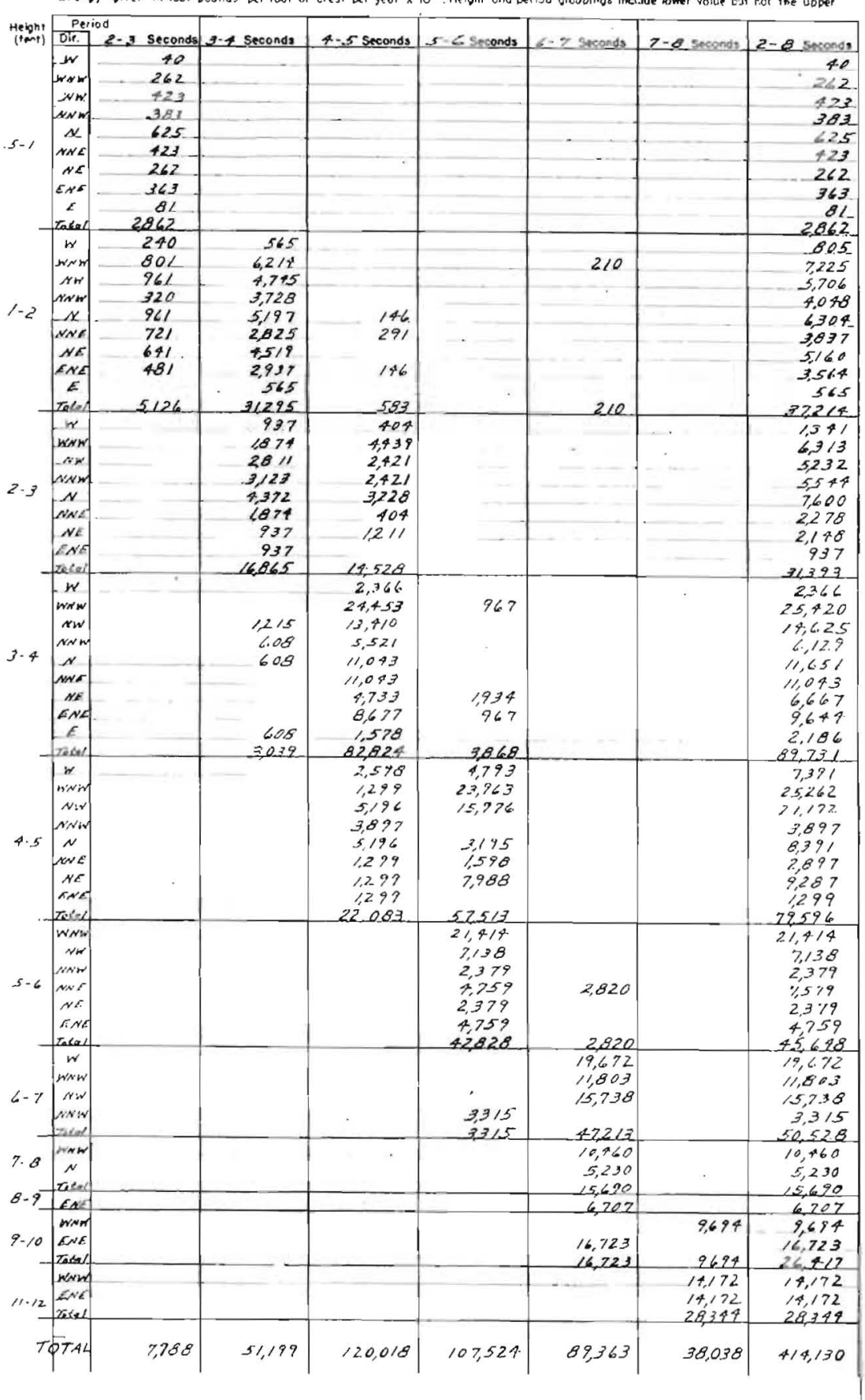


TABLE B-5

STATISTICAI. ENERGY DATA FOR LAKE DNTARIO STATION B, ROCHESTER, N.Y.

FULL YEAR

Energy aiven in foot.pounda per foot of crest per year $\times 10^{-4}$. Height ond period grouplngs inglude lower volue but not the upper

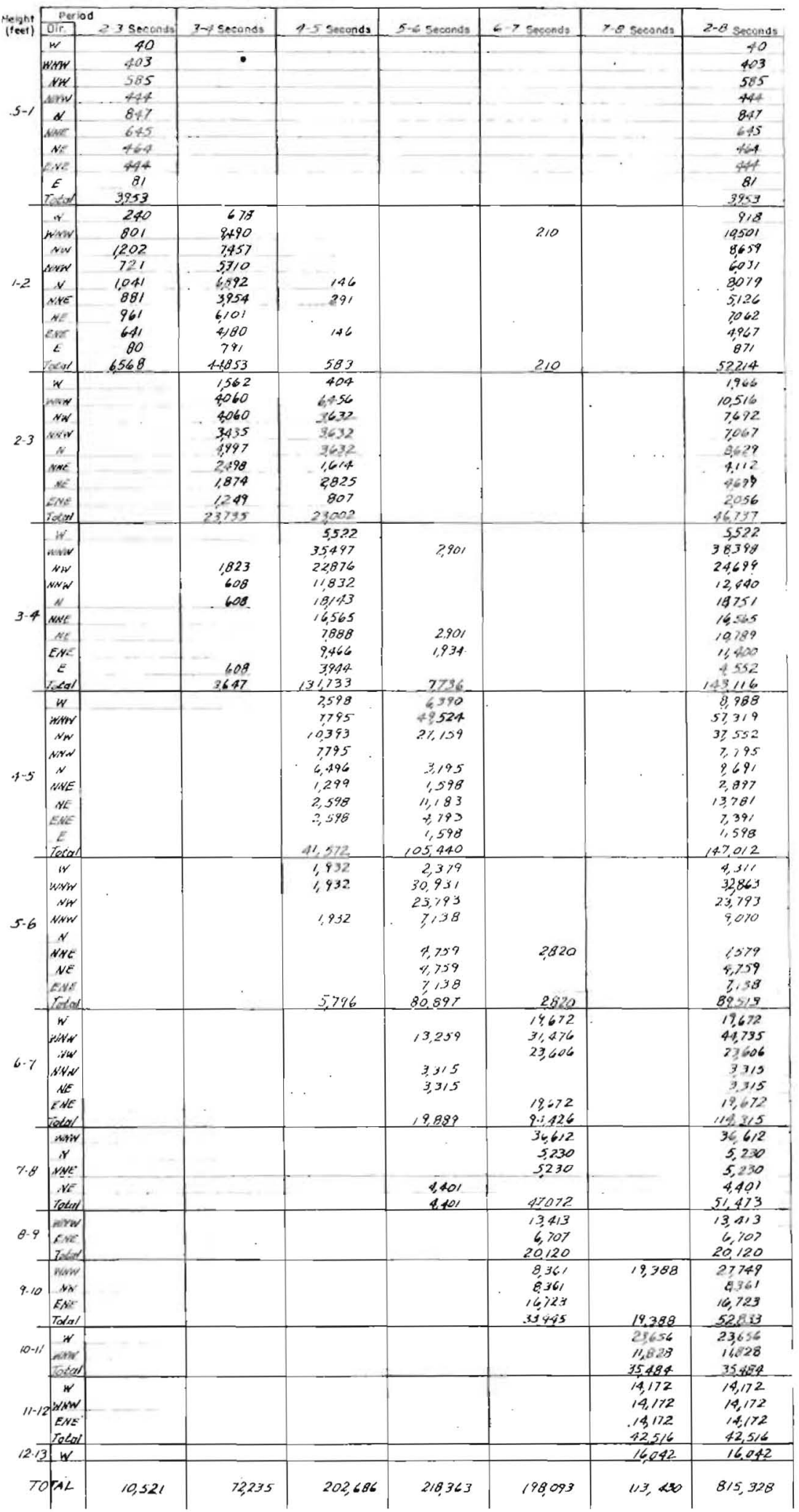




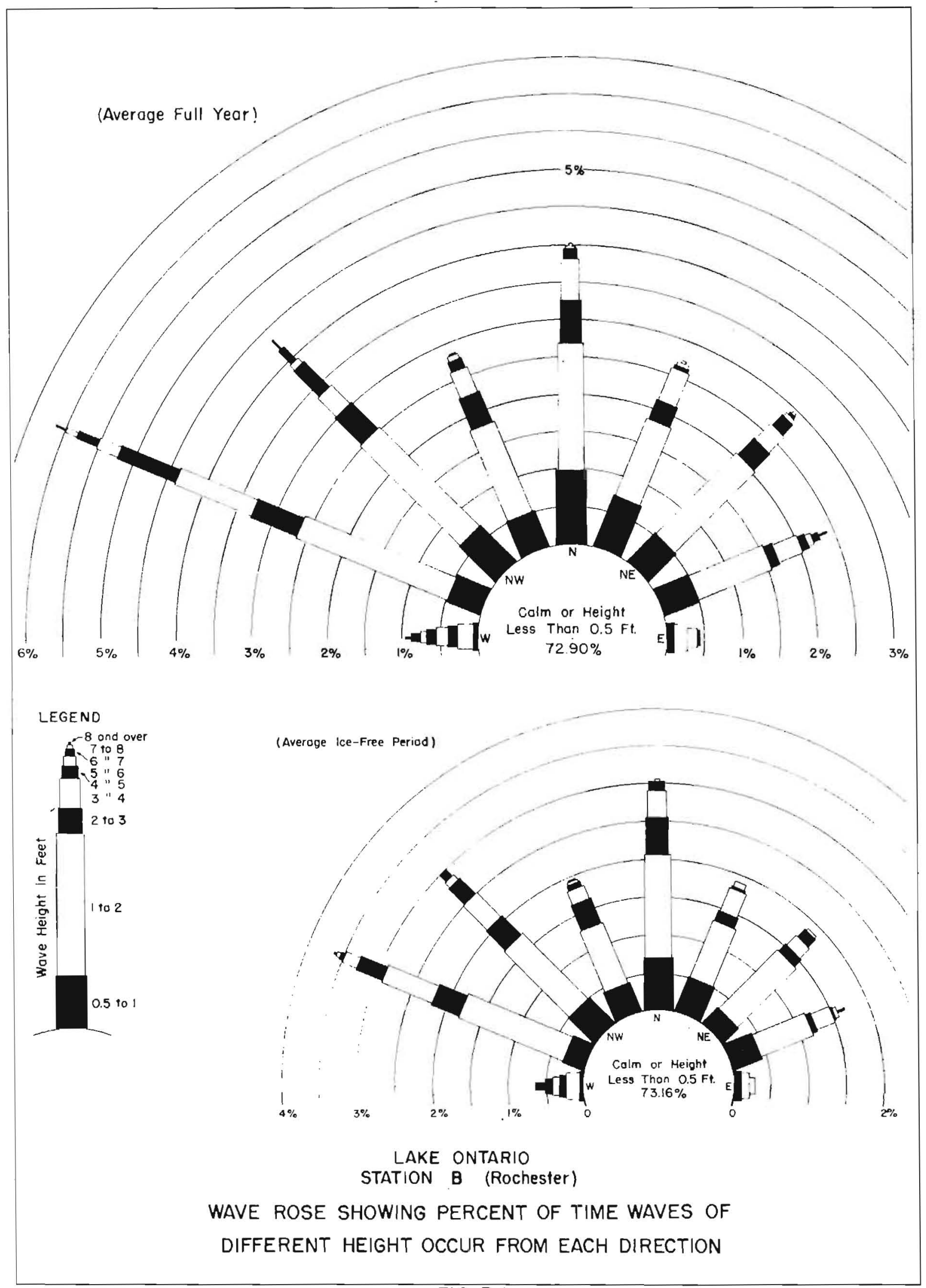

FIG. B-I 

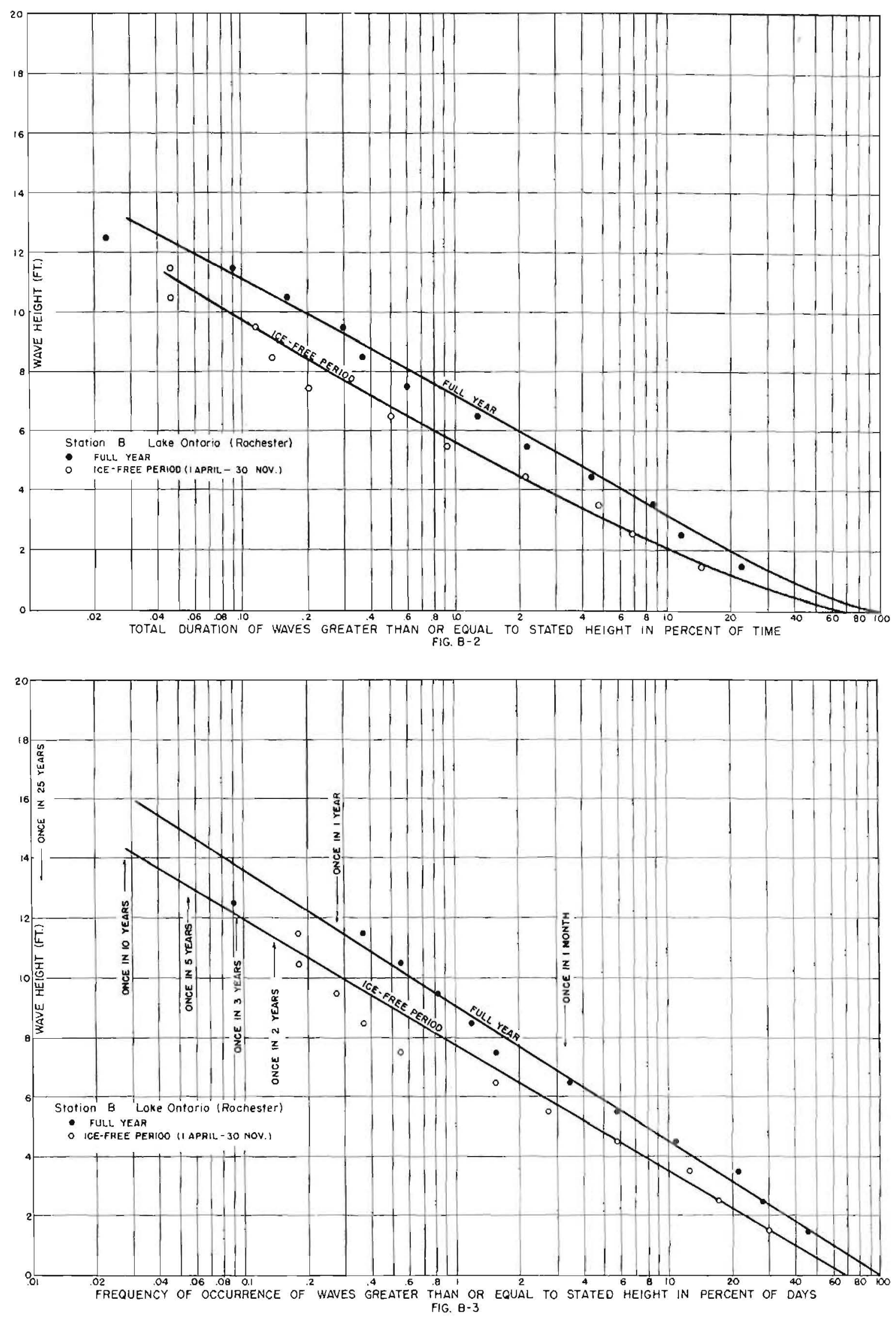

$B-15$ 


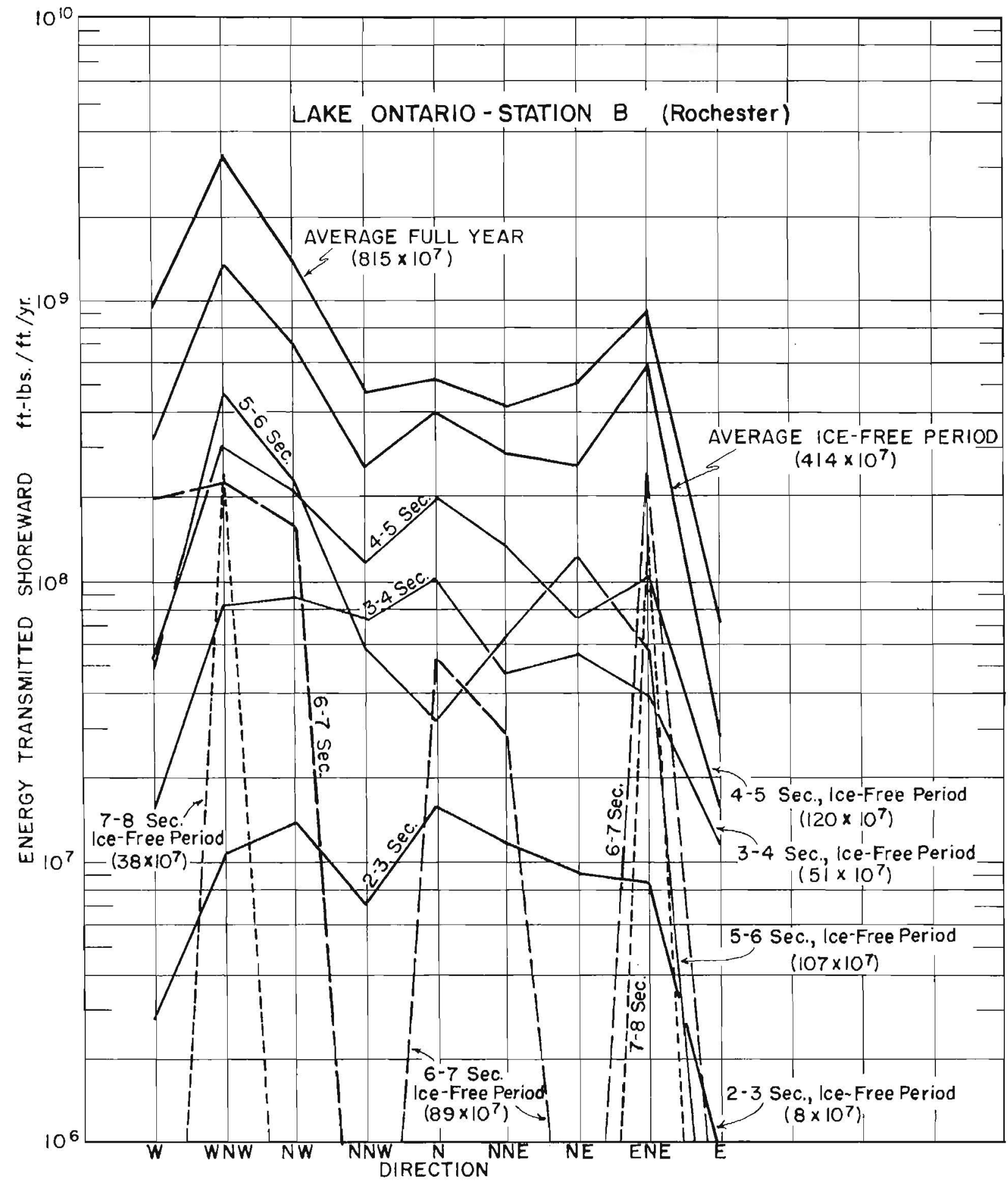

AVERAGE AMOUNT OF ENERGY TRANSMITTED SHOREWARD PER FOOT OF CREST LENGTH PER YEAR, IF WAVE SYSTEM IS CONSIDERED AS AN HYPOTHETICAL UNIFORM SYSTEM COMPOSED OF WAVES OF SIGNIFICANT HEIGHT AND PERIOD ONLY

FIG. $B-4$

$B-16$ 
WAVE AN D LAKE LEVEI STATISTICS

FOR

LAKE ONTARIO

APPENDIX C

WAVE STATISTICS

POR

STONY POINT, NEW YORK 


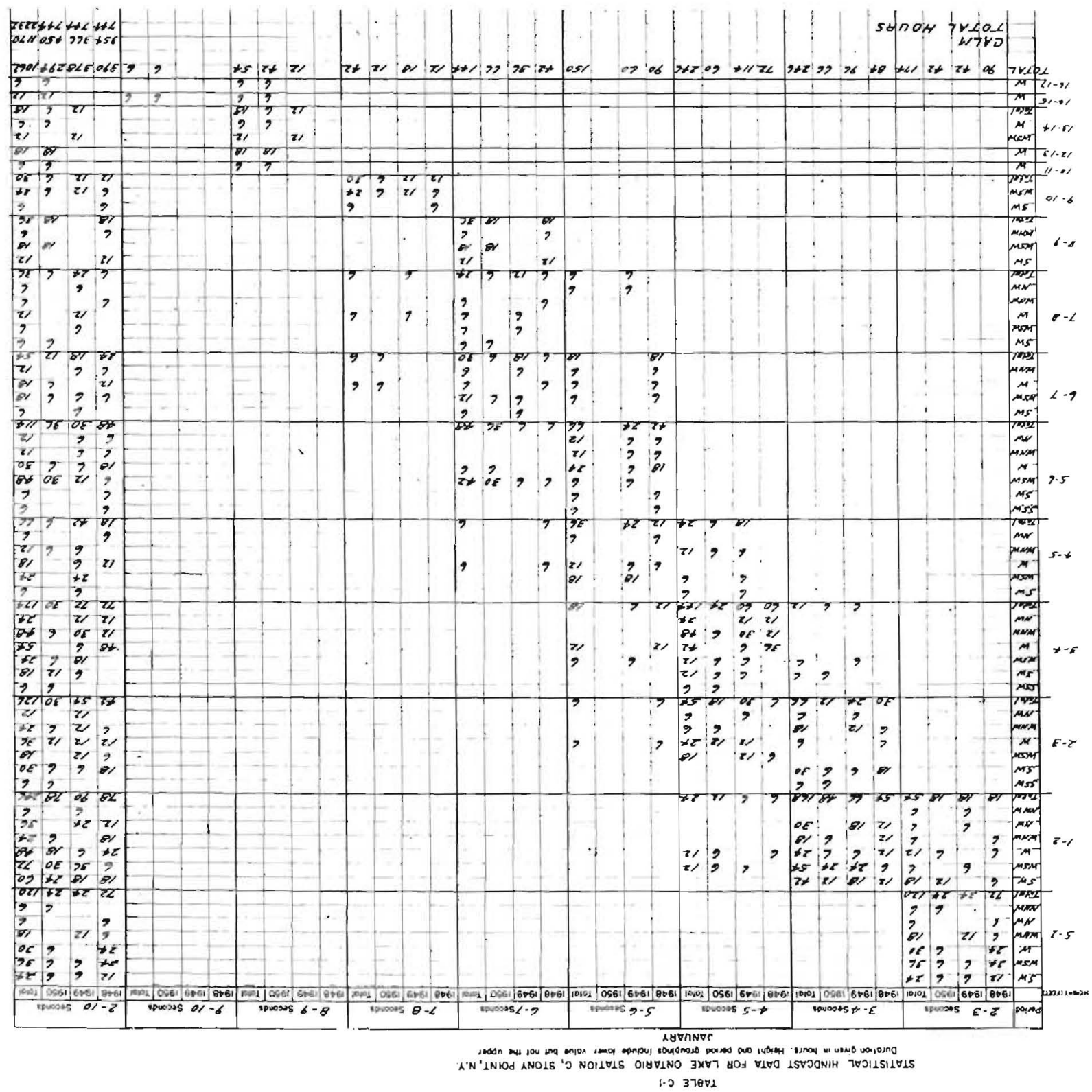




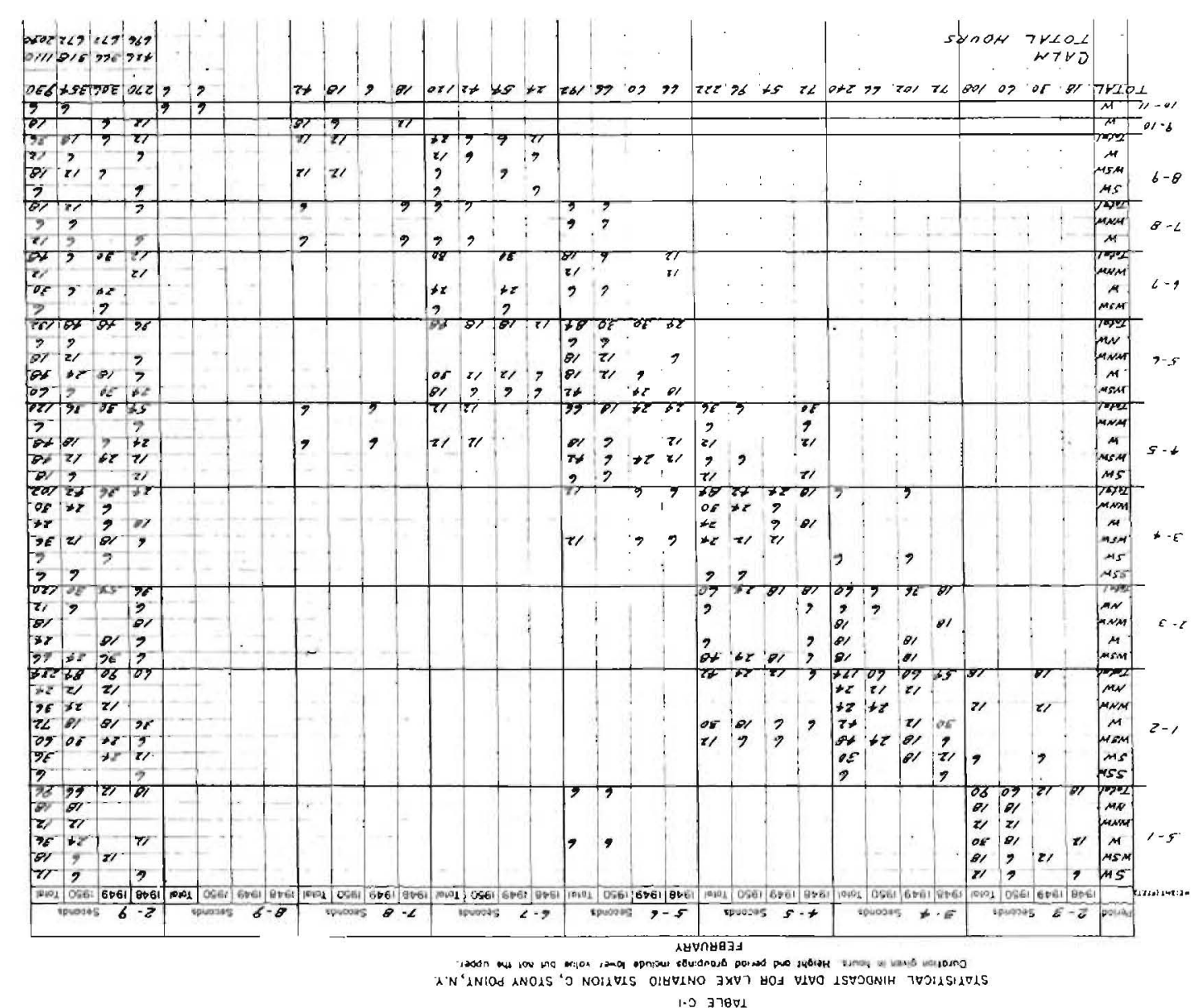


TABLE C.I

STATISTICAL MINDCAST DATA FOR LAKE ONTARIO STAYION C, SYONY POINT, N.Y

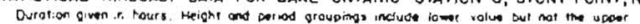

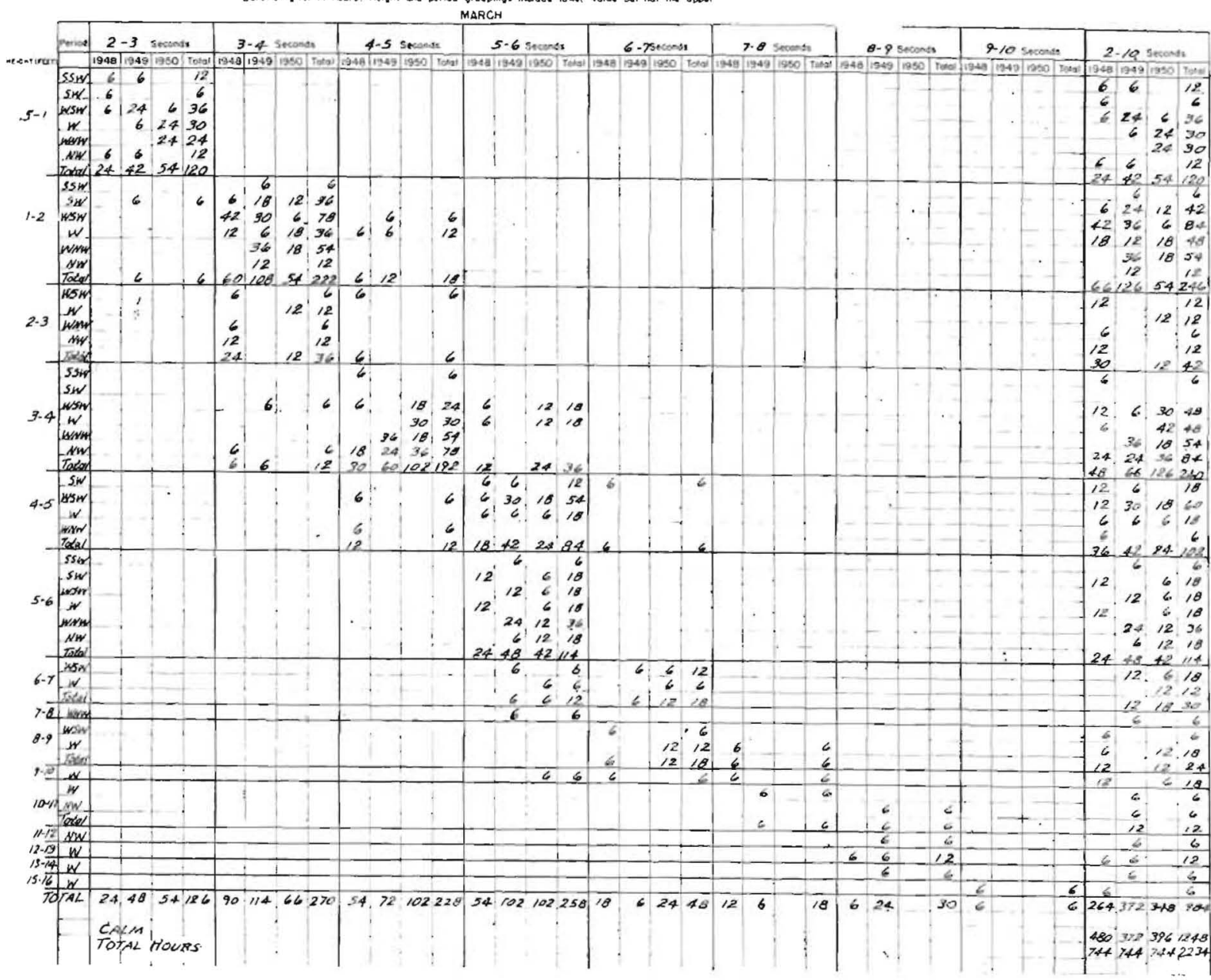


TABLE C-I

STATISTICAL, HINDCAST DATA FOR LAKE ONTARIO STATION C, STONY POINT, N.Y

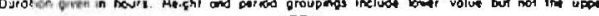
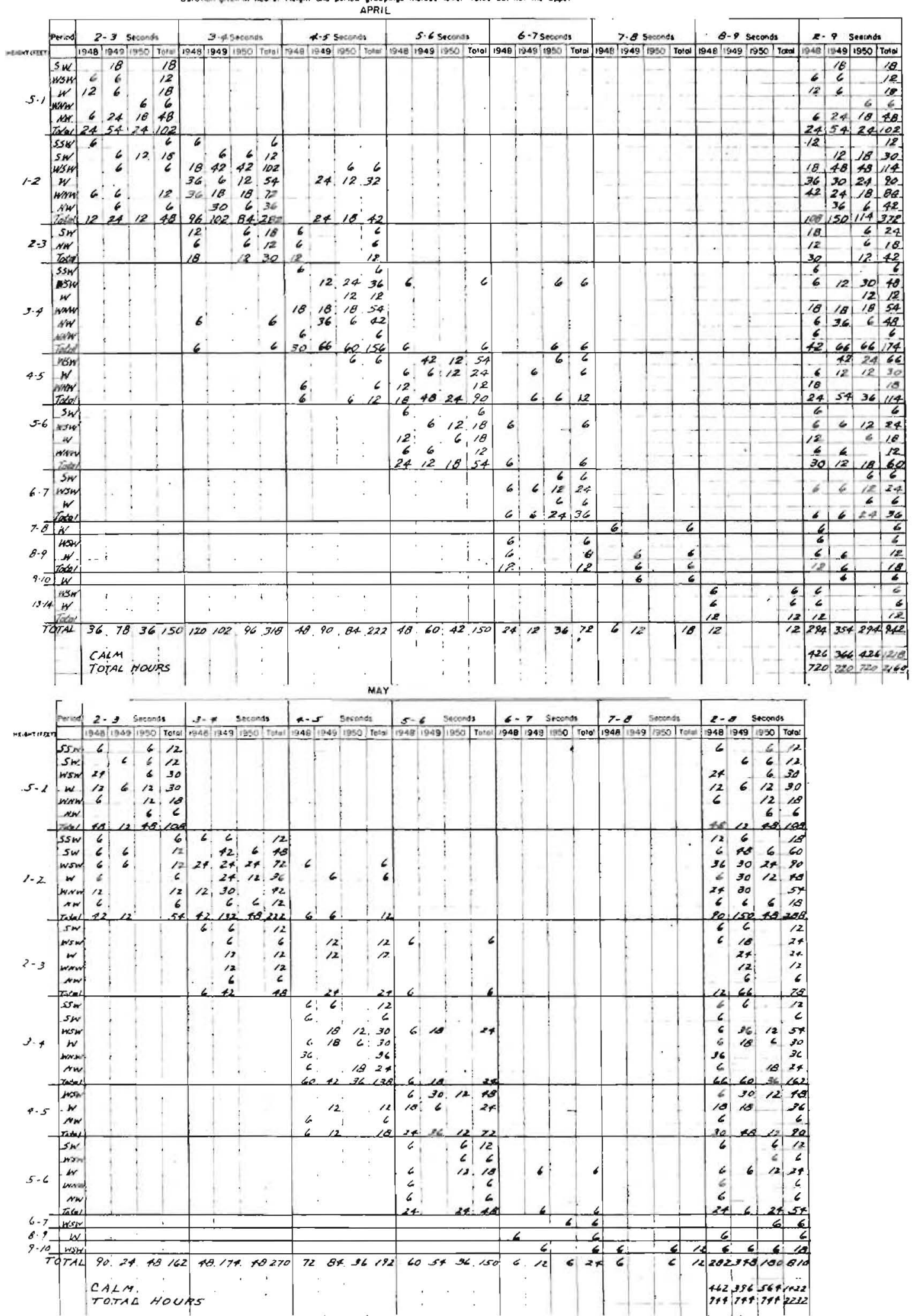
TABLE C.I

STATISTICAL MINDCAST DATA FOR LAKE ONTARIO STATION C, SYONY POINT, N.Y

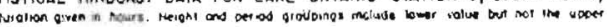

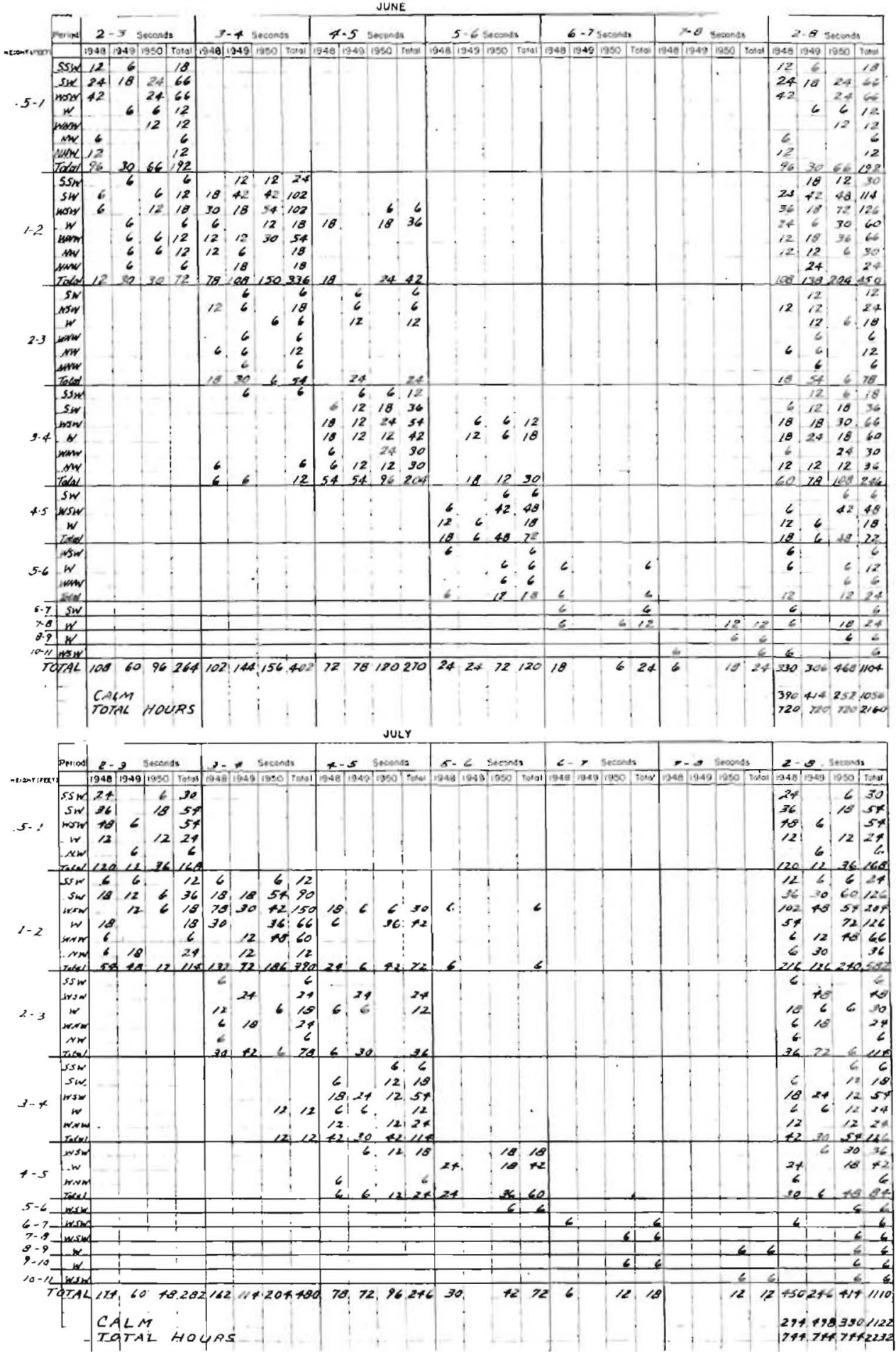




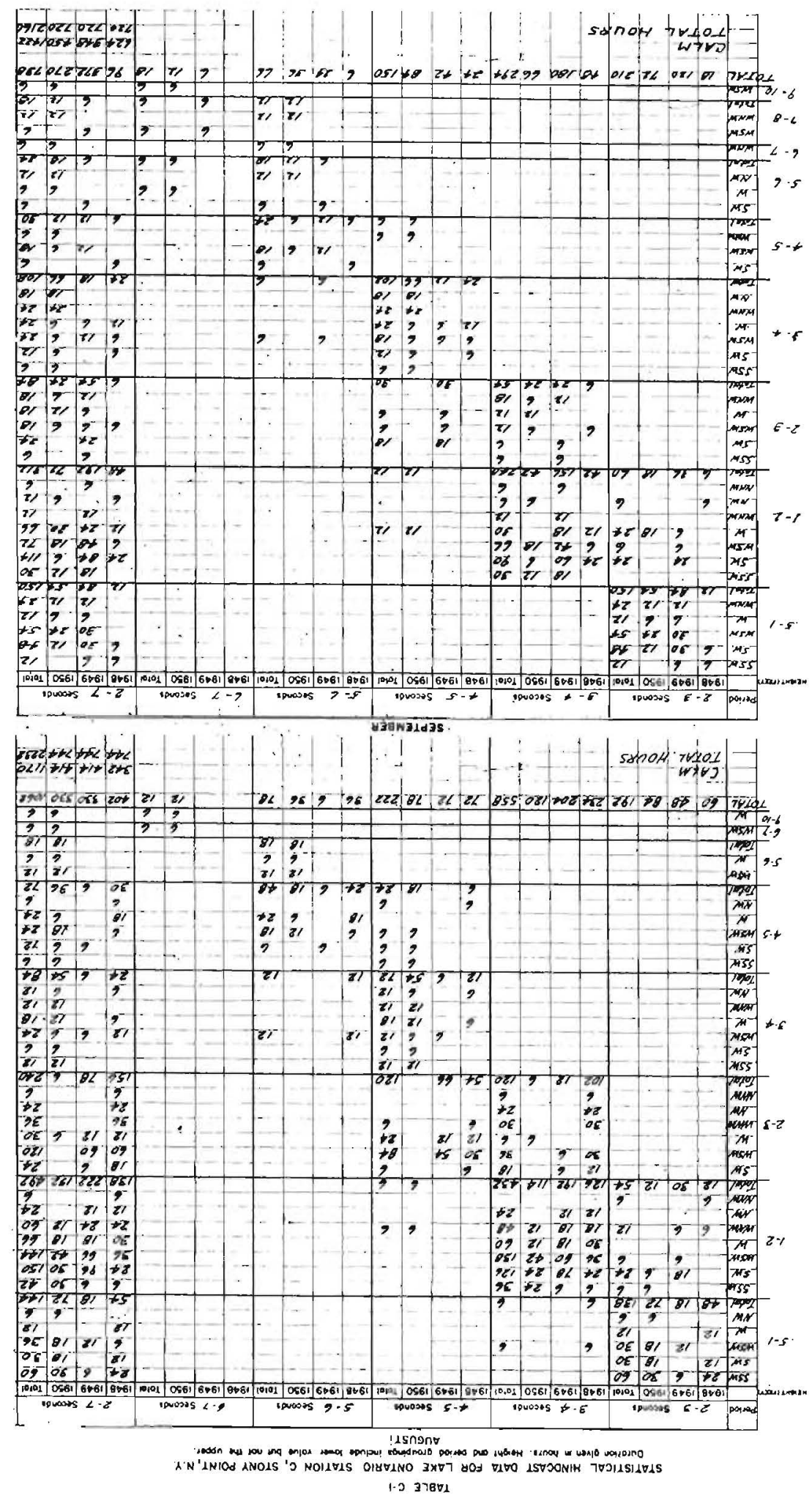


TABLE C-I

STATISTIGAL MINOCAST DATA FOR LAKE ONTARIO STATION C, STONY POINT, N.Y.

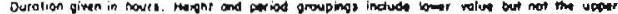

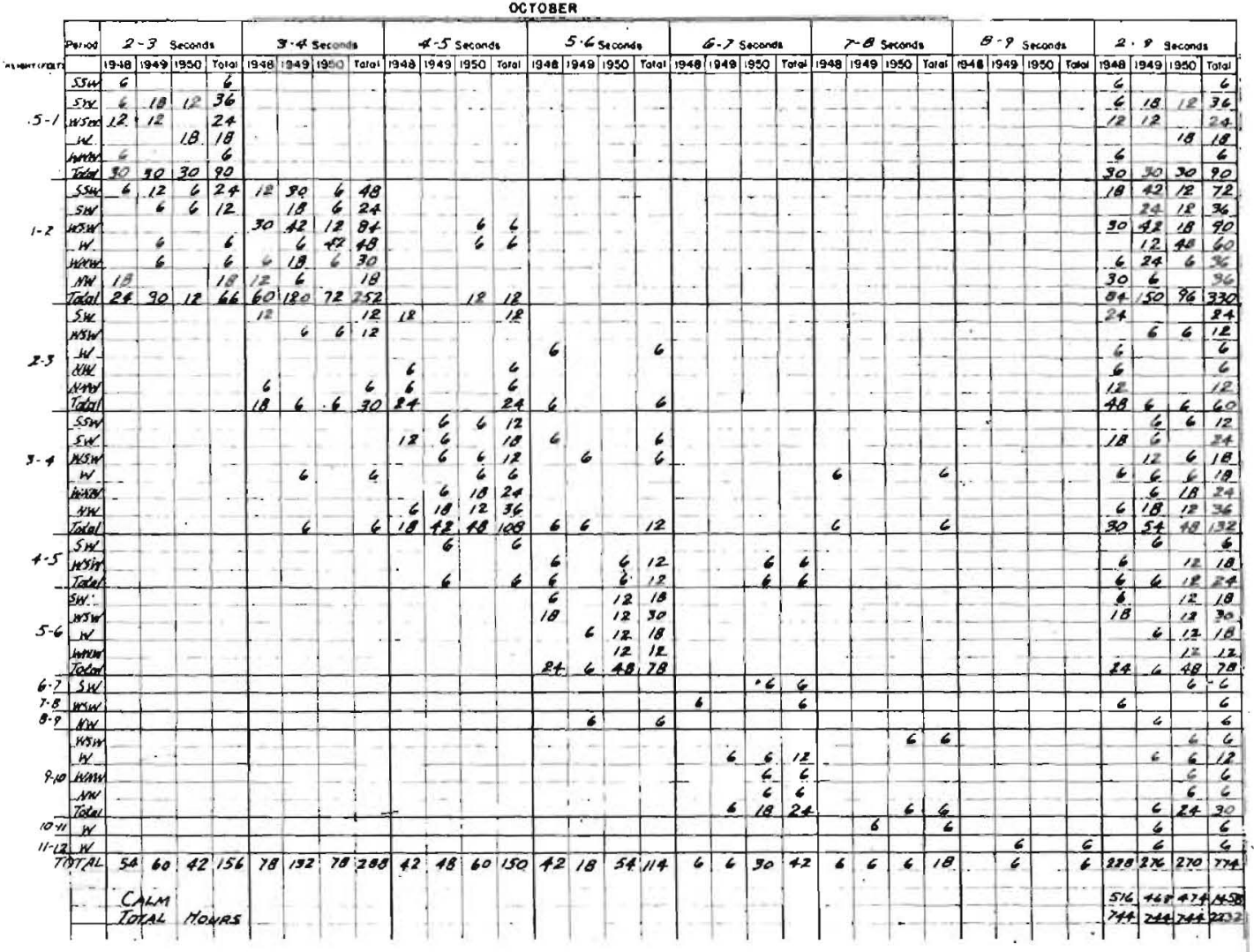


TABLE C.I

STATISTICAL HINDCAST DATA FOR LAKE ONTARIO STATION C, STONY POINT, N.Y

Diston oun

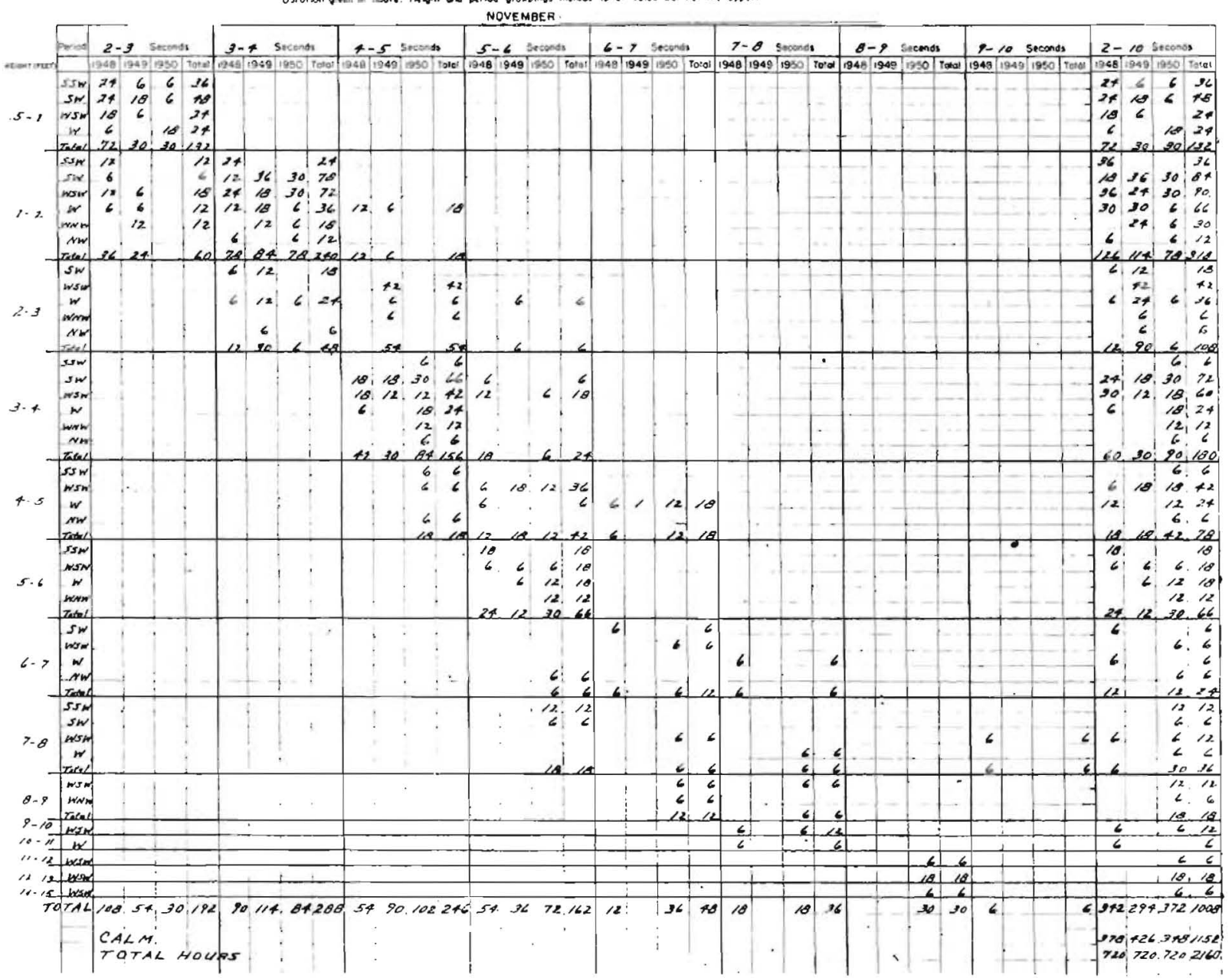


TABLE C-I

STAYISTICAL MINDCAST DATA FOR LAKE ONTARIO STATION C, STONY POINY, N.Y

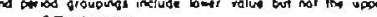

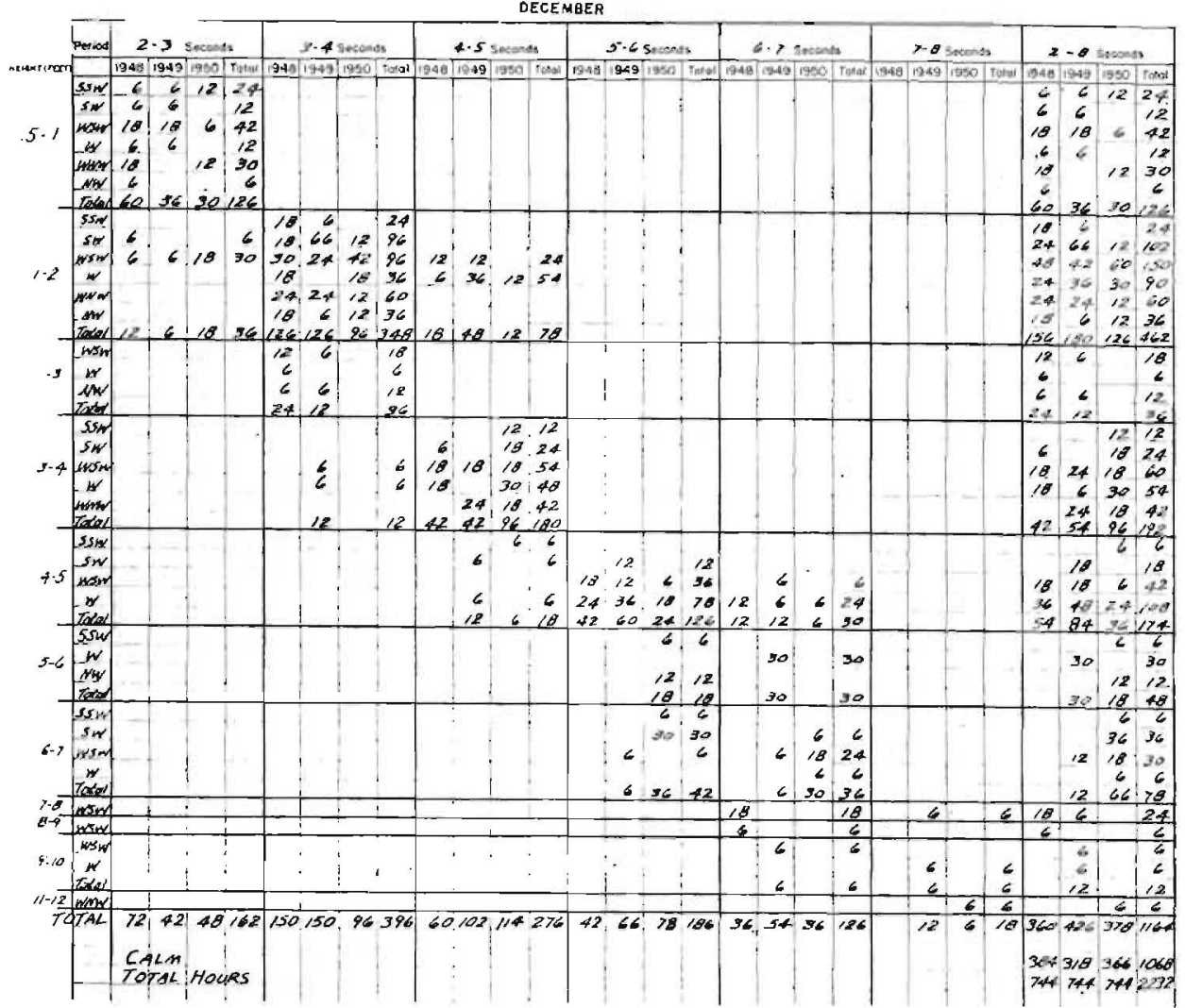


TAQLE C-2

STATISTICAL HINECAST DATA FOF LAKE ONTARIO STATION C, STONY POINT, NY

FULL YEAR

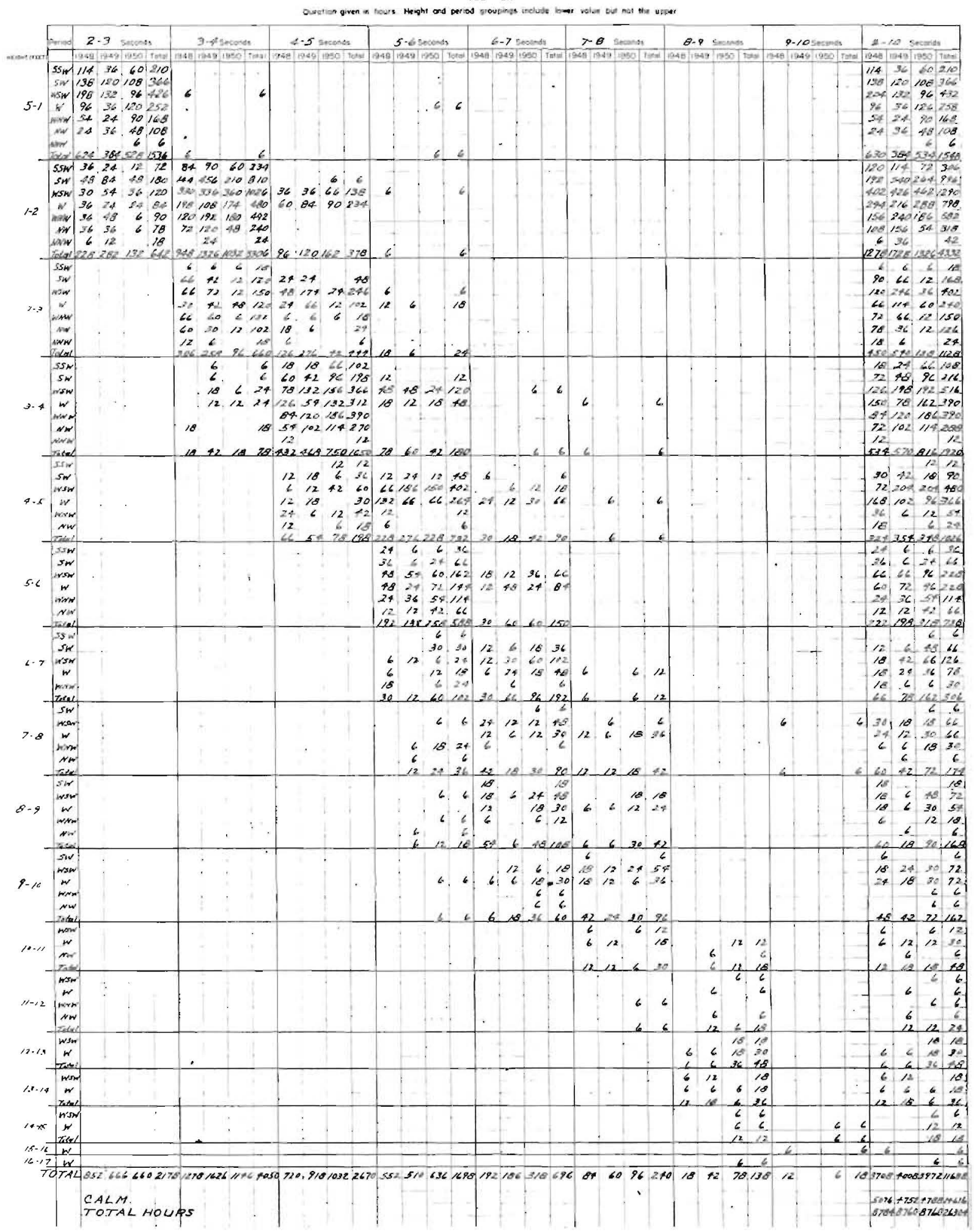


TABLE C-3

STAYISTICAL MINOCAST OATA FOR LAKE ONTARIO STATION C, STONY POINY, N.Y

ICE- FREE PERIOD (I APRIL - 30 NOW )

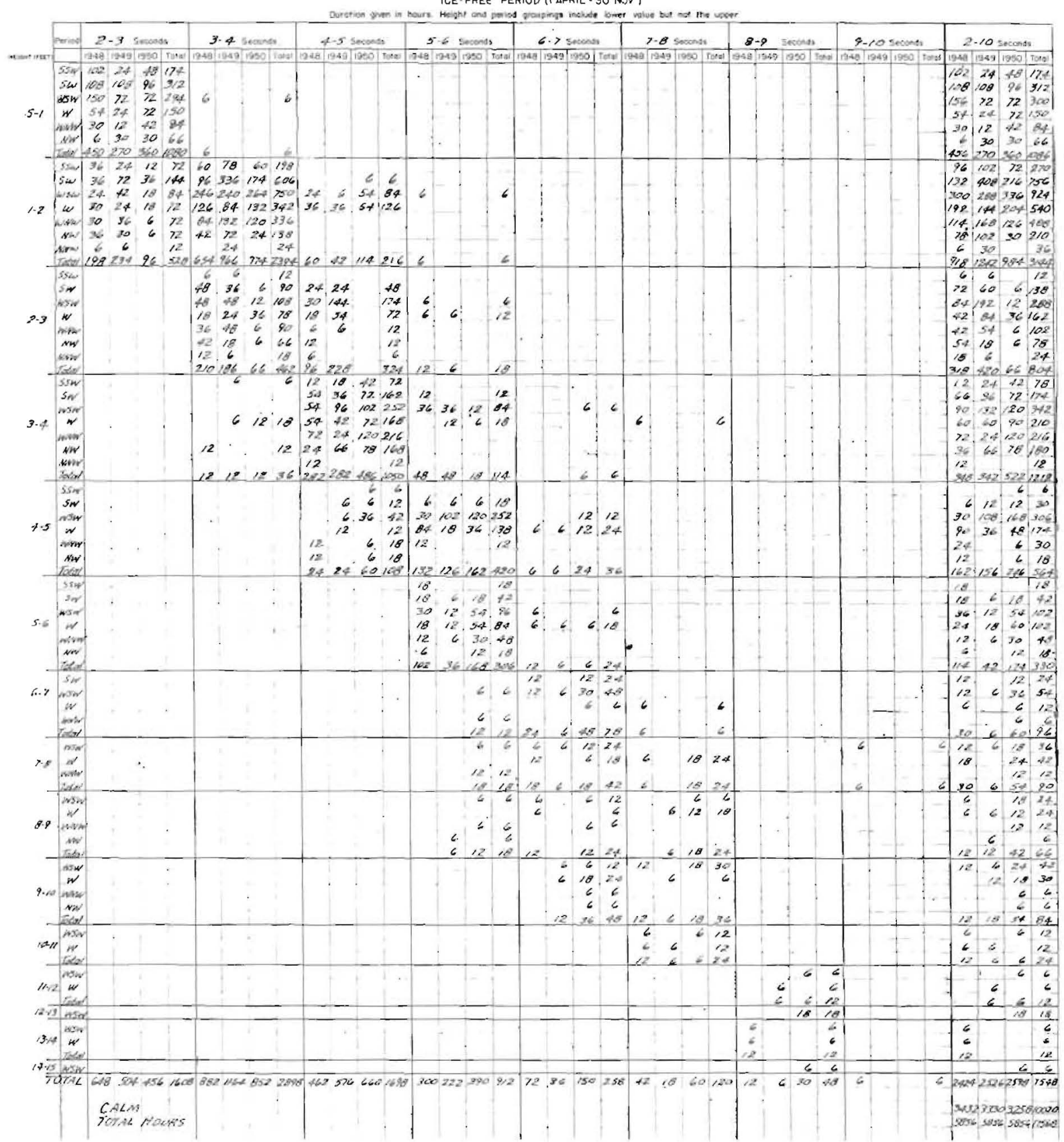


TABLE C-A

5TATISTICAL ENERGY DATA FOR LAKE ONTARIO STATION C, STONY POINT, N.Y

ICE-FREE PERIOD (I APRIL- 30 NOV)

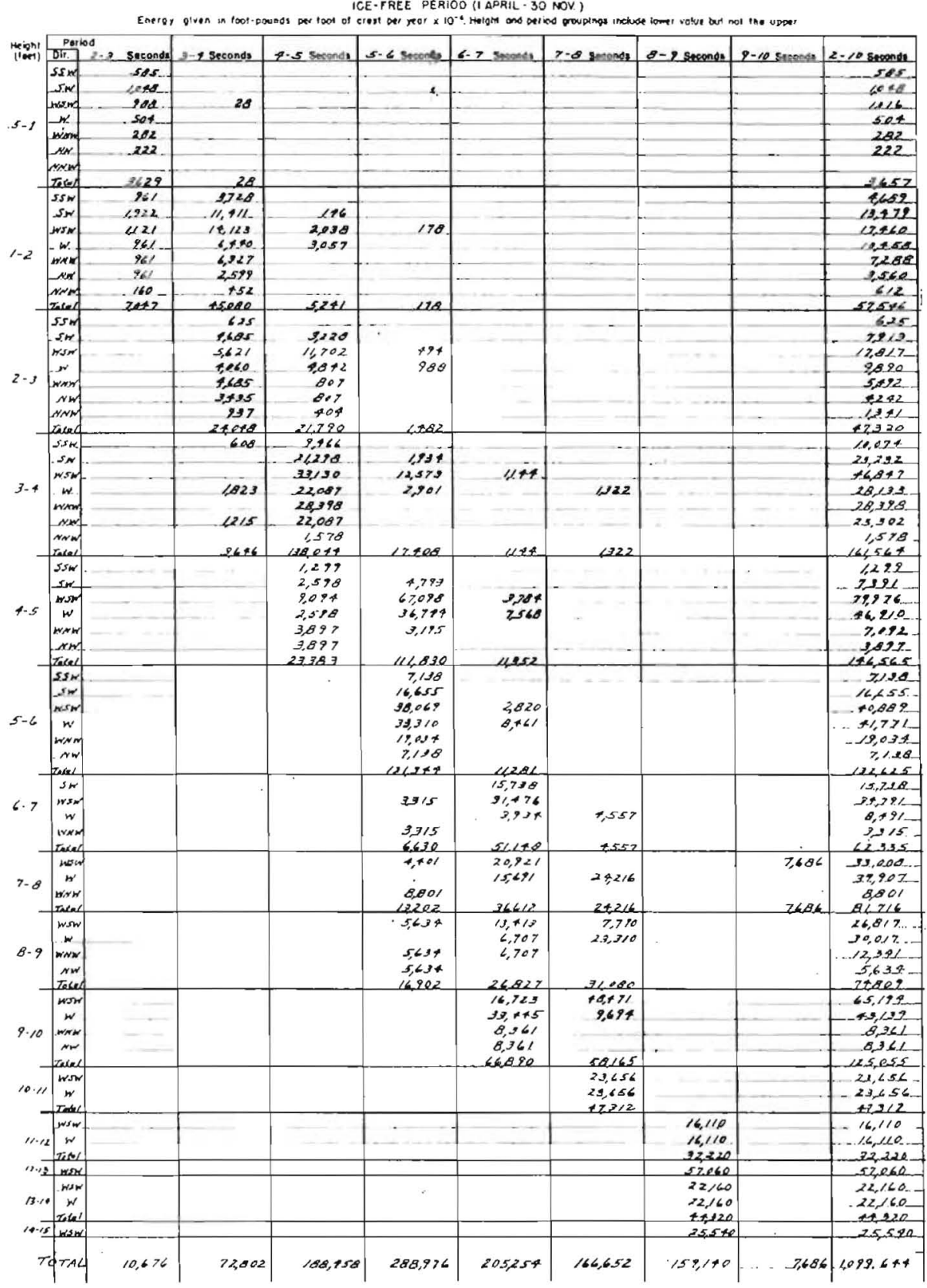


TABLE C-5

STAYISTILAL ENERGY DaTA FOR LAKE ONYARIO STATION C, STONY POINY, N.Y.

FULL YEAR

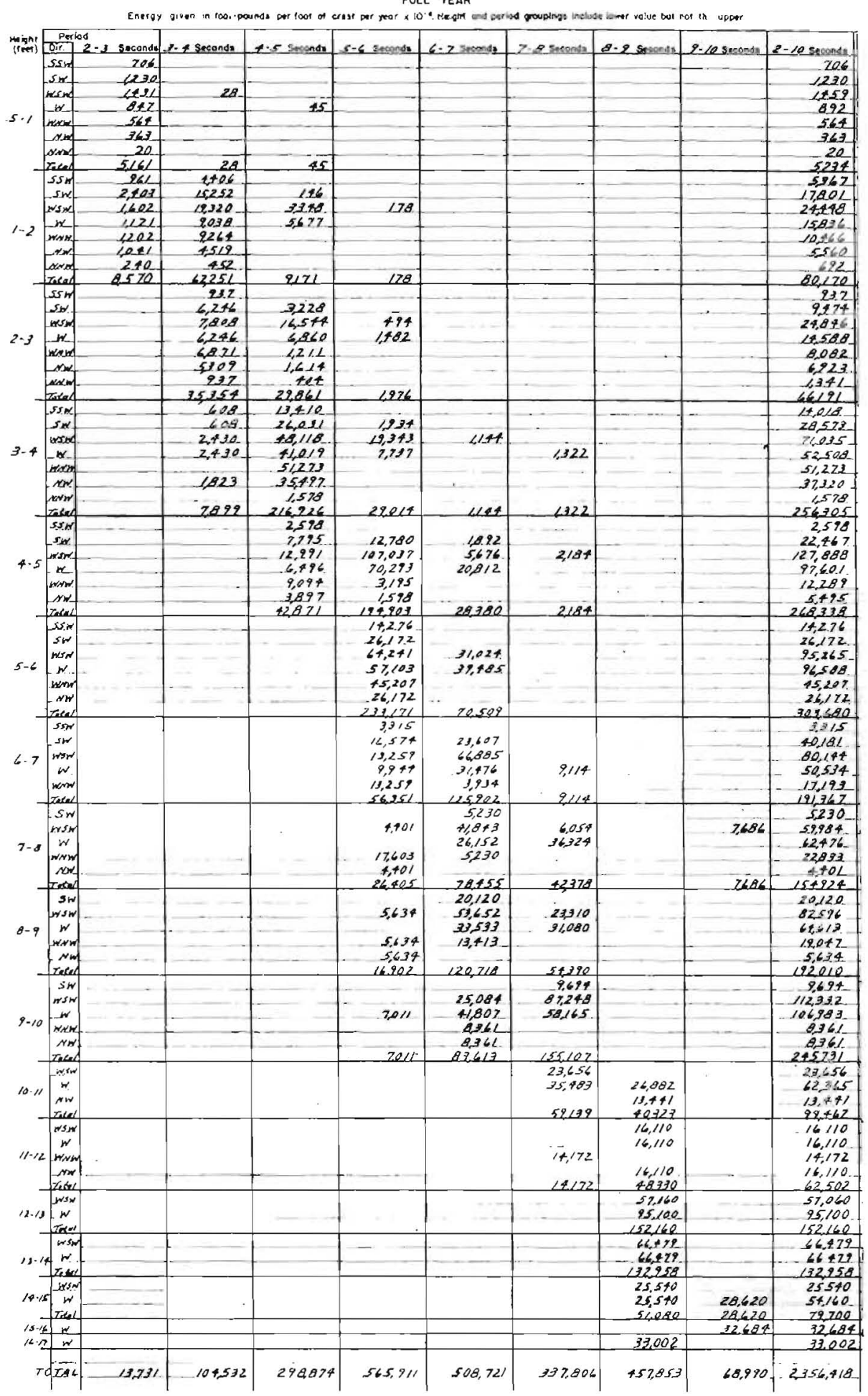




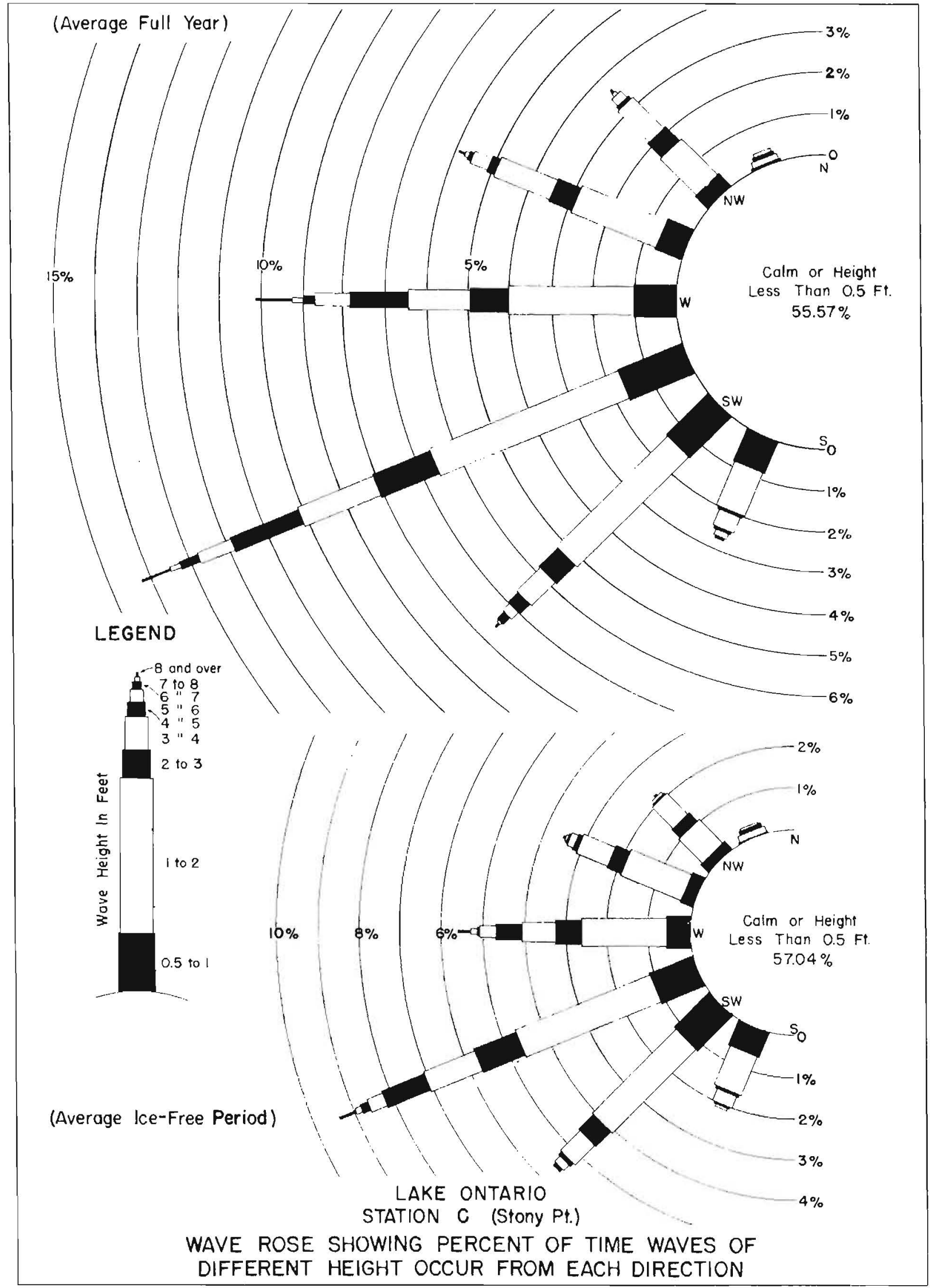

\section{FIG. C-I}



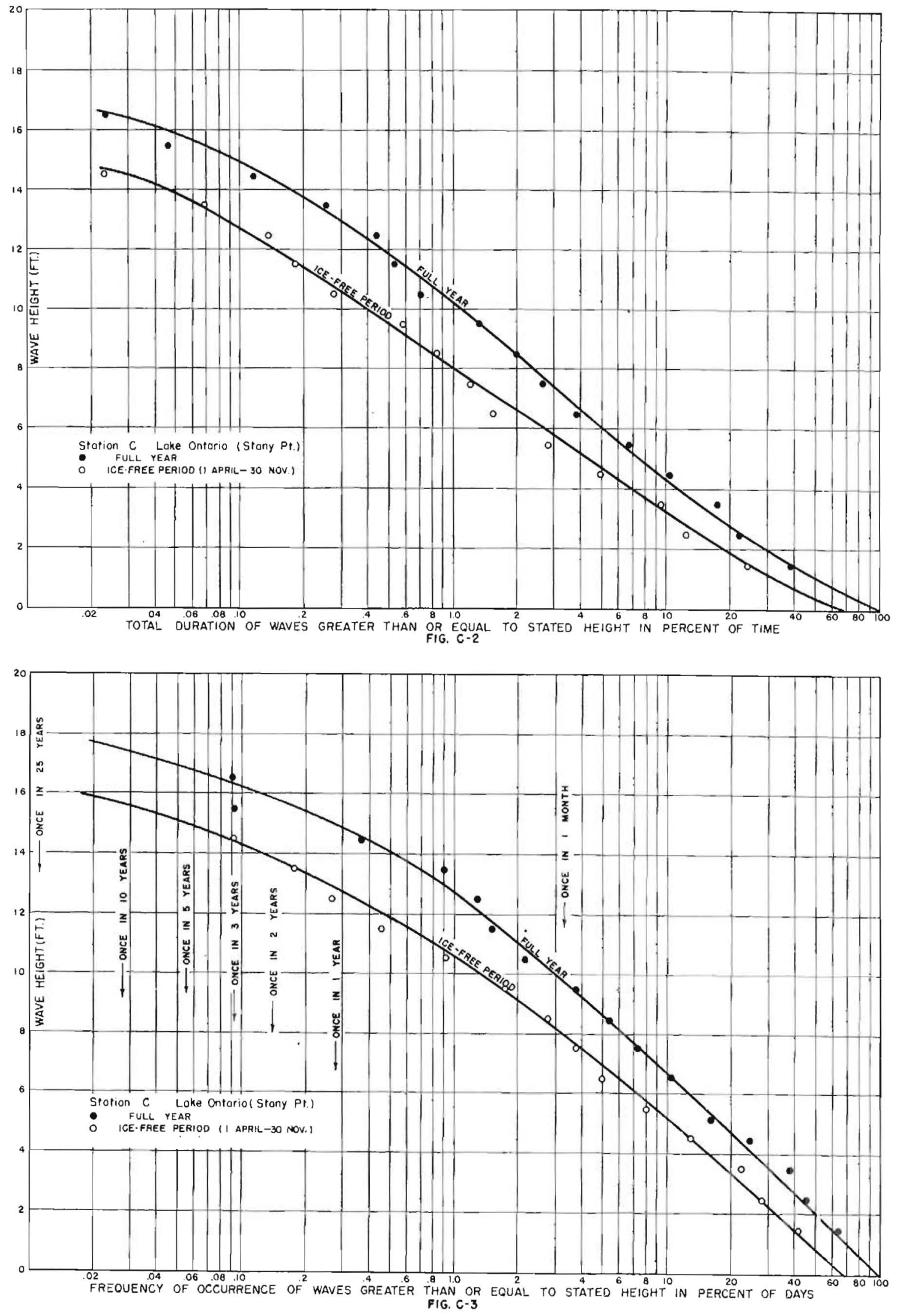


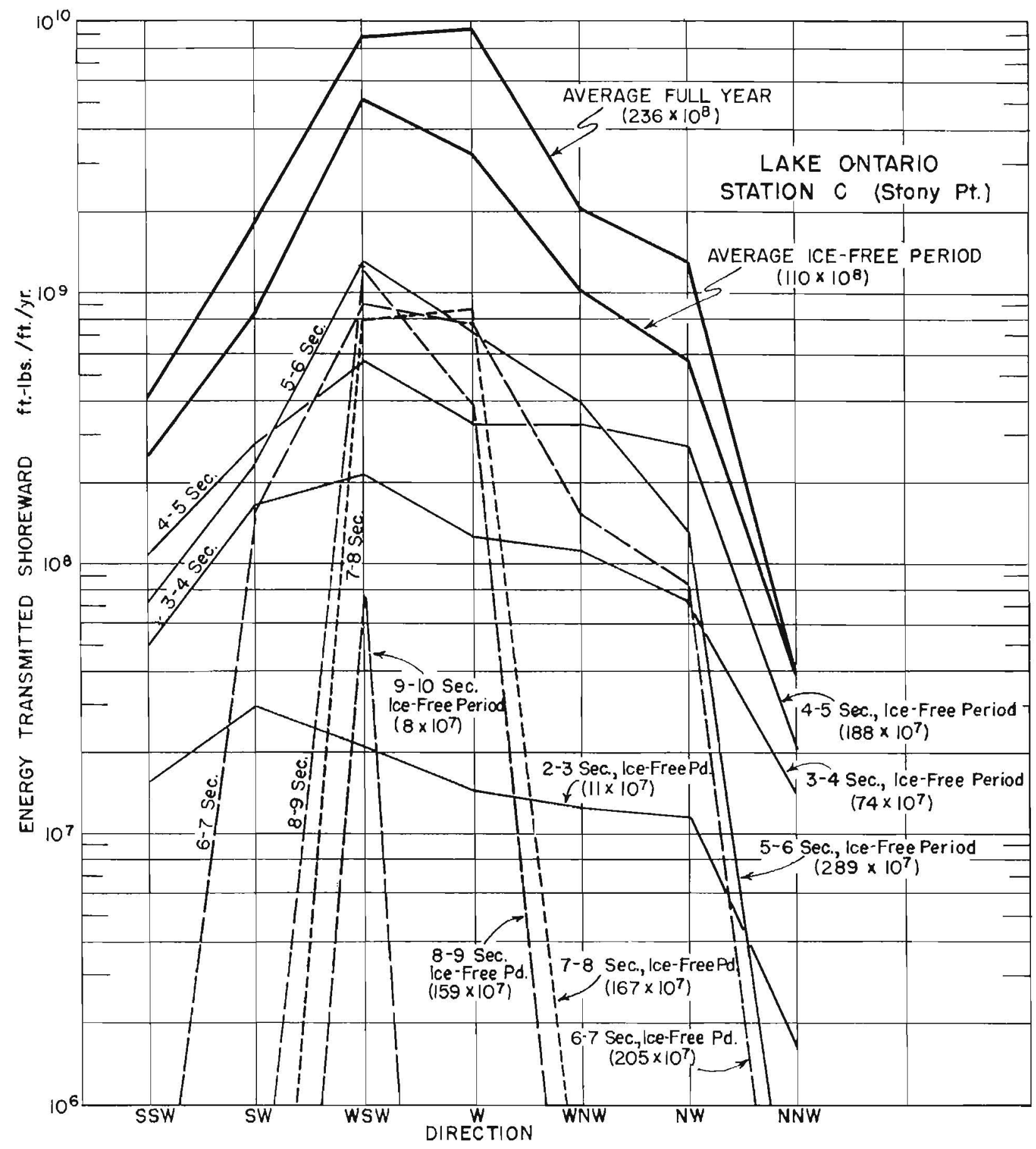

AVERAGE AMOUNT OF ENERGY TRANSMITTED SHOREWARD PER FOOT OF CREST LENGTH PER YEAR, IF WAVE SYSTEM IS CONSIDERED AS AN HYPOTHETICAL UNIFORM SYSTEM COMPOSED OF WAVES OF SIGNIFICANT HEIGHT AND PERIOD ONLY

FIG. C-4

$9593052^{\text {inf } \quad c-16}$ 